University of Louisville

ThinkIR: The University of Louisville's Institutional Repository

$5-2020$

\title{
The making of a person: the relationship of job crafting and leisure crafting on work engagement, occupational role salience, job performance and psychological well-being.
}

Joshua D. Anna

University of Louisville

Follow this and additional works at: https://ir.library.louisville.edu/etd

Part of the Organizational Behavior and Theory Commons, and the Performance Management Commons

\section{Recommended Citation}

Anna, Joshua D., "The making of a person: the relationship of job crafting and leisure crafting on work engagement, occupational role salience, job performance and psychological well-being." (2020).

Electronic Theses and Dissertations. Paper 3369.

https://doi.org/10.18297/etd/3369

This Doctoral Dissertation is brought to you for free and open access by ThinkIR: The University of Louisville's Institutional Repository. It has been accepted for inclusion in Electronic Theses and Dissertations by an authorized administrator of ThinkIR: The University of Louisville's Institutional Repository. This title appears here courtesy of the author, who has retained all other copyrights. For more information, please contact thinkir@louisville.edu. 
THE MAKING OF A PERSON: THE RELATIONSHIP OF JOB CRAFTING AND LEISURE CRAFTING ON WORK ENGAGEMENT, OCCUAPTIONAL ROLE SALIENCE, JOB PERFORMANCE AND PSYCHOLOGICAL WELL-BEING

By

Joshua D. Anna

BA, Bellarmine University, 2009

MA, Spalding University, 2011

A Dissertation

Submitted to the Faculty of the

College of Education and Human Development of the University of Louisville In Partial Fulfillment of the Requirements

For the Degree of

Doctor of Philosophy

In Educational Leadership and Organizational Development

Department of Educational Leadership, Evaluation and Organizational Development University of Louisville

Louisville, KY

May 2020 
Copyright 2019 by Joshua D. Anna

All rights reserved 

THE MAKING OF A WHOLE PERSON: THE RELATIONSHIP OF JOB CRAFTING AND LEISURE CRAFTING ON WORK ENGAGEMENT, OCCUAPTIONAL ROLE SALIENCE, JOB PERFORMANCE AND PSYCHOLOGICAL WELL-BEING

By

Joshua D. Anna

BA, Bellarmine University, 2009

MA, Spalding University, 2011

A Dissertation Approved on

January $10^{\text {th }}, 2020$

By the following Dissertation Committee

Dr. Meera Alagaraja, Chair (ELEOD)

Dr. Namok Choi (ELEOD)

Dr. Brad Shuck (ELEOD)

Dr. Keith Gatto (UC Berkeley College of Engineering 


\section{DEDICATION}

To my wife, Samantha 


\section{ACKNOWLEDGEMENTS}

I would like to thank my advisor and dissertation chair, Dr. Meera Alagaraja, for never giving up on me and believing in my ability to fulfill the requirements of this degree. A special thanks to Dr. Namok Choi for her support, feedback and guidance through the study's methodology and writing process. I would also like to thank Dr. Brad Shuck for agreeing to serve as a member of my dissertation committee and his positivity throughout this entire process. Lastly, a very special thank you to Dr. Keith Gatto for being a member of my dissertation committee though he lives thousands of miles away. To all of you, I am grateful for your time and patience, and hope that you will recognize the results of your advices in this final product. 


\title{
ABSTRACT
}

THE MAKING OF A WHOLE PERSON: THE RELATIONSHIP OF JOB CRAFTING AND LEISURE CRAFTING ON WORK ENGAGEMENT, OCCUAPTIONAL ROLE SALIENCE, JOB PERFORMANCE AND PSYCHOLOGICAL WELL-BEING

\author{
Joshua D. Anna \\ January 10, 2020
}

This study looks at how an individuals' ability to job craft relates to work engagement, job performance and their psychological well-being; and when job crafting opportunities are low, how leisure crafting can compensate to provide the individual similar personal outcomes. This study also examines when job-crafting opportunities are high, how these positive effects can spillover onto other aspects of an individuals' life such as leisure. This study also examines the extent to which an individual views work as a mean of self-identification and how this relates to job crafting. A total of 303 respondents met the inclusion criteria and completed the survey. Structural equation modeling was used to analyze collected data and determine the best fitting model. The results show ORS having a strong and statistical significant predictive effect on both JC and LC, though there was no dual interaction between LC and JC. Based on the conclusions, an individuals' self identification to work (the extent to which work defines who a person is) has a significant effect on their likelihood of engaging in job crafting; the same self identification to work has a significant effect on their likelihood of engaging in leisure crafting which also has a significant effect on their ability to job craft. 
The relationships and effects that ORS has on JC and LC as well as the relationship of LC to JC creates significant impact on WE, PWB and JP. This study yields two key findings: the intervening effect of leisure crafting on job crafting and the predictive value of occupational role salience within this model. 


\section{TABLE OF CONTENTS}

PAGE

\section{DEDICATION}

ACKNOWLEDGEMENTS

\section{LIST OF TABLES}

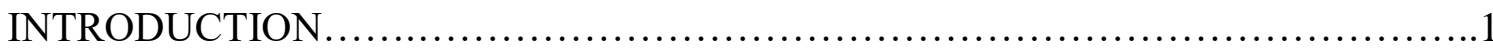

Statement of Problem..........................................................

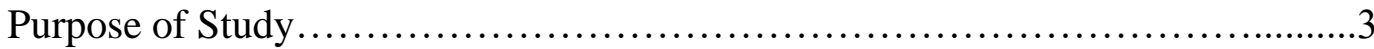

Research Questions...................................................

Definition of Variables and Terms ...........................................

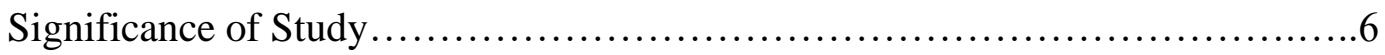

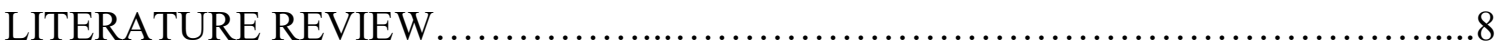

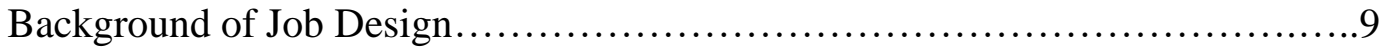

Theoretical Framework for Job Characteristics Model............................9

Job Characteristics Model..................................................13

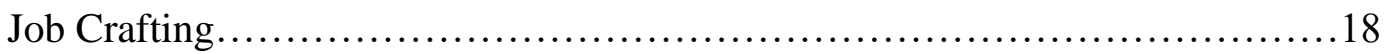

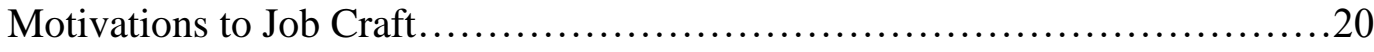

Job Demands-Resource Model..........................................23

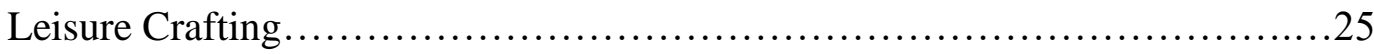

Spillover and Compensation Hypotheses.....................................27 
Occupational Role Salience.........................................28

Work Engagement..................................................... 30

Psychological Well-Being.......................................... 32

Job Performance....................................................... 34

Job Performance and Leisure Crafting .................................... 37

Summary of Job Crafting and Leisure Crafting............................. 38

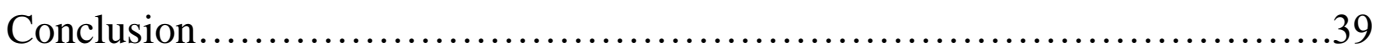

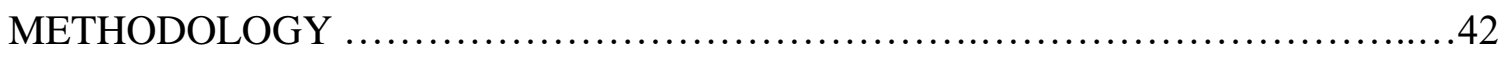

Research Questions and Hypotheses...................................42

Population and Sample............................................43

Inclusion Criteria......................................................43

Procedures......................................................... 44

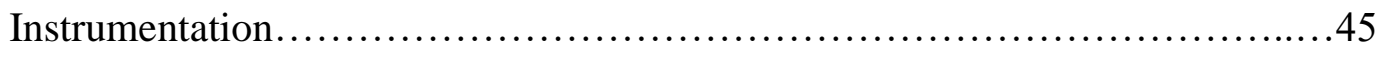

Major variables...................................................46

Job crafting .................................................... 46

Leisure crafting ....................................................... 48

Work engagement...............................................50

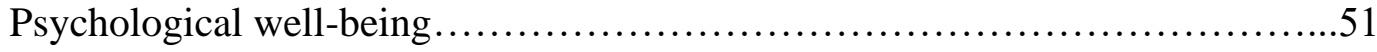

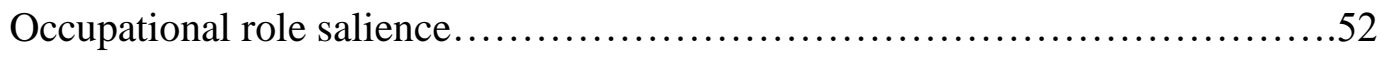

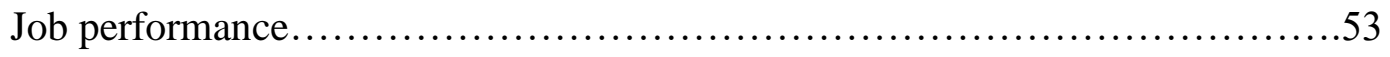

Demographic variables...............................................54

Endogenous variables............................................ 54

Exogenous variables................................................55 


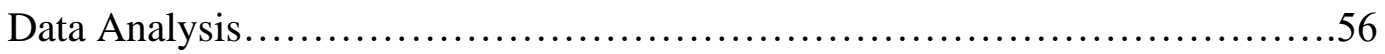

Descriptive statistics and correlations ....................................56

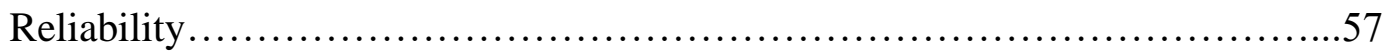

Structural Equation Modeling............................................5

Measurement model.......................................................58

Structural model......................................................59

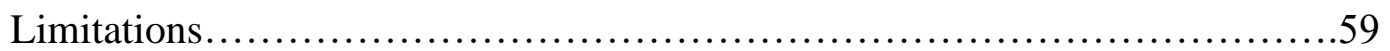

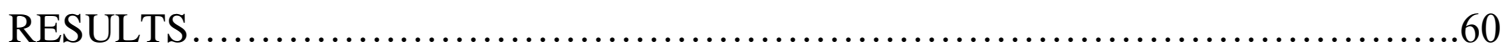

Descriptive Statistics................................................60

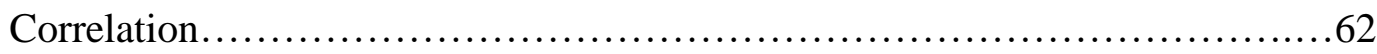

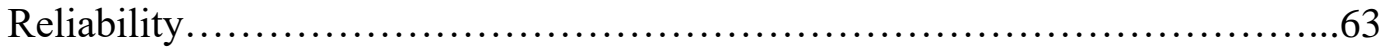

Exploratory Factor Analysis..............................................64

Measurement Model..................................................... 77

Structural Model............................................................. 83

DISCUSSION AND CONCLUSIONS ........................................ 91

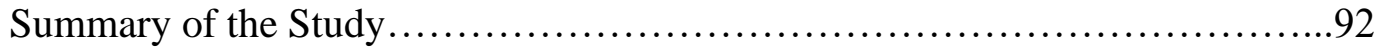

Discussion of Results................................................ 92

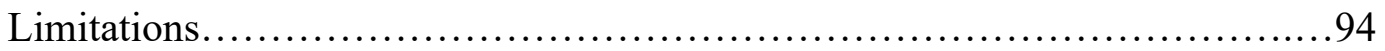

Implications for Theory, Research and Practice................................95

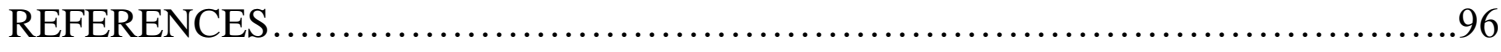

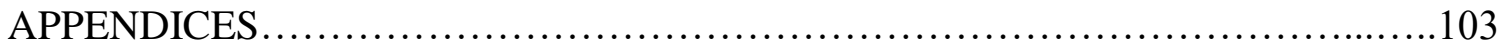

Appendix A........................................................... 103

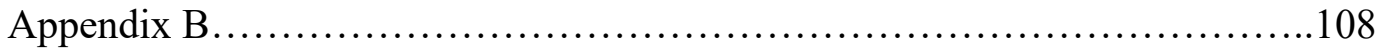




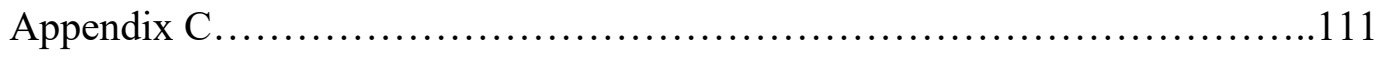

Appendix D......................................................113

CURRICULUM VITAE.................................................. 142 


\section{LIST OF FIGURES}

FIGURES

PAGE

1. Job Characteristics Model.............................................. 15

2. The Motivating Potential Score............................................. 17

3. Hypothesized Model.................................................41

4. Measurement Model....................................................57

5. Final Measurement Model.................................................82

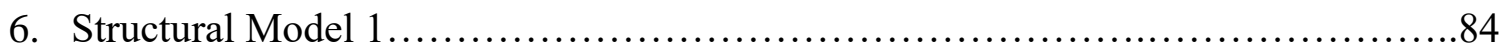

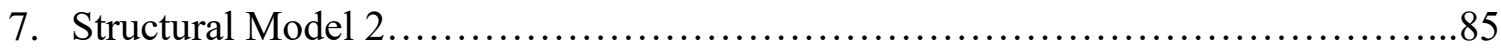

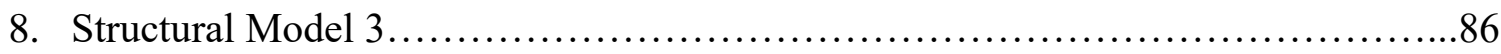

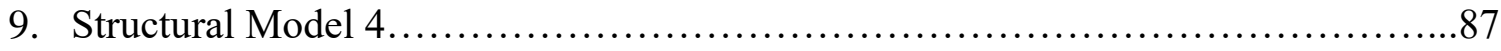




\section{LIST OF TABLES}

TABLES

PAGE

1. Selected Instruments.................................................46

2. Participant Personal and Professional Attributes.................................54

3. Respondents Demographics...........................................61

4. Correlation and Significance...........................................62

5. Reliability Analysis...................................................64

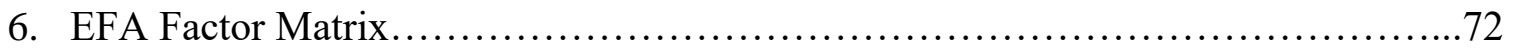

7. CFA Fit Indices for Measurement Model.......................................79

8. Standardized Path and Structure Coefficients for Finalized Measurement Model.....80

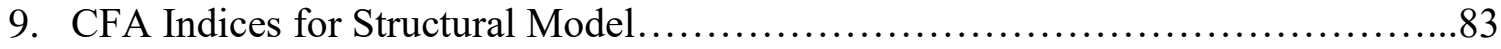

10. Direct, Indirect and Total Effects for Latent Factors............................90 


\section{CHAPTER I}

\section{INTRODUCTION}

In previous decades, most people viewed work as a linear progression to

retirement. Step 1: graduate high school. Step 2: start working. Step 3: start family. Step

4: retire. This ideology of work has evolved and is now viewed by most individuals as a part of their self-definition. To accompany this evolution, the workplace is

accommodating alternative work schedules, work from home options, telecommuting, etc. to meet this thirst for self-exploration. Though these alterations do result in increases in work engagement and task performance, there is no "one size fits all" solution and certain individuals are left out. Job crafting brings the individual back into the process, allows each person to take control and make the decisions that will ultimately affect who they are inside and outside work (Wrzesniewski \& Dutton, 2001). This study aims to explore the relationship between how an individual identifies with their work and the changes employees engage inside and outside of work with the aim to align their jobs with their own preferences to affect engagement at work, well-being and performance on the job.

Job crafting is a strategy employees use to reshape and improve their job conditions by seeking job resources and job challenges thus shaping more engaging jobs (Tims, Bakker, \& Derks, 2012; Wrzesniewski \& Dutton, 2001). Petrou, Bakker, and van den Heuvel (2017) suggest that when employees craft their working conditions according to their needs, their behavior will not only lead to an increase in meaningfulness at work, 
but also an increased tendency to actively make sense and reflect on what is happening in changing environments. Job crafting consists of three focus areas: task crafting, relational crafting and cognitive crafting; when each of these areas have opportunities to exist in the workplace and the individual takes advantage of these, they are seen to have high levels of job crafting. But what if these opportunities are not available to the employee? Does the individual accept that customizing their position to match their preferences doesn't exist? Consistent with the compensation hypothesis, individuals use domains with favorable conditions (non-work) to realize states they cannot achieve in other domains (work) with unfavorable conditions (Petrou \& Bakker, 2016). Under this theory, employees may seek growth experiences during leisure time as a means of compensation for their unattained personal goals at work (Berg, Grant, \& Johnson, 2010). This is referred to as leisure crafting. Berg et al. (2010) addressed leisure crafting as an alternative crafting strategy employee utilize in their free time to compensate for their unfulfilled needs at work.

Although research on job crafting has increased in recent years, the lack of literature and further research on the compensation effect between job crafting and leisure crafting have limited our understanding of the topic of leisure crafting. There is also limited research on the integration of work as a means of self-identification on leisure crafting as well as this mode of self-identification as a predictor of these terms. Lastly, there is a gap in the literature exploring the effect of job and leisure crafting on psychological well-being. The job crafting literature explores varying definitions and terminology of "meaningfulness" compared to "mean making" as job crafting has its roots oriented from the Job Characteristics Model, but this study focuses on the 
individuals' overall psychological well-being. The variables "meaningfulness" and "mean making" have been highlighted as "creating meaning in one's job" (Wrzesniewski, LoBuglio, Dutton, \& Berg, 2013) and "aligning the job with one's needs and values" (Wrzesniewski, Dutton, \& Debebe, 2003) but the effects of job and leisure crafting on psychological well-being remain uncharted.

\section{Statement of the Problem}

Job crafting and leisure crafting are important topics of research because of their relevance to employees and effect on the whole person. Further scientific inquiry may contribute new developments to the subject as it relates to other variables. Few studies have examined the relationship occupational role salience and job crafting have and how leisure crafting can compensate for the lack of job crafting opportunities. To address these limitations, empirical research on these relationships must receive greater attention, as the results from this study could provide additional data to support practical recommendations of its use in organizations.

Moreover, job crafting has been linked to higher levels of work engagement and job performance but the relationship between job and leisure crafting on psychological well-being remains undefined. If this body of work can contribute to defining this interaction, the ultimate advantage of fostering job/leisure crafting and psychological well-being comes to employees who can engage in tasks that improve well-being as well as inform managers on how to motivate and understand those they manage.

\section{Purpose of the Study}


The purpose of this study is to look at how an individuals' ability to job craft relates to work engagement, job performance and their psychological well-being; and when job crafting opportunities are low, how leisure crafting can compensate to provide the individual similar personal outcomes. Along these same terms, this study examines when job-crafting opportunities are high, how these positive effects can spillover onto other aspects of an individuals' life such as leisure. This study also examines the extent to which an individual views work as a mean of self-identification and how this relates to job crafting.

\section{Research Questions}

There are nine overarching research questions that this study seeks to answer:

RQ 1: Is there a significant mediating effect of job crafting on the relationship between leisure crafting and work engagement?

RQ 2: Does leisure crafting have a significant mediating effect on the relationship between job crafting and work engagement?

RQ 3: Does job crafting have a significant direct effect on work engagement?

RQ 4: Does job crafting have a significant direct effect on job performance?

RQ 5:Does job crafting have a significant direct effect on psychological wellbeing?

RQ 6: Does leisure crafting have a significant direct effect on work engagement? RQ 7: Does leisure crafting have a significant direct effect on job performance? RQ 8:Does leisure crafting have a significant direct effect on psychological wellbeing?" 
RQ 9: Does occupational role salience have a significant direct effect on job crafting?

\section{Definition of Variables and Terms}

Terms used throughout the study are defined as follows:

Job crafting is the physical and cognitive changes individuals make in the task or relational boundaries of their work (Lyons, 2008; Petrou, Demerouti, Peeters, Schaufeli, \& Hetland, 2012; Tims \& Bakker, 2010; Wrzesniewski \& Dutton, 2001) The process of revising one's position to expand these cognitive and relational boundaries is called job crafting. An employee who engages in these constructs is known as a job crafter (Tims \& Bakker, 2010).

Task crafting involves shaping the task boundaries of a job such as changing the number, scope and type of job tasks. For example, design engineers engage in tasks that move a project towards completion and alter the meaning of their jobs to guardians and movers of projects.

Relational crafting looks at changing the quality and/or amount of interaction with others encountered in the job. For example, hospital cleaners actively caring for patients and families by integrating themselves into the workflow of their floor units which adjusts the meaning of the cleaners' job as an integral part of the treatment team. 
Cognitive crafting refers to altering how one sees the job and changing the cognitive task boundaries. For example, nurses taking responsibility for all information and "insignificant" tasks that may help them to care more appropriately for a patient Leisure crafting is "the proactive pursuit of leisure activities targeted at goal setting, human connection, learning and personal development” (Petrou \& Bakker, 2016). Based on this definition, three elements of leisure crafting arise: leisure crafting is proactive, serious and intentional (Fritz, 1995), through leisure crafting, individuals learn new things and develop themselves through challenges that enhance their feelings of mastery (Sonnentag \& Fritz, 2007) and leisure crafting experiences involve companionship and the development of interpersonal relations (Snir \& Harpaz, 2002)

Occupational role salience is the extent to which an individual agrees that work is an important means of self-definition and/or personal satisfaction and the individuals' willingness to commit personal resources to assure success at work (Amatea, Cross, Clark, \& Bobby, 1986). For each employee, work fulfills various levels of self-definition and personal satisfaction. For some, work is central to who they are and how they describe themselves but for others, work serves as a means to an end or an exchange of services for financial gains.

Work engagement is defined as a positive, fulfilling, work related state of mind that is characterized by vigor, dedication, and absorption (Schaufeli, Salanova, GonzalezRoma, \& Bakker, 2002). This model of work engagement is represented in the Job Demands-Resource Model (Bakker \& Demerouti, 2008) as job and personal resources are the most important predictors of work. 
Psychological well-being is defined as the pleasantness dimension of individual feelings. Psychological well-being has at least three characteristics: a subjective experience (Cropanzano \& Wright, 2001), includes both the relative presence of positive emotions and the relative absence of negative emotions (Diener \& Larsen, 1993) and is a global judgment to one's life as a whole (Cropanzano \& Wright, 2001)

Task performance is the proficiency with which job incumbents perform activities that are formally recognized as part of their jobs (Borman \& Motowidlo, 1993).

Spillover hypothesis states that positive experiences within one domain such as work repeat themselves in other domains such as leisure (Petrou \& Bakker, 2016).

Compensation hypothesis states that unattained goals or desired states in one domain can be achieved through activities in other domains (Petrou \& Bakker, 2016).

\section{Significance of the Study}

Organizations are consistently seeking out methods to increase work engagement, develop employee psychological well-being, increase job performance among other work-related aspects. The research on job and leisure crafting has shown that when employees are allowed to adapt their jobs and/or utilize leisure skills within their job, positive outcomes become apparent. But the number of studies that address the interaction of job and leisure crafting are limited. 


\section{CHAPTER II}

\section{LITERATURE REVIEW}

Work. What does that word mean to you? No two people will have the exact same answer to that question. We all know that work in a basic sense is a means to an end as it provides us financial benefits to survive and satisfy our needs as human i.e., food, shelter and water. But what else does work provide you? Social outlets? A sense of accomplishment and meaning? Work provides a routine experience that can impact daily life either positively or negatively. We spend a significant amount of our life at work but our commitment to work and how we view its existence can drastically vary. The same can be said for individuals outside of work. But why is this? Do some people have more innate personalities that make them better workers? Is family of origin a factor? Our identities are shaped by how we experience the world; and work and leisure are significant contributors to this interaction. The concept of job and leisure crafting suggest that being able to mold your job and leisure activities to alter your view of work are strategies that are useful for improve work commitment, overall performance (Tims, Bakker, \& Derks, 2013) and well-being.

Job crafting looks at how employees can directly change the physical, social and cognitive aspects of their work by altering the boundaries of each of these dimensions whereas leisure crafting focuses on when the opportunities to job craft are not available or are not supported by an organization, individuals can seek fulfillment and shape their 
leisure activities to reflect their passion and values. As individuals engage in either or both of these types of crafting, research shows that employees display more engagement in the workplace, increased task performance and an overall better sense of psychological well-being. The idea of job and leisure crafting is to give individuals an outlet for taking more personal control of their work environment to make a positive change that essentially affects both work and outside work. This proposal evaluates the effect of work centrality (how meaningful work is to our identity) on what is known as job crafting and leisure crafting as an outcome of work engagement and task performance.

\section{Background of Job Design}

The stage for job design research was set by economic perspective on the efficiencies of specialization and division of labor. Early in the 20th century, time-andmotion studies in scientific management brought the design of work to the attention of organizational scholars. In part as a reaction to the unintended satisfaction and motivation costs of specialization and division of labor, researchers launched the human relations movement. This movement began with the study of whether improving environmental and social conditions would enhance employee motivation, satisfaction, comfort, and productivity (Mayo, 1933, 1945; Roethlisberger \& Dickson, 1939). In the following decades, scholars planted the roots of contemporary work design research. Herzberg and colleagues proposed that jobs could be enlarged and enriched to increase motivation and satisfaction (Herzberg, 1966; Herzberg, Mausner, \& Snyderman, 1967). Turner and Lawrence (1965) called attention to the importance of task attributes in shaping job perceptions and behaviors, and the Tavistock scholars examined the interdependencies of social and technical systems (Trist \& Bamforth, 1951; Walker \& Guest, 1952). During 
the 1970s, Hackman and colleagues synthesized and expanded previous ideas about work design into the Job Characteristics Model (JCM).

\section{Theoretical Framework for Job Characteristics Model (JCM)}

The Job Characteristics Model (JCM) was developed by Hackman and Oldham (1976) who proposed a model that specifies conditions under which individuals would become internally motivated to perform effectively on their jobs. The JCM (Hackman \&

Oldham, 1976) model was built on several existing theoretical approaches to job redesign including motivation hygiene theory (Herzberg, 1966), activation theory (Scott, 1966), socio-technical systems theory (Emery \& Trist, 1969) and the jobs an individual differences interactive approach (Turner \& Lawrence (1965).

Herzberg (1966) two-factor theory of satisfaction and motivation proposes that the primary determinants of employee satisfaction are factors intrinsic to the work that is done. Herzberg (1966) calls these factors "motivators" because they are believed to be effective in motivating employees to superior effort and performance. Herzberg (1966) describes "hygiene factors" leading to dissatisfaction that are extrinsic to the work itself. Herzberg (1966) two-factor theory specifies that a job will enhance motivation and satisfaction only to the degree that "motivators" are designed into the work itself. Herzberg (1966) theory prompted research in the area of job redesign to spike but a number of researchers were not able to provide empirical support for the two-factor theory itself (Hinton, 1968; King, 1970; Dunnette, Campbell \& Hakel, 1967). Criticism of the two factor theory (Herzberg, 1966) includes that the theory does not provide for difference among people in how responsive they are likely to be to "enriched" jobs. In a research study conducted by AT\&T based in the theory, Ford (1969) assumed that the 
motivating factors could potentially increase the work motivation of all employees. Ford (1969) found that some individuals are much more likely to respond positively to an enriched, complex job than others. This issue became one of the fundamental concepts for the job characteristics model.

Activation theory was originally developed to study the antecedents and consequences of heightened and depressed levels of psychological and physiological activation in organisms (Berlyne, 1967). Scott (1966) studied how people react to chronic states of under-activation at work by engaging in arousal-enhancing behaviors, some which are clearly counterproductive to work effectiveness. Scott (1966) found that activation theory may be useful in understanding jobs that are highly repetitive and in planning task designs. Though Scott (1966) saw benefits to applying the activation theory to organization settings, two problems were identified by other researchers (Thayer, 1967; Hinton, 1968). Firstly, a measurement system needed to be developed for assessing current levels of activation of individuals in actual work settings and for evaluating the “optimal level" of activation for different individuals. Secondly, activation theory (Scott, 1966) contains ambiguities regarding the processes by which individuals adapt to changing levels of engagement. Scott (1966) presented future implications of the research including developing a more complete understanding of the "waxing and waning" of activation in various circumstances which could have more implications for job design practices; i.e., the practice of "job rotation". Hackman \& Oldham (1976) state that the theory offers less guidance for the design of work that will elicit and maintain positive and self-reinforcing work motivation.

The interdependencies between technical aspects of work itself and the broader 
social contexts in which work is performed is explained by Emery \& Trist (1969) theory of socio-technical systems. A core concept within socio-technical systems theory is the notion of "autonomous work group" where members of a work team share among themselves the majority of decision making having to do with planning and the execution of work (Gulowsen, 1972). The creation of autonomous work groups promised to become increasingly prominent and useful as a strategy for redesigning work systems but fell short in applied literature. Socio-technical systems approach did not provide adequate specifications of how the work itself and the social surrounding affected one another. Because of this, it is difficult to test the adequacy of the theory. Also, the theory provides little guidance to researchers on how to proceed in carrying out job redesign activities other than the aspects of an autonomous work group (Hackman \& Oldham, 1976). Based on the lack of theoretical discussion, the value of socio-technical systems theory (Gulowsen, 1972) appears to be its usefulness as a way of thinking about work systems and their redesign.

Turner \& Lawrence's (1965) research on job design that focuses on the objective characteristics of jobs appeared to be the catalyst for the research performed by Hackman \& Oldham (1976) regarding the core dimensions used in the job characteristics model. Turner \& Lawrence (1965) developed six measures of "requisite task attributes" that were designed to relate the positive correlation between employee satisfaction and attendance at work. The Requisite Task Attributes Index (RTA Index) (Turner \& Lawrence, 1965) was derived from these six measures and was used to test the relationship between the nature of jobs and employee reactions to them. Hackman \& Lawler (1971) provided further evidence that job characteristics can directly affect 
employees' attitudes and behaviors at work. Hackman \& Lawler (1971) suggested that employees should react positively to four core dimensions of the RTA Index (variety, task identity, autonomy, feedback) and proposed that individuals who wanted higher job satisfaction at work should respond positively to jobs high on the core dimensions. Hackman \& Lawler (1971) also found that number of dependent measures was moderated as predicted by growth need strength: employees with high measured needs for growth more positively responded to complex jobs than employees who were low in growth need strength.

\section{Job Characteristics Model}

By illustrating the models and theories presented above, Hackman \& Oldham (1976) were able to further develop upon their frameworks and create the Job Characteristics Model. At its most general level, the job characteristics model contain 5 "core" job dimensions which are seen as prompting three psychological states which in turn, lead to a number of beneficial personal and work outcomes. Based on Figure 1 displayed below, there are three core job dimensions (skill variety, task identity, task significance) that determine the psychological meaningfulness of job (Hackman \& Oldham, 1976). Skill variety is defined as (Hackman \& Oldham, 1976) the degree to which a job requires a variety of different activities in carrying out the work, which involves the use of a number of different skills and talents of the person (p.22). When a task required a person to engage in activities that challenge or stretch his skills and abilities, the task is inadvertently experienced as meaningful by the individual (Hackman \& Oldham, 1976). When a job draw upon several skills of an employee, the individual may find the job to be of enormous personal meaning even if it is not of 
significant importance (Hackman \& Oldham, 1976). Task significance is defined as (Hackman \& Oldham, 1976):

The degree to which the job has substantial impact on the lives or work of other people, whether in the immediate organization or in the external environment. (p.21)

This is explained as when an individual understands that results of his work may have a significant effect on the well-being of other people, the meaningfulness of the work is enhanced (Hackman \& Oldham, 1976). For example, an employee who tightens nuts on aircrafts are much more likely to perceive their work as meaningful than workers who fill small boxes of paper clips. Task identity is defined as (Hackman \& Oldham, 1976):

The degree to which the job requires completion of a "whole" and identifiable piece of work; doing a job from beginning to end with a visible outcome. (p. 21)

The example of an employee who assembles a complete product should find the work more meaningful than someone who was only responsible for a small part of the whole job, assuming other dimensions such as skill variety are held constant. 
Figure 1

The Job Characteristics Model of Work Motivation

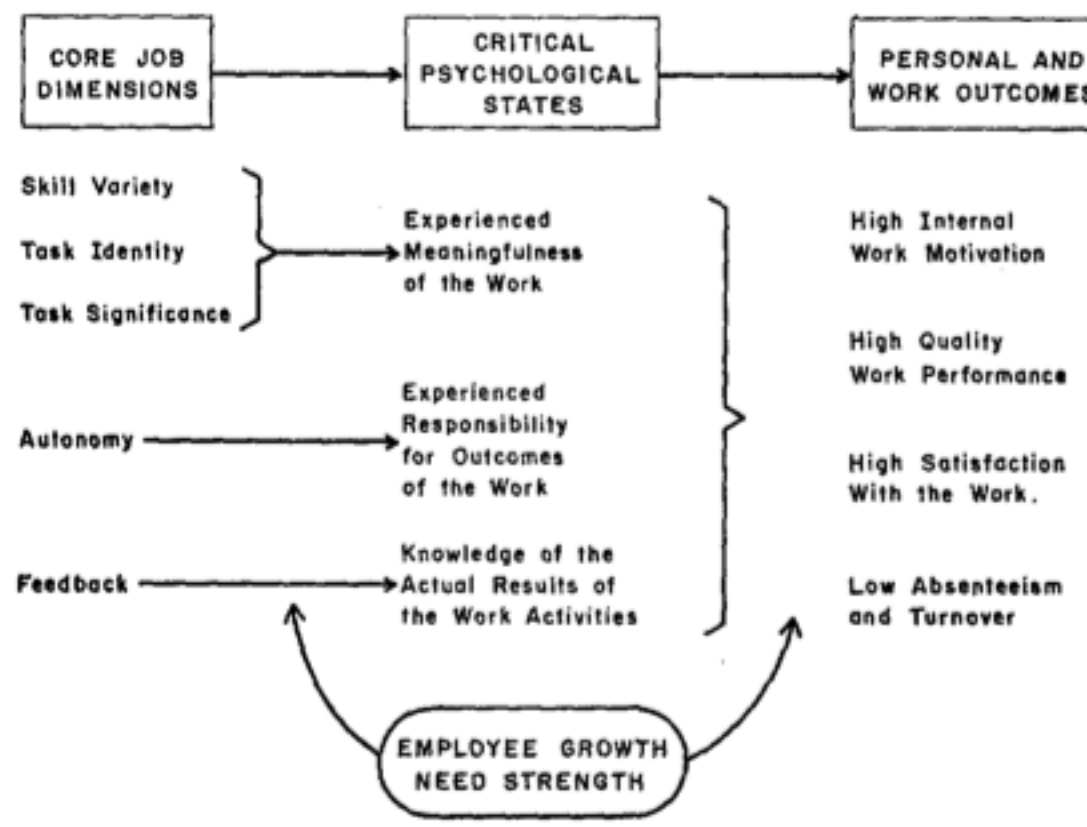

FIG. 1. The job characteristics model of work motivation.

The next psychological state described by Hackman \& Oldham (1976) is

experienced responsibility for outcomes of the work. The job characteristic that predicts employee feeling of personal responsibility for the work outcome is autonomy, which is defined as (Hackman \& Oldham, 1976):

The degree to which the job provides substantial freedom, independence, and discretion to the individual in scheduling the work and in determining the procedures to be used in carrying it out. (p. 24) 
Hackman \& Oldham (1976) represent autonomy as to the extent that a job has high autonomy, the outcomes depend increasingly on the individual's own efforts, initiatives and decisions rather than on the adequacy of instructions or on a manual of job procedures. The employee should feel a strong connection for the successes and failures that occur on the job. Feedback is the last core job dimension within the job characteristics model and the dimension that leads to the knowledge of actual results of work activities. Hackman \& Oldham (1976) define feedback as:

The degree to which carrying out the work activities required by the job results in the individual obtaining direct and clear information about the effectiveness of his/her performance (p.221)

Based on the job characteristics model presented, high levels of each core dimension will lead to increasing levels of critical psychological states, resulting in more satisfying personal and work outcomes such as high internal motivation, work motivation, high work quality, high satisfaction with the work and low absenteeism and turnover. Though the job characteristics model lays out a linear flow chart of how job dimensions affect psychological states and personal/work outcomes, it doesn't represent how each dimension/state is weighed relative to each other or the predictability of the model for an employee with high motivation vs. low motivation. Hackman \& Oldham (1976) further the research by developing a measure that would predict an employee's motivating potential. According to Hackman \& Oldham (1976), the overall potential of a job to prompt internal work motivation should be highest when all of the following are true: the job is high on at least one of the three job dimensions that lead to experienced meaningfulness, the job is high on autonomy and the job is high on feedback. This 
suggests that an employee who is rated high on each of these criteria would have the optimal motivating work potential and perform their job at a high capacity. Hackman \& Oldham (1976) present the following equation as a means of quantify the relationship between each of the criteria and their effect on an employees' motivating potential:

Figure 2

The Motivating Potential Score (MPS)

$$
\begin{aligned}
& \text { Motivating } \\
& \text { Potential }= \\
& \text { Score (MPS) }
\end{aligned}\left[\begin{array}{c}
\text { Skill } \\
\text { Variety }
\end{array}{ }^{\text {Tdentity }}+\begin{array}{c}
\text { Task } \\
\text { Significance }
\end{array}\right] \times \text { Autonomy } \times \text { Feedback }
$$

Hackman \& Oldham (1976) point out that based on the above formula, a near score on either autonomy or feedback will reduce the overall MPS scores to near zero, whereas a near zero score on one of the three job dimensions that contribute to experienced meaningfulness cannot do so. To increase an employees' motivating potential, it appears that based on this equation, it is more important to focus on external variables (autonomy and feedback) vs. interval variables (skill variety, task identity and task significance). A higher score on an external "motivator" will result in significantly higher motivating potential. Moreover, since motivating potential will differ across people, individual need strength will also vary based on individual scoring. In Figure 1, Hackman \& Oldham (1976) show a connection between core job dimensions and personal/work outcomes that are linked by employee growth need strength. The basic prediction for employee growth need strength is that people who have high need for personal growth and development could respond more positively to a job high in 
motivating potential than people with low growth need strength (Hackman \& Oldham, 1976). There are only two sites in JCM where individual growth need strength can be measured and addressed: the link between job dimensions and psychological states and the link between psychological states and outcome variables. An employee who has high or low levels of growth need strength can range based on where the deficit lies in the motivating potential. Employee growth need strength between core job dimensions and psychological states would "imply that high growth needs people are more likely to experience the psychological states when the objective job is good than are this low growth counterparts" (Hackman \& Oldham, 1976). Employee growth need strength between psychological states and outcomes "allows the possibility that nearly everybody may experience the psychological states when job conditions are right, but that individuals with high growth needs respond more positively to that experience" (Hackman \& Oldham, 1976).

From the job characteristics model developed by Hackman \& Oldham (1976) came more than two decades of research inspired by the JCM. Through research across multiple industries and individuals, two main conclusions about the JCM arose: the collective effects of the core job dimensions on affective responses (satisfaction and motivation) have been largely supported, but those for behavior (work, performance, turnover and absence) are less consistent; the more specific features of the model remain unproven (Parker \& Wall, 1998). Job crafting aims to address these deficits by examining the individual and how they relate to their work through the work they do, the relationships they foster and how they think about their work. 


\section{Job Crafting}

The job-crafting model was developed by Wrzesniewski \& Dutton (2001) on the premise that employees exert some influence on what work means for the person. Traditionally, organizational researchers have focused on either individual determinants (Dubin, 1956; Roberson, 1990) such as attitude and personality types or external characteristics of the job itself (Griffin, 1987; Hackman \& Oldham, 1976) such as work tasks, work schedule and work design. Work tasks and interactions that compose the days, the jobs and the lives of employees are the raw material that employees use to construct their jobs (Wrzesniewski \& Dutton, 2001). With these materials, employees build the experience of work including the meaning of work and their work identities, but these are not fully determined by formal job requirements. Individuals have leverage to define and enact the job, which Wrzesniewski \& Dutton (2001) define as "job crafters". Job crafting as the "physical and cognitive changes individuals make in the task or relational boundaries of their work" (Lyons, 2008; Petrou et al., 2012; Tims \& Bakker, 2010; Wrzesniewski \& Dutton, 2001) The process of revising one's position to expand these cognitive and relational boundaries is called job crafting. An employee who engages in these constructs is known as a job crafter (Tims \& Bakker, 2010).

Job crafting can be viewed in three boundaries: task, relational and cognitive (Petrou et al., 2012; Tims, Bakker, \& Derks, 2015); Wrzesniewski and Dutton (2001). Task crafting involves shaping the task boundaries of a job such as changing the number, scope and type of job tasks. For example, design engineers engage in tasks that move a project towards completion and alter the meaning of their jobs to guardians and movers of projects. Relational crafting looks at changing the quality and/or amount of interaction 
with others encountered in the job. For example, hospital cleaners actively caring for patients and families by integrating themselves into the workflow of their floor units which adjusts the meaning of the cleaners' job as an integral part of the treatment team. Cognitive crafting refers to altering how one sees the job and changing the cognitive task boundaries. For example, nurses taking responsibility for all information and "insignificant" tasks that may help them to care more appropriately for a patient. By engaging in cognitive crafting, in this example, nurses change the way they see the work to be more about patient advocacy and high quality healthcare. But what motivates someone to want/need to job craft? What issues stand in the way of job crafting taking place? These questions are pertinent to the purpose of the dissertation and are discussed below.

\section{Motivations to Job Craft}

Wrzesniewski and Dutton (2001) looked at three main motivations for job crafting: to assert control over their jobs in order to avoid alienation from their work (Braverman, 1974), to create a positive self-image in their work and to fulfill a basic need for connection to others (Baumeister \& Leary, 1995).

\section{Personal Control}

It can be argued that the need for personal control is a basic human instinct that affects every environment in which humans are apart. The implications of having little control over one's work are hallmarks of alienating work. When employees take control of or reframe personal control, job crafters make their job their own even in low autonomy jobs where employees create new domains for mastery and shape facets of job tasks. 


\section{Positive Self Image}

It can be argued that people also desire to create and sustain a positive sense of self in their our own eyes and in the eyes of others. This is also the case when individuals are at work. When the jobs that people have made this positive construction of selfdifficult, individuals are motivated to remedy the situation. Roger (1995) describes how temporary workers change the pace of the work while working in temporary jobs to separate negative impressions of temp work from the positive image they have of themselves as people. This pressure to create a positive image affects many aspects of employees' work activities.

\section{Connection to Others}

It can be argued that human beings are motivated to forge connections with others as a way to introduce meaning into their lives. Most theories of the meaning of work are individually based but job crafting extends this view by showing that employees build relationships with others at work to reframe the meaning of work and their work identities. For example, when hospital cleaners integrate themselves into patient care functions, they are able to see their work as being about healing people and to see themselves as a key part of this process. This dynamic shift enhances work meaning, creates a more positive work identity and allows employees to narrate a different sense of who they are at work and why the work matters.

Individuals who look to fulfill these needs at work likely will look for opportunities to craft their jobs in ways that allow them to meet their needs. But others may have these needs met outside of work, their job may not be conducive for job 
crafting to be implementing or the perception of job crafting opportunities are not present.

Even when there is motivation to job craft, moderating variables may be present that hinder an employees' ability to job craft such as the perceived opportunity to job craft. Wrzesniewski and Dutton (2001) show two main contributors that examine an employees' ability to job craft: the level and form of task interdependence and the level of freedom to job craft implied by monitoring systems in the job. Each task carried out at work has some level of task interdependence built in and is defined as "the extent to which the items or elements upon which work is performed or the work processes themselves are interrelated so that changes in the state of one element affect the state of the others" (Scott, 1987, p. 214). Those with more task interdependence work under more constraints and have less freedom to alter tasks and relational boundaries as a result (Wrzesniewski \& Dutton, 2001). The level of supervision implemented by management can also affect whether employees perceive opportunities to job craft. Because job crafting aims at improving person-job fit and work motivation Tims et al. (2012) and does not imply managerial consent, it may be less welcomed and frowned upon. Task and relational crafting tend to be more observable to supervisors and customers and with customer service focused jobs, employees may perceive less opportunities to craft their jobs due to the level of oversight. For example, employees in traveling positions or who work from home may perceive more opportunities to be creative and crafting their jobs because they are not directly supervised by a superior. The perceived opportunities to job crafting is a distinct difference between job crafting theory and job design theory especially on the view of autonomy in the work. Job crafting theory asserts that job 
autonomy leads to perceived opportunities to job craft, allowing employees to alter the tasks and relational boundaries of their jobs (Wrzesniewski \& Dutton, 2001), whereas the job design perspective assumes that autonomy in the work leads to enhanced meaning in the work and employees feel responsible for the job.

\section{Job Demands-Resource Model}

Though Wrzesniewski and Dutton (2001) seminal article defining job crafting made strides in the field of job redesign, studies found that the established definition of job crafting limited changes to those changes that employees may make in their work tasks, relationships at work and cognitions about work. Lyons (2008) found that the salespersons in the corresponding study engaged in self-initiated skill development and Grant et. al. (2010) showed employees working in a service job reprimanded or avoided serving unpleasant clients. Based on the current definition of job crafting, these activities would not be considered job crafting because of their ineffective means to alter task, relational or cognitive activities at work. In order to capture these representations of job crafting presented in the literature, Tims et al. (2012) theoretically framed their definition of job crafting in accordance to the Job Demands-Resource Model. Under this model, job crafting is defined as "the changes that employees may make to balance their job demands and job resources with their personal abilities and needs" (Tims \& Bakker, 2010). The JD-R model reduces all job characteristics into two broad categories: job resource and job demands. Job demands are all aspects of the job that require sustained physical and/or psychological (cognitive and emotional) effort or skills (Tims \& Bakker, 2010). Job demands are associated with certain psychological costs such as heavy workload and emotionally demanding interactions with others. Job resources refer to 
"aspects of the job that are either functional in achieving work goals, reduce job demands, and the associated physiological and psychological costs and stimulate personal growth, learning and development" (Bakker \& Demerouti, 2007). Autonomy and performance feedback are examples of job resources.

Job crafting consists of three conceptually different dimensions when using the JD-R model (Bakker \& Demerouti, 2007): increasing structural job resources, increasing social job resources, increasing challenging job demands and decreasing hindering job demands.. Job resources are defined as "the aspects of the job that are either/or functional in achieving work goals, reduce job demands and the associated physiological and psychological costs and stimulate personal growth, learning and development”(Bakker \& Demerouti, 2007). Examples include autonomy and performance feedback. Job resources are important predictors of positive work outcomes such as work engagement, commitment and client satisfaction but can also act as a buffer to undesired work outcomes (Tims \& Bakker, 2010). Salanova, Agut, and Peiro (2005) showed that job resources foster work engagement and in turn lead to positive organizational outcomes (Xanthopoulou, Bakker, Demerouti, \& Schaufeli, 2009). Job resources are also able to buffer the negative effects of job demands and may lead to high levels of work engagement when job demands are high.

The second dimension of job crafting looks at increasing social job demands. The second dimension of job crafting concerns increasing the level of challenging job demands. Employees may create more challenges at their work when they feel that their job is not offering them enough opportunities to use all their skills (Tims \& Bakker, 2010). These demands are defined as challenging demands and may include employees 
adding tasks to their jobs, volunteering for interesting project groups or taking over tasks from their supervisor and all produce positive work outcomes. This is essential in understanding the difference between challenging demands and hindering demands that will be examined in the third dimension. Lepine, Podsakoff, and LepIne (2005) found that challenging job demands stimulate employees to develop their knowledge and skills and to attain more difficult goals and offer mastery experiences that in turn may lead to satisfaction and high levels of self-efficacy.

The third dimension of job crafting refers to decreasing the level of hindering job demands. Job demands are defined as "all aspects of the job that require sustained physical and/or psychological (cognitive and emotional) effort or skills thus have physiological or psychological costs" (Tims et al., 2012). Examples include a heavy workload and emotionally demanding interactions with others. Employees may proactively lower their job demands when they perceive that their job demands have become overwhelming (Tims et al., 2012). Prolonged exposure to high demands in combination with low levels of job resources may lead to negative health consequences such as burnout and negative organizational consequences such as personnel turnover (Bakker, Emmerik, \& Euwema, 2006). The reduction in hindering job demands may also be achieved by asking colleagues to help them with their tasks or by reducing the number of interactions they have with demanding customers or colleagues (Tims \& Bakker, 2010). Examples of hindering demands include role ambiguity, concerns about job security and role conflict (Lepine et al., 2005). For employees, identifying hindering job demands and finding a way to reduce them is important in order to perform well and to be satisfied with their jobs. 


\section{Leisure Crafting}

As stated above, job crafting can be a valuable tool for shaping one's experience and engagement at work but, the perceived opportunities to job craft may be low and it acceptance in the workplace not welcomed. In these situations, the notion of "leisure crafting" takes affect so employees can fit their preferences and values into the workplace (Wrzesniewski \& Dutton, 2001). In leisure crafting, individuals seek fulfillment and shape their leisure activities to address their passions and values (Berg et al., 2010) in very much the same way job crafters reshape their jobs to increase personal fulfillment. Berg et al. (2010) defines leisure crafting as "the proactive pursuit of leisure activities targeted at goal setting, human connection, learning and personal development”. Based on this definition, three elements of leisure crafting arise: leisure crafting is proactive, serious and intentional (Fritz, 1995; Stebbins, 2001), through leisure crafting, individuals learn new things and develop themselves through challenges that enhance their feelings of mastery (Sonnentag \& Fritz, 2008) and leisure crafting experiences involve companionship and the development of interpersonal relations (Snir \& Harpaz, 2002). Leisure crafting operates in a similar manner as job crafting but focuses on the reshaping of the task and relational boundaries of leisure by looking for new challenges and building new and inspiring relationships (Petrou \& Bakker, 2016). When assessing the presence of leisure crafting, we must distinguish between participation in leisure activities and leisure crafting. The distinction between these terms is vital because of three additional elements identifying leisure crafting as contact with others and the development of human relations, entails goal setting and is a behavior of long term 
commitment (Petrou \& Bakker, 2016). An example from Petrou and Bakker (2016) further outlines the distinction between these terms:

Tom plays in an amateur theatre group that prepares a theatre performance. He happily attends the weekly meeting of the group but he is not busy with the group the rest of the week. His reason for attending is the satisfaction he experiences when on stage. Amanda is a member of the same group and one of the members who started up the group. She is constantly busy with the development of the performance during the week. Although immediate satisfaction motivates her too, she is willing to put up with the occasional pains of the group so as to be rewarded with an end product of extraordinary performance she has envisioned. (p. 520)

In the above example, Tom was participating in a leisure activity whereas Amanda engaged in leisure crafting. But why would someone engage in leisure crafting vs. just participating in a leisure activity? Is leisure crafting really that much more effective at improving passion and values at work? The two hypotheses that dominate the literature on how work interferes with leisure are the compensation and spillover hypotheses (Guest, 2002; Snir \& Harpaz, 2002).

\section{Spillover and Compensation Hypotheses}

The spillover hypothesis states that positive experiences within one domain such as work repeat themselves in other domains such as leisure (Petrou \& Bakker, 2016). Karasek (1979) was one of the first to explore the impact of the spillover hypothesis on work and leisure. Karasek (1979) developed the Demand-Control Model to suggest that jobs are categorized by the level of demand it requires and the amount of control an 
employee has over the job itself. An "active job" is a job with high demands but also high control, which allows the employee to balance its relationship. A "high strain" job is a job with high demands but low control, resulting in an imbalance in the demand-control relationship. According to Karasek (1979), an active job motivates employees to develop new behavioral patterns on and off the job including home as well as leisure activities. According to the compensation hypothesis, unattained goals or desired states in one domain can be achieved through activities in other domains (Petrou \& Bakker, 2016). For example, work may be routine and undemanding but it is compensated for by a major role in local community activities outside of work (Guest, 2002). Leisure crafting has the potential to transcend negative life events and help individuals compensate for undesired states of other life domains. Petrou et al. (2017) showed that when the resources of a job (i.e., tasks, relations, and knowledge) are depleted (e.g. via job crafting) employees are most likely unable to address their unmet needs within their jobs and therefore, they can be expected to compensate for these needs via leisure crafting. This research will focus mainly on the compensation hypothesis and employees' inability to compensate for unmet needs at work with job crafting with leisure activities outside of work via leisure crafting. But an important measure of job crafting is the amount an employee identifies with work and more specifically their job. The next section details the importance of occupational role salience and how someone views work as a part of who they are.

\section{Occupational Role Salience}

For each employee, work fulfills various levels of self-definition and personal satisfaction. For some, work is central to who they are and how they describe themselves but for others, work serves as a means to an end or an exchange of services for financial 
gains. This phenomenon is known as role salience, more specifically occupational role salience (ORS). Employees with high occupational role salience treat their work as an important means of self-definition and personal satisfaction (Amatea et al., 1986). Individuals whose work is central in their life tend to be characterized by work ethic endorsement which means work is desirable and rewarding in its own right, not because of extrinsic rewards (Hirschfeld \& Feild, 2000). Bal and Kooij (2011) showed that individuals with high ORS are more likely to invest time and energy into the work domain and display extra role efforts at work. Based on these findings, Petrou et al. (2017) suggested that job crafting activities are indicative of work commitment and strong action readiness thus, leading to desired end states such as work engagement.

When an employee has high ORS suggesting strong work centrality, they may also treat work as a primary source of meaning and identity (Rosso, Dekas, \& Wrzesniewski, 2010). This relationship also suggests that individuals with strong beliefs about work centrality are likely to perceive greater meaningfulness in their work but also experience increased devastation when losing a job or retiring from the workforce (Rosso et al., 2010). The more important work is for employees, the more likely it is that they will spend more of their time on work related activities and that they will derive purpose from their jobs. Wrzesniewski et al. (2003) suggested that employees would use cues and information from their work environment to either reinforce their meaning of work or alter this meaning to be more effective in the specific setting. Though Wrzesniewski et al. (2003) work mainly focused on the effect of co-workers on one's meaning of work, their research highlighted the importance of work being the primary source for self-reflection especially for employees with high work centrality. 
Based on the literature of occupational role salience and job crafting presented, there appears to be a relationship between how important and meaningful work is to an employee and the likelihood that they will use job crafting to alter its status within their jobs. Wrzesniewski and Dutton (2001) state "such actions (task, relational, cognitive crafting) affect both the meaning of work and one's work identity" (p.180). Petrou et al. (2017) explored the mediating role of occupational role salience on job and leisure crafting and work engagement and meaning making, resolving that when the occupational roles more salient to employees, they will engage in job crafting in order to create such jobs that will make them enthusiastic and capable of seeking and finding meaning.

\section{Work Engagement}

When an employee is able to craft their job due to high occupational role salience, they are more likely to be engaged in their work and within their organization. An increase in work engagement has also positively related to task performance within the workplace (Van Wingerden, Derks, \& Bakker, 2017). Work engagement is defined as a "positive, fulfilling, work related state of mind that is characterized by vigor, dedication, and absorption" (Schaufeli et al., 2002). This model of work engagement is represented in the Job Demands-Resource Model (Bakker \& Demerouti, 2008) as job and personal resources are the most important predictors of work engagement. As explained in the JD$\mathrm{R}$ literature, the balance of job resources and job demands is necessary to keep an employee actively engaged and maintain the meaning of work. Van Wingerden, Derks, et al. (2017) find work engagement occurring "when employees have an optimal balance 
between their job demands, such as workload and demanding pupils, and their resources, such as feedback, self-efficacy, and social support" (p.52).

The Schaufeli and Bakker (2004) definition of work engagement outlines three characteristics: vigor, dedication and absorption. Vigor is identified by high levels of energy and mental resilience while working, the willingness to invest effort in one's work and persistence even in the face of difficulties and is seen as the direct positive opposite of exhaustion (Schaufeli \& Bakker, 2004). Dedication is seen as being strongly involved in one's work and experiencing a sense of significance, enthusiasm, inspiration, pride and challenge and is seen as the direct positive opposite of cynicism. Lastly, absorption is characterized by being fully concentrated and happily engrossed in one's work, where time passes quickly.

Research has also shown that there is a positive relationship between job resources and work engagement (Bakker \& Demerouti, 2008), thus encouraging the use of the JD-R model. Previous studies have consistently shown that job resources such as social support from colleagues and supervisors, performance feedback, skill variety, autonomy and learning opportunities have all resulted in a positive association with work engagement (Bakker \& Demerouti, 2007; Schaufeli \& Salanova, 2007). Schaufeli and Bakker (2004) found evidence for a positive relationship between three job resources (performance feedback, social support and supervisory coaching) and work engagement among four different samples of Dutch employees. Hakanen, Bakker, and Schaufeli (2006) replicated these results with Finnish teachers and showed that job control, information, supervisory support, innovative climate and social climate were positively related to work engagement. 
The use of the JD-R approach to job crafting has spark interests in how employee driven changes in job characteristics contribute to work engagement (Tims, Bakker, Derks, \& van Rhenen, 2013). The JD-R model shows that job characteristics are motivational and which job characteristics are health impairing (job resources coupled with challenging job demands and hindering job demands). According to JD-R theory, every job consists of job demands and job resources and Tims et al. (2012) postulates that employees can craft their own jobs by increasing social job resources, increasing structural resources, increasing challenging job demands or decreasing hindering job demands. Job crafting entails the changes individuals make in their level of job demands or job resources, which directs attention to the proactive bottom up ways in which employees alter the tasks and boundaries of their jobs (Van Wingerden, Derks, et al., 2017). Through job crafting, employees can improve the fit between their personal needs, abilities, and passions about the job and as a consequence, employees may be more able to increase their own work engagement (Tims \& Bakker, 2010).

But the question still remains: why do engaged workers perform better? Van Wingerden, Derks, et al. (2017) show four reasons why engaged workers perform better than non-engaged workers and those reasons include: experience positive emotions including joy, happiness and enthusiasm; better health; create their own job and personal resources; and transfer their engagement to others. Happy people are more sensitive to opportunities at work, more outgoing and helpful to others and more confident and optimistic (Cropanzano \& Wright, 2001). Schaufeli \& Bakker (2004) found in their study among four different Dutch service organizations that engaged workers suffer less from self reported headaches, cardiovascular problems and stomach aches. Schaufeli et. al. 
(2008) showed among managers, engagement was predictive of increases in next year's job resources including social support, autonomy, learning opportunities and performance feedback.

\section{Psychological Well-being}

The topic of welling being has been focused on in the job crafting literature but the combined effect of job crafting and leisure crafting on well-being has not been sufficiently researched. Previous research and philosophical approaches have created two distinct views of well-being: hedonic and eudemonic. The hedonic approach to wellbeing concentrates on the preferences and pleasures of the mind as well as the body. Hedonic psychologist believe that well-being consist of subjective happiness and concerns the experience of pleasure versus displeasure construed to include all judgments about the good/bad elements of life. Kahneman et. al. (1999) defined hedonic psychology as the study of "what makes experiences and life pleasant and unpleasant" and by defining well-being in terms of pleasure vs. pain, hedonic psychology poses itself a clear target for maximizing human happiness. Most research on hedonic psychology has used assessments of subjective well-being to evaluate the pleasure/pain continuum of human experience and Diener \& Lucas (1999) consisted of three components: life satisfaction, the presence of positive mood and the absence of negative mood.

The eudemonic approach to well-being suggests that true happiness is found in the expression of virtue or in doing what is worth doing. Eudemonic theories hold that not all outcomes that a person might value would yield well-being when achieved. The eudemonic concept of well-being calls upon people to live in accordance with their true self and suggests that full well-being occurs when people's life activities are most 
congruent with deeply held values and are fully engaged. Ryff \& Singer (1998) explored the question of well-being in the context of developing a lifespan theory of human flourishing. Ryff \& Keyes (1995) spoke of psychological well-being (PWB) as distinct from subjective well-being (SWB) and presented a multidimensional approach to the measurement of PWB. Ryff \& Keyes (1995) multidimensional measurement model includes six distinct aspects of human actualization: autonomy, personal growth, selfacceptance, life purpose, mastery and positive relatedness.

The effect of job crafting on well-being has been widely researched and several studies show that job crafting has an overall positive effect on increasing employee wellbeing. van Wingerden, Bakker, and Derks (2017) found that job-crafting interventions resulted in increased levels of basic needs satisfaction including competence, autonomy and relatedness. Tims, Bakker, and Derks (2013) showed that job crafting could build well-being in the form of increased engagement, job satisfaction and decreased burnout over time. Petrou et al. (2012) used a modified version of Tims et al. (2012) job crafting scale and found associations between some facets of job crafting, employee engagement and well-being. Nielsen and Abildgaard (2012) expanded on these findings by detecting longitudinal associations between job crafting and increased levels of job satisfaction and engagement which provides support for a positive association between job crafting and employee well-being.

\section{Job Performance}

The relationship between job crafting and task performance has been widely studied in the current literature. Borman and Motowidlo (1993) define task performance as "the proficiency with which job incumbents perform activities that are formally 
recognized as part of their jobs" (p. 73). Within the job crafting conceptual model developed by Wrzesniewski and Dutton (2001), task, relational and cognitive crafting are found to improve overall task performance based on their distinct attributes for modifying behaviors for individual employees. By engaging in each of these crafting styles, employees essentially create a different job and increase autonomy, competence and relatedness at work (Deci \& Ryan, 2000).

To better comprehend the connection between task performance and job crafting, the motivation theory behind its existence needs to be well understood. According to the self determination theory (SDT), the satisfaction of psychological needs for relatedness, competence and autonomy enables intrinsic motivation (Deci \& Ryan, 2000). With task crafting, while still fulfilling prescribed tasks, employees focus or take on additional tasks that satisfy their needs to enrich their job (Wrzesniewski \& Dutton, 2001). The SDT proposes that intrinsically motivated people put more effort and energy into their actions including their prescribed tasks with positive consequences for their performance (Weseler \& Niessen, 2016). Research has shown a positive relationship between extending behaviors and peer rated task performance as well as employees who develop their occupational skills and who volunteer for extra tasks (Bakker, Tims, \& Derks, 2012; Tims et al., 2012). Though extending behaviors leads to an increase in performance, the inverse is also true. When task reductions are not negotiated with supervisors, these will more than likely be viewed as counterproductive work behaviors, which have been found to be negatively related to task performance (Gruys \& Sackett, 2003). Tims et al. (2012) demonstrated that employees who tried to reduce hindering job demands in order to protect their health had poor peer rated task performance ratings. The tight rope balance 
between increasing challenging job demands, structural job resources and meeting organizational expectations is difficult and carries over to the other forms of job crafting.

As highlighted above, employees can also craft their jobs by extending and deepening their social relationships at work (Weseler \& Niessen, 2016). According to SDT, spending more work time with valued and liked individuals can satisfy needs for relatedness and employees will then be motivated to perform better (Grant, 2007). Daniels et. al. (2014) found that talking to others at work in order to express affect was related to self rated performance by increasing one's understanding of their own work goals. Zou and Ingram (2013) found that social networking is positively related to task performance evaluations from supervisors and colleagues, especially when networks are built within one's team or within network boundaries. But Tims et al. (2012) and Bakker et al. (2012) found inconsistent results regarding the relationship between crafting social resources, such as calling for feedback and promotion and peer rated task performance.

As for the reduction of relational crafting in the workplace, employees who reduce relationships isolate themselves from others with whom they do not get along well with (Weseler \& Niessen, 2016). The self determination theory (SDT) states that when the need for relatedness is lowered, employee motivation and task performance should also decrease (Deci \& Ryan, 2000). Golden, Veiga, and Dino (2008) found that supervisors rated task performance low when teleworkers reported having limited faceto-face interactions and being professionally isolated from others. From an organizational perspective, organizations have a vested interest in having well functioning work teams and by reducing contacts, this could be viewed as a behavior that is against the 
organization's interest and listed as counterproductive work behavior (Gruys \& Sackett, 2003).

Research on cognitive crafting and its effect on task performance are currently limited but according to the SDT, employees who are intrinsically motivated and who identify with their tasks are proposed to be motivated to perform at a high level (Deci \& Ryan, 2000). Parker (2016) found that employees who had a broader view of their role received higher performance ratings from their supervisors. Steger, Dik, and Duffy (2012) and van den Heuvel, Demerouti, Schreurs, Bakker, and Schaufeli (2009) both discovered that a feeling of meaning at work was positively related to intrinsic motivation and mean making was positively related to self rated in-role performance.

\section{Job Performance and Leisure Crafting}

As discussed in the above section, though job crafting has shown to be beneficial in allowing employees to craft their individual jobs and create more autonomy, relatedness and competency, there are times when job crafting would not be appropriate or seen as counterproductive by the organization. There are also occupations where the existence of job crafting would be dangerous and unsafe such as in manufacturing or construction. According to the SDT, individuals are determined to satisfy their innate psychological needs and when it is not possible in one domain (e.g., work), they may compensate for this within another domain (e.g., leisure) (Deci \& Ryan, 2000). What is not discussed in the literature, as much is the inter-relationship between job crafting and leisure crafting and the extent to which leisure crafting can compensate for the lack of job crafting, leading to a consequential effect on an employee's engagement and performance at work. For example, if a line worker at an automotive manufacturing facility has 
relatively little opportunity to craft their job but during leisure activities engages in high levels of leisure crafting, will that employee maintain the same or higher levels of work engagement and performance compared to another employee who has more opportunities to craft their job? This will be one of the questions addressed in the following research.

\section{Summary of Job Crafting and Leisure Crafting}

Research on job crafting has yielded positive results across multiple outcomes including work engagement, well-being, performance, job satisfaction, person-job fit and physical health. Tims, Derks, and Bakker (2016) found that job crafting was related to increased employee "person-job fit" after one week and to increased meaningfulness two weeks later. Ghitulescu (2007) showed that job crafting activities have a positive influence on individuals' well-being via increased job satisfaction. By changing job demands and resources with proactive strategies like job crafting is expected to decrease exhaustion and increase both work engagement and health because individuals are actively making their work more what they want it to be, given their strengths, skills and working preferences (Tims et al., 2012). Lyons (2008) found positive correlations between episodes of work modification and the variables of self-image, perceived control and readiness to change. Leana, Appelbaum, and Shevchuk (2009) conducted performance assessments in 62 childcare centers and surveyed 232 teachers and aides to examine the extent to which workers crafted their jobs and how such crafting affected classroom quality. Results showed that collaborative crafting was positively related to performance and was also associated with higher levels of satisfaction and commitment.

Though the current literature on leisure crafting is scarce, the impact of what has been currently found is significant. Petrou and Bakker (2016) discovered a positive link 
between high strain job conditions and leisure crafting under the condition of sufficient home autonomy. Petrou and Bakker (2016) also found that employees engaged in leisure crafting when they experience a stressful job, particularly when their home situation provides them with the freedom to craft their leisure time. Berg et al. (2010) showed that individuals are able to use crafting techniques to pursue their occupational calling outside the workplace by shaping their leisure activities via leisure crafting and highlighted the use of hobby participating and vicarious experiencing. Vogel, Rodell, and Lynch (2015) studied how job crafting and leisure activity mitigate the negative effects of value incongruence and found that both crafting one's job to improve their experience of work and involvement in leisure activity can help employees stay engaged and productive at work. Petrou et al. (2017) researched the effects of weekly job crafting and leisure crafting on mean making and work engagement and found that leisure crafting related positively to mean making especially when employees reported limited opportunities to engage in job crafting, suggesting that they compensate with leisure activities for the crafting behaviors they cannot display at work.

\section{Conclusion}

Even with all of the current research stated above, there are still gaps that need to be addressed. Though research has been performed on the relationship between occupational role salience (ORS) and job crafting, the majority of outcomes have focused on the mediating effect of ORS, not as a predictor variable. The effect of job crafting on well-being, task performance and work engagement has been well established in the literature but the intersection of leisure crafting and the establishment of ORS as a predictor of job crafting has not been explored by researchers. In the job and leisure 
crafting literature, well-being has been mainly defined as affective or subjective wellbeing, varying in nature from the definition of psychological well-being which is the primary focus of this research.

The following hypothesized model will be used to explore the significance of each pathway between each variable. An important aspect of this model is the measurement analysis for job crafting. As described in this chapter, job crafting theoretically consists of three sections: task crafting, cognitive crafting and relational crafting (Wrzesniewski \& Dutton, 2001). The cumulation of these types of crafting result in an individualized level of job crafting. But this definition of job crafting limits changes employees may make in their work tasks, relationships at work and cognitions about work (Tims, Bakker \& Derks, 2012). The JD-R model is comprised of three dimensions: increasing job resources, increasing challenging job demands and decreasing hindering job demands (Tims, Bakker \& Derks, 2012). When employees experience unbalanced levels of job resources and job demands, this may trigger the individual to use the three complementary strategies of job crafting (task, relational, cognitive) to adapt the environmental conditions. This research will adopt the Job Demands-Resource Model (JD-R) for measuring job crafting to better capture job characteristics that employees may alter that are not accounted for by the previous definition. 
Figure 3

Hypothesized Model

Job crafting

Occupational role salience
Work

Engagement

Job

Performance

Leisure crafting
Psychological

Well Being 


\section{CHAPTER III}

\section{RESEARCH DESIGN AND METHODOLOGY}

The purpose of this study is to look at how an individuals' ability to job craft relates to work engagement, job performance and their psychological well-being; and when job crafting opportunities are low, how leisure crafting can compensate to provide the individual with similar personal outcomes. This study also examines the extent to which an individual views work as a means of self-identification and how this relates to job crafting.

This chapter discusses the research design and methodology and is organized according to the following sections: (a) research questions and hypotheses; (b) population and sample; (c) variables and instrumentation; (d) controlling for survey errors; (e) data collection; (f) data analysis and (g) assumptions and limitations.

\section{Research Design}

\section{Research questions and hypotheses}

There are nine research questions in this study which include:

1. Is there a significant mediating effect of job crafting on the relationship between leisure crafting and work engagement?

2. Does leisure crafting have a significant mediating effect on the relationship between job crafting and work engagement?

3. Does job crafting have a significant direct effect on work engagement? 
4. Does job crafting have a significant direct effect on task performance?

5. Does job crafting have a significant direct effect on psychological well-being?

6. Does leisure crafting have a significant direct effect on work engagement?

7. Does leisure crafting have a significant direct effect on task performance?

8. Does leisure crafting have a significant direct effect on psychological well-being?

9. Does occupational role salience have a significant direct effect on job crafting?

\section{Population and Sample}

In this study, the population is defined as employees working in professional positions across the United States. The sample for this study was full-time employees in the United States who met the research criteria and completed the online survey instrument. A convenience sample is an example of a non-probability sampling technique which should not be used to make inferences about the total population but can serve to suggest ideas that may be tested using more generalizable methods when the population is assumed to be homogenous (Ilker, Sulaiman, \& Rukayya, 2016). The researcher distributed 400 surveys and 303 surveys were returned that met the inclusion criteria.

\section{Inclusion Criteria}

The specific inclusion criteria included professional workers that work more than 30 hours a week on average, are employed at a single organization, have worked for the organization for at least 6 consecutive months and are classified as professional.

Based on the intent of this study to examine data on employees' behaviors and experiences in a workplace setting, respondents were screened out if they were selfemployed and primarily work from home. US Bureau of Labor Statistics (BLS) defines full-time workers as individuals who, in general, work more than 30 hours per week. 
Self-employed individuals earn income through conducting profitable operations from a trade or business they operate directly, instead of working for an employer that pays a salary or wage (US Bureau of Labor Statistics, 2016). In 2010, BLS report indicated that $83 \%$ of employee did some or all of their work at their workplace (US Bureau of Labor Statistics, 2010).

Tenure and type of industry were also used as inclusion criteria for respondents. This study focused on sampling from individuals who were employed at the same organization for at least 6 months and the industry is classified as professional. Tenure was applied to ensure that respondents had a baseline level of experience within the organization. The classification of "professional" is defined as a salaried professional or educated worker who performs semi-professional office, administrative or sales-coordination tasks (Karasek, 1990). This population was selected for sampling based on the likelihood of exposure to the survey items and to control for variance between white and blue-collar workers.

\section{Procedures}

A cross sectional survey design was used to examine how an individuals' ability to job craft relates to work engagement, job performance and their psychological wellbeing; and when job crafting opportunities are low, how leisure crafting can compensate to provide the individual similar personal outcomes. This study also examined the extent to which an individual views work as a means of self-identification and how this relates to job crafting. The survey design included collecting survey data using Qualtrics. Qualtrics is a privately held experience management company that collects and analyzes data for market research, customer satisfaction, product and concept testing, employee 
evaluations and website feedback. An online survey was conducted to gather data on demographic variables as well as data on participants' work engagement, job performance and their psychological well-being. An electronic web-based survey was chosen due to convenience, rapidity of data collection and because sensitive personal information is not being sought in this research.

The researcher chose to use Qualtrics to collect data based on convenience, ability to sample specific populations and quick turnaround of survey item results. The researcher contacted Qualtrics to discuss the research and the inclusion criteria that each candidate needs to meet to be selected to participate in the study. Qualtrics searched databases of potential candidates that meet the qualifications until the sample size has been reached. Through this entire process, Qualtrics agreed to be in contact with the researcher to ask questions and verify steps being taken regarding the sampling and distribution of survey scales. Once all responses have been received, Qualtrics sent the researcher the raw collected data in SPSS format so further data analysis can be completed. Payment for services rendered was given at this time. No financial contribution was given to the researcher during this entire process. The total data collection period took between 15-20 days.

\section{Instrumentation}

\section{Major variables}

The major variables in this study include job crafting, leisure crafting, work engagement, job performance, occupational role salience and psychological well-being. Occupational role salience served as the exogenous variables for the study. Work 
engagement, job performance, job crafting, leisure crafting and psychological well-being served as the endogenous variables.

Table 1

Selected Instruments and Reliability Statistics of Survey Items

\begin{tabular}{ccccc}
\hline Instrument section & Items $(\mathrm{n})$ & $\begin{array}{c}\text { Variable(s) } \\
\text { measured }\end{array}$ & Source of items & $\begin{array}{c}\text { Reported } \\
\text { Cronbach's alpha }\end{array}$ \\
\hline Job crafting & 21 & $\begin{array}{c}\text { Job resources } \\
\text { and demands } \\
\text { adaptations } \\
\text { Proactive } \\
\text { pursuit of } \\
\text { leisure } \\
\text { Veisure crafting }\end{array}$ & $\begin{array}{c}\text { Tims et.al. } \\
(2012)\end{array}$ & 0.78 \\
Work engagement & 9 & $\begin{array}{c}\text { Petrou \& } \\
\text { Bakker (2016) }\end{array}$ & 0.92 \\
Psychologication, \\
being
\end{tabular}




\section{Job crafting}

Job crafting is defined as "the changes that employees may make to balance their job demands and job resources with their personal abilities and needs" (Tims \& Bakker, 2010). In this study, job crafting is measured by Tims, Bakker \& Derks (2012) job crafting scale which consists of 21 items measuring 4 dimensions: increasing structural job resources, decreasing hindering job demands, increasing social job resources and increasing challenging job demands. These dimensions of job crafting were theoretically framed by Tims, Bakker \& Derks (2010) based on the practical limitations of the job crafting definition given by Wrzesniewski \& Dutton (2001) which potentially reduce the organizational value of job crafting and increase the difficulty for employees to report job crafting outcomes to their superiors. Also, Tims, Bakker \& Derks (2012) job crafting scale quantitatively measures job crafting behavior whereas previous scales (Berg, Wrzesniewski \& Dutton, 2010; Lyons, 2008) measure job crafting using theortical or qualititative constructs. All scale items were reviewed by three work and organizational psychologists working on their $\mathrm{PhD}$ about the proposed definition of job crafting, clarity of constructed items and fit with the respective dimensions. All items were measured on a 5-point Likert scale ( $1=$ never, $5=$ often).

Job crafting is measured by the job crafting scale developed by Tims et al. (2012). Tims, Bakker \& Derks (2012) constructed a pool of 42 items to capture all four jobcrafting dimensions. Specifically, 19 of the 42 items were adapted from Dutch validated scales that were used to measure the occurrence of specific job resources (Bakker, Demerouti, Taris, Schaufeli \& Schreurs, 2003) such that they measured whether the participant took the initiative to increase these job resources. The inclusion of certain 
scale items were based on Kompier (2007) analysis that examined several influential work design models including the job characteristics model, the demand control model and the effort reward imbalance model (Siegrist, 1996).

For the "increasing challenging job demands" dimension, Tims, Bakker \& Derks (2012) aimed to address employee behaviors that would result in additional challenging demands and lead to an experience of personal growth and achievement as well as feelings of accomplishment. Fourteen scale items were developed to fit this conceptualization. For the "decreasing hindering job demands" dimension, Tims, Bakker \& Derks (2012) identified emotional and mental job demands to be important to include due to the increase in knowledge-based jobs and the shift from manufacturing to serviceoriented economy. Nine existing items from Bakker et. al. (2004) were rewritten so they refer to initiatives of employees to decrease their level of job demands.

\section{Leisure crafting}

Leisure crafting is defined as "the proactive pursuit of leisure activities targeted at goal setting, human connection, learning and personal development" (Petrou \& Bakker, 2016). Leisure crafting consists of four dimensions: job demands, job autonomy, home demands and home autonomy. Leisure crafting is measured using a 14-item scale developed by Petrou and Bakker (2016). This scale is based on existing literature on job crafting and leisure crafting as well as Petrou \& Bakker (2016) views of leisure crafting. The purpose of the scale was to measure leisure crafting for research and practical purposes, create a valid scale to quantify leisure crafting and to test the hypothesis that leisure behavior is purposeful and challenging. Responses to this scale were captured using a 5-point Likert scale, $1=$ not at all and 5=very much. 
In the development of the leisure crafting scale, Petrou and Bakker (2016)

recruited and asked two job crafting experts with extensive experience in job crafting research and intervention to indicate the extent to which each item fitted the definition of leisure crafting. This pool of items was administered in the form of a survey to respondents in order to test the factorial, discriminant and construct validity of this measure.

\section{Work engagement}

Work engagement is defined as "the positive, fulfilling, work related state of mind that is characterized by vigor, dedication and absorption" (Schaufeli et al., 2002). Work engagement is measured using the Utrecht Work Engagement Scale (UWES-9), which consists of 9 items. Work engagement consisted of three dimensions: vigor, dedication and absorption. UWES-9 was adapted from the UWES-17 (Schafeli et. al., 2002) to strive to include as few items as possible for measuring a particular construct to reduce the likelihood of attrition.

The UWES-9 is separated into 3 dimensions reflecting the dimensions of work engagement (vigor, dedication and absorption). Vigor is defined as high levels of energy and resilience, the willingness to invest effort, not being easily fatigued and persistence in the face of difficulties (Schaufeli et al., 2002). Dedication is assessed as deriving a sense of significance from one's work, feeling enthusiastic, proud about one's job and feeling inspired and challenged by it (Schaufeli et al., 2002). Absorption is measured as being totally and happily immersed in one's work and having difficulties detaching oneself from it so that time passes quickly and one forgets everything else that is around (Schaufeli et al., 2002) 


\section{Psychological well-being}

Psychological well-being is defined as "the satisfaction of basic psychological needs for autonomy, competence and relatedness" (Blais \& Baity, 2009). Psychological well-being was measured using the Schwartz Outcome Scale-10 (SOS-10), developed by Blais \& Baity (2009), a 10 item scale with six subscales. The SOS-10 has a 7 point Likert scale with $0=$ never and $6=$ all or nearly all of the time. Psychological well-being contains five dimensions: life satisfaction, interpersonal effectiveness, positive self appraisal, optimism and the absence of psychiatric symptoms.

\section{Occupational role salience}

Occupational role salience is defined as "the degree to which one's occupation is an important means of self definition and/or personal satisfaction" (Amatea et al., 1986). Occupational role salience served as a variable with two dimensions: occupational role reward value and occupational role commitment. Occupational role salience was measured using the Occupation Role Reward Value and Occupation Role Commitment subscale of the Life Role Salience Scales developed by Amatea et al. (1986), a 10-item scale using a five point Likert scale, $1=$ totally disagree and $5=$ totally agree. The original purpose of the scale was to assess men's and women's personal expectations concerning occupational roles as well as assess the personal importance or value attributed to participation in a particular role and the intended level of commitment of personal time and energy resources to enact a specific role (Amatea et al., 1986). 


\section{Job performance}

Job performance is defined as "the degree and quality in which an employee performs specific tasks outlined by an organization" (Williams and Anderson (1991). Job performance was measured by using Williams and Anderson (1991) in role behavior scale which contains 7 items assessed on a 5 point Likert scale, $1=$ totally disagree and $5=$ totally agree. These items were selected from a larger scale ( 21 items) that measured organizational citizenship behaviors and in role behaviors. Job performance contained three dimensions: performance, satisfaction and organizational commitment.

\section{Reliability}

To ensure scale reliability, exploratory factor analyses were performed on each scale in prior literature. Cronbach's alphas are reported for these analyses. Some scales required confirmatory factor analyses and the results of those analyses are discussed when executed.

\section{Job crafting}

An exploratory factor analysis was performed on increasing social job resources, decreasing hindering job demands, increasing social job resources and increasing challenging job demands and yielded coefficient alphas of 0.82, 0.79, 0.77 and 0.75, respectively averaged across items per section (Tims, Bakker \& Derks, 2012). A confirmatory factor analysis on the four-factor model followed and reported significantly better model fit compared to the three factor model initially proposed (chi square $=478.87$; $\mathrm{df}=6$; RMSEA $=0.04 ; \mathrm{CFI}=0.90)$. Cronbach's alphas were assessed as follows: increasing 
social job resources $(0.81)$, decreasing hindering job demands $(0.78)$, increasing social job resources (0.76) and increasing challenging job demands (0.78).

\section{Leisure crafting}

Exploratory factor analysis was conducted on the 14-item scale and revealed unidimensionality, based on both the scree plot and eigenvalues, leaving nine remaining items. A test of model fit resulted in reasonable model fit (chi square $=175.55, \mathrm{p}=0.000$, $\mathrm{df}=77, \mathrm{CFI}=0.937, \mathrm{TLI}=0.926, \mathrm{GFI}=0.896, \mathrm{SRMR}=0.063)$. Content validity was measured by reviewing the answers received from two experts in the field of job and leisure crafting on the content of the items and it was decided to remove five items. To establish discriminant validity, a two-factor solution in AMOS was created with items from leisure crafting and novelty seeking behavior items (Fritsch, Smyth, Debanne, Petot \& Friedland, 2005) on two separate factors. The two-factor solution had marginal fit to the data (chi square $=210.29, \mathrm{df}=89, \mathrm{p}=0.000, \mathrm{CFI}=0.932, \mathrm{TLI}=0.920, \mathrm{GFI}=0.872$, SRMR $=0.073$ ) but was significantly and substantially better than a one factor solution. These findings reveal that leisure crafting relates to but is different from novelty seeking. The 14-item leisure crafting scale also correlated significantly and positively with proactive personality $(r=0.24, p<0.001)$, which also reveals that proactive individuals report more leisure crafting. In conclusion, Petrou and Bakker (2016) findings show first evidence that this leisure crafting measure has adequate factorial, discriminant and construct validity. The scale items indicated acceptable reliability (Cronbach's alpha=0.93). 


\section{Work engagement}

UWES-17 consistently maintained Cronbach alphas between 0.80 and 0.90 .

Schafeli, Bakker \& Salavona (2006) showed that in $90 \%$ of cases using the UWES-9, Cronbach alphas were maintained at or above 0.70. Responses to the UWES are reported on a 7 point Likert scale, $0=$ never and $6=$ everyday. The authors reported that the results of the confirmatory factor analysis showed that between a one and three factor model, the three-factor model was superior (chi square $=3227.29, \mathrm{df}=240, \mathrm{GFI}=0.95, \mathrm{RMSEA}=0.03$, CFI, 0.96) and fits well to the data of various samples from the Netherlands, Spain and Portugal (Salanova, Schaufeli, Llorens, Pieró \& Grau, 2000; Schaufeli et al., 2002a; Schaufeli, Martínez, Marques-Pinto, Salanova \& Bakker, 2002b; Schaufeli, Taris \& Van Rhenen, 2003). Cronbach's alpha for the total nine-item scale varied between 0.85 and 0.92 (median=0.92) across all 10 countries, which is deemed adequate for research purpose (Henson, 2001; Nunnally, 1967).

\section{Psychological well-being}

Based on two studies that implemented the SOS-10 and reported 1 week of testretest reliability, internal consistency was $0.91(\mathrm{~N}=362)$ and test-retest was 0.88 which is in the acceptable range. Haggerty, Blake, Naraine, Siefert \& Blais (2009) looked at the construct validity of the SOS-10 against jother similar measures and found that the SOS10 was positively correlated with those measures and supported the construct validity of the SOS-10 as a measure of overall quality of life and psychological well-being in a college sample. 


\section{Occupational role salience}

Amatea et al. (1986) established empirical reliability of the instrument sampling male/female undergraduate students, females in higher education and married couples. The internal consistency reliability coefficient generated by the Amatea et al. (1986) scale was 0.86, which is deemed adequate for research purpose (Henson, 2001; Nunnally, 1967).

\section{Job performance}

Exploratory factor analysis indicated that in all cases the items had their highest loading on the appropriate factor and met the established 0.35 criteria to remain acceptable. The in role behavior scale yielded an eigenvalue of 8.37 and accounted for $39.9 \%$ of explained variance. A confirmatory factor analysis was also performed and after correlating the error terms of two in role performance items that were reverse scored, the fit of the one-factor model was adequate (chi square $=203.35, \mathrm{df}=75$, $\mathrm{CFI}=0.93, \mathrm{TLI}=0.91, \mathrm{RMSEA}=0.08)$. Cronbach's alpha of in role performance measure was 0.86, which is deemed adequate for research purpose (Henson, 2001; Nunnally, 1967). 
Table 2

Participant Personal and Professional Attributes

\begin{tabular}{|c|c|c|}
\hline Variable & Scale of measurement & Coding \\
\hline Gender & Nominal & 1=Female; 2=Male; 3=Other \\
\hline Race/ethnicity & Nominal & $\begin{array}{l}\text { 1=Asian/Pacific Islander; } 2=\text { Black/African } \\
\text { American; 3=Hispanic; } 4=\text { Mixed Ethnicity; } \\
\text { 5=Native American; 6=White/Caucasian; } \\
\text { 7=Other }\end{array}$ \\
\hline $\begin{array}{l}\text { Average \# of hours } \\
\text { worked per week }\end{array}$ & Ratio & $\begin{array}{l}1=30-34 \mathrm{hrs} / \mathrm{wk} ; 1=35-39 \mathrm{hrs} / \mathrm{wk} ; 3=40 \text { or } \\
\text { more } \mathrm{hrs} / \mathrm{wk}\end{array}$ \\
\hline Age & Ratio & $\begin{array}{l}1=18-25 ; 2=26-33 ; 3=34-41 ; 4=42-49 ; 5=50- \\
57 ; 6=58 \text { and older }\end{array}$ \\
\hline $\begin{array}{l}\text { Highest level of } \\
\text { education }\end{array}$ & Ordinal & $\begin{array}{l}\text { 1=High school diploma/GED; 2=Associate's; } \\
\text { 3=Bachelor's; 4=Master's; 5=Doctorate }\end{array}$ \\
\hline Tenure & Nominal & $\begin{array}{l}1=0-6 \text { months; } 2=7-12 \text { months; } 3=13-18 \\
\text { months; } 4=19=24 \text { months; } 5=\text { over } 24 \text { months }\end{array}$ \\
\hline Industry & Nominal & $\begin{array}{l}\text { 1=Healthcare; } 2=\text { Manufacturing; } 3=\text { Service; } \\
\text { 4=Media; } 5=\text { Computer; } 6=\text { Financial }\end{array}$ \\
\hline
\end{tabular}

\section{Variables}

\section{Demographic variables}

Demographic variables include age, gender, race/ethnicity, average number of hours worked per week, highest level of education, tenure and type of industry employed in. Demographic data were collected from respondents for comparison with BLS data to verify that a random sample had been obtained and the proportions were similar to the general population. 


\section{Endogenous variables}

The endogenous variables in this study are the participants' scores on the work engagement, job crafting, leisure crafting, job performance and psychological well-being scales. These variables will be assessed using a 5 -point Likert scale ( $1=$ never; $5=$ often).

\section{Exogenous variables}

The background variables in this study are operationalized as specific measurable attribute as follows:

1. Age - variable expressing the respondent's chronological age in years.

2. Race/Ethnicity - variable representing the race or ethnicity with which the respondent self-identifies with the choices being Asian/Pacific Islander, Black/African American, Hispanic, Mixed Ethnicity, Native-American, and White.

3. Highest Level of Education - variable denoting the respondents' level of education, identified as either high school diploma/GED, Bachelor's degree, Master's degree, Specialist's degree, or Doctoral degree.

4. Gender - variable indicating whether the respondent identifies as either male, female or other.

5. Average number of hours worked per week - variable measuring the number of hours each week a respondent works on average at their current organization

6. Industry - variable depicting the type of industry a respondent currently works in

7. Tenure - variable indicating the duration a respondent has been employed at their current organization 
The exogenous variables in this study are operationalized as specific measurable attribute as follows:

8. Occupational role salience -variable measuring the degree to which one's occupation is an important means of self definition and/or personal satisfaction

\section{Data Analysis}

Data screening procedures for data quality were used to inspect for: missing values and outliers. Missing values were evaluated via Little's MCAR test (Little \& Rubin, 2002); outliers were evaluated via Z-scores to ensure that data were within acceptable limits. Considering absolute values, in a normal distribution about $5 \%$ of the data would be expected to have values greater than 1.96 , and $1 \%$ to have absolute values greater than 2.58, and none to be greater than about 3.29 (Tabachnick \& Fidell, 2007).

\section{Descriptive statistics and correlations}

After data screening was concluded, descriptive statistics including unweighted means, standard deviations and $t$ statistics for each major variable were reported. The researcher examined skewness, kurtosis of the variables and linearity was assessed using scatterplots. Correlation coefficients among the major variables were reported (Gall, Borg, \& Gall, 1996).

\section{Structural Equation Modeling}

Structural equation modeling (SEM) was also conducted using AMOS to focus on estimating the relationships among hypothesized latent constructs and to test theoretical propositions regarding how constructs are theoretically linked and the directionality of 
significant relationships (Schreiber, Nora, Stage, Barlow \& King, 2006). The analysis will include two models: a measurement and structural model.

\section{Measurement Model}

The measurement model depicted the pattern of observed variables for the latent constructs in the hypothesized model and the structural model displayed the interrelations among latent constructs and observable variables as a succession of structural equations.

Direct, indirect and total effects among latent constructs were depicted and supported by theory or empirically based research. The analyses of these models were examined based on the coefficients of the hypothesized model and indicated whether the hypothesized model was a good fit to the observed data. An examination of the residuals was also occur to judge good model fit. 
Figure 4

Measurement Model

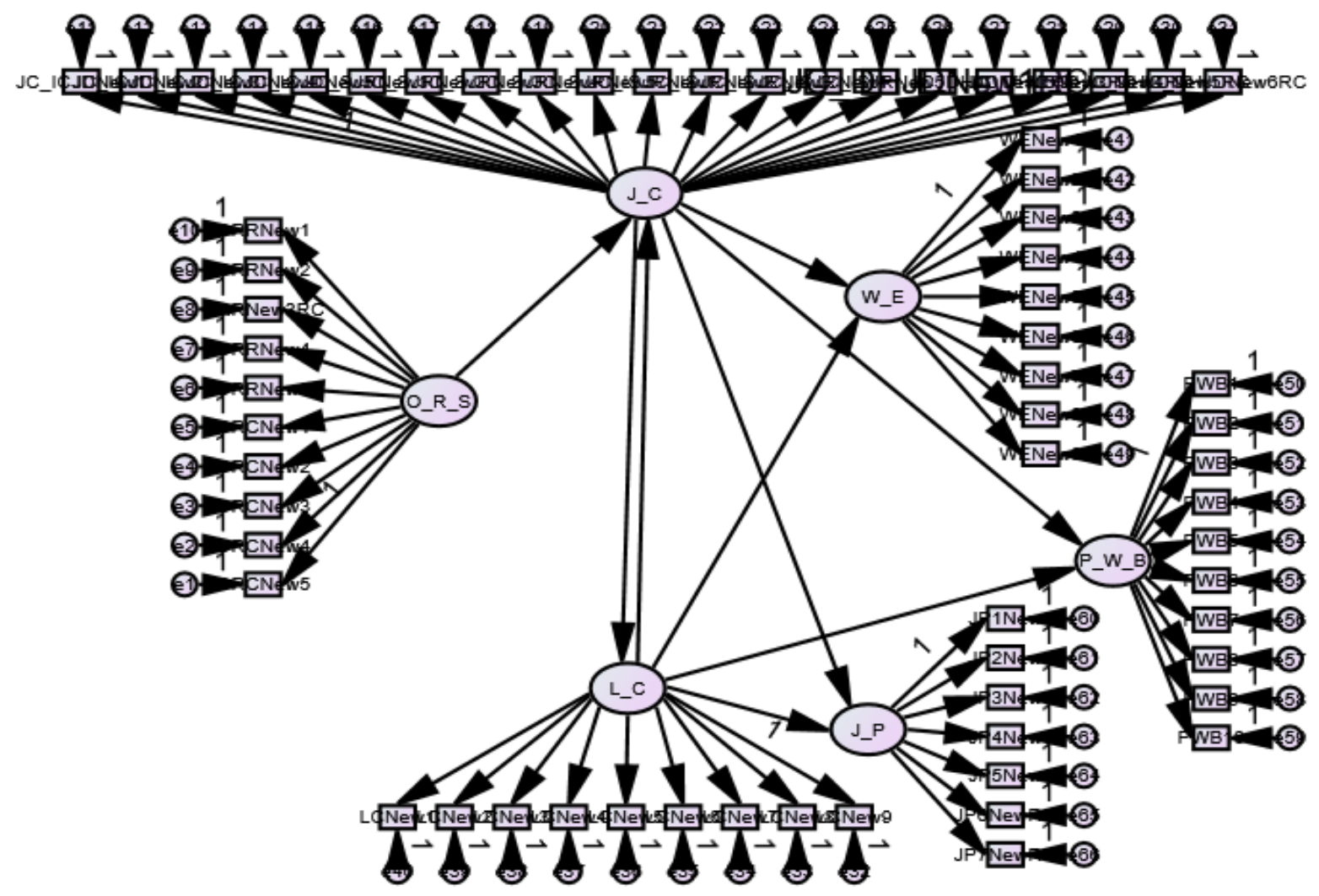

\section{Structural Model}

The significance of each individual structural path representing the impact of one

latent variable on another was assessed based on t values associated with structural coefficients. The researcher assessed model fit using a combination of the following goodness of fit indicators: comparative fit index (CFI), root mean square error of approximation (RMSEA) and non-normed fit index (also known as TLI). For continuous outcomes, $\mathrm{Yu}(2002)$ reported that RMSEA $<0.06$, TLI $>0.95$ and CFI $<0.95$ are acceptable measures of good model fit. Q-plots and standardized residuals will be analyzed to determine the number of standard deviations of observed residuals and 
indicated whether the residuals significantly depart; this departure could suggest that the model is in some way misspecified (Bryne, 1989).

After these analyses were performed and model fit is stable, model modifications to the original hypothesized model may occur to have a better fitting model. Any modification made shall make theoretical sense and the author will report the modification test used, why that test was used and whether the modification makes theoretical sense for the model. If the model has been modified, the author shall provide evidence via the chi-square test to show that the modified model is statistically superior to the original model.

\section{Limitations}

There are several limitations of this study. The inclusion criteria that were used to select the sample limited the data to young, professional, full-time employees. The results from this study will only be generalizable to those demographics, which leaves out a substantial percentage of the entire population. Another limitation to this study relates to coverage error. This study utilized online surveys for sampling. Individuals without internet access and the population with internet access that opted out of the survey were prevented from being included in the sample. According to Baker et al. (2013), an estimated $30 \%$ of the U.S. adult population does not use the Internet on a regular basis, which indicates that part of the population without Internet access cannot be included in the sample. Due to the presence of survey data, there is also the chance of nonresponse error in the study. Qualtrics distributed the surveys to prospective participants. Participation in the study was fully voluntary and each individual was allowed to 
discontinue activity at any point. The rate of nonresponse error can vary based on data collection methods and can be a confounding variable within this study.

Self-report was used and may lead to common method bias, though this is appropriate when people report private events or subjective observations (Conway \& Lance, 2010). There is sufficient support for the proposition that in work settings, individual's self impressions are magnified by a common tendency to self enhance and tend to view themselves more positively than appraisals of them from other sources (Podsakoff \& Organ, 1986). Despite these limitations, the results should provide some original findings and make a contribution to the ongoing research and the development of organizational theory related to the interaction between job crafting and leisure crafting, work engagement, job performance, psychological well-being and occupational role salience.

The findings from this study may be susceptible to common method variance as affective variables and self reported data were used. Common method variance is the tendency for respondents to respond positively to positively worded questions (Podsakoff \& Organ, 1986). Another limitation is the overall lack of studies that address leisure crafting. Though the theoretical framework and principles for leisure crafting exist, there are few research studies especially when compared to job crafting. The number of scale items measuring each factor could also limit the generalizability of the results. As observed during the initial EFA, several items loaded on different factors that were not validated by the original scale. Future research may want to look at reducing the number of items associated with each factor so more parsimonious statistical models can be performed for more clear analyses. 
Another limitation is the use of inclusion criteria for data collection. By using inclusion criteria to screen for specific populations of respondents, generalization of the results can only be viewed through a specific lens. Another limitation to the inclusion criteria pertains to the job responsibilities section. This section only included four choices to identify the respondents' primary job responsibilities (book keeping, computer competencies, accounting, other. The majority of respondents selected "other" for this question, which does not provide much information for further analysis. Future research should add more options to this question so the effectiveness of this inclusion criterion can be evaluated. 


\section{CHAPTER IV}

\section{RESULTS}

This chapter presents the results from the analysis of the data collected for this study. The chapter begins with a discussion of the demographic characteristics of the respondents who completed this survey along with the correlations of the major variables within the data set. Then the results of an exploratory factor analysis (EFA) of the major variables and the indicators that describe them will be presented. Next, based on the outcome of the EFA, the results of a confirmatory factor analysis of the latent and indicator variables will be presented and discussed followed by the final iteration of the measurement model used for this analysis. Lastly, the results of the structural equation model are presented to address the proposed research questions individually.

\section{Descriptive statistics}

Table 1 details the descriptive statistics of the sample for this study. A total of 303 respondents met the inclusion criteria and completed the survey administered by Qualtrics. The respondents themselves were primarily single white females, between 2633 years old, no children, with a high school diploma or GED, who work 40 or more hours a week and who have been at their current organization for over 24 months. The majority of respondents work within the service industry $(41.3 \%)$ and primary responsibilities were listed as "other" (45.5\%) among other options such as bookkeeping (7.9\%), computer competencies (35.6\%) and accounting (10.9\%). 
Table 3.0

Respondents Demographics

\begin{tabular}{|c|c|c|c|c|c|}
\hline Category & Percentage & Category & Percentage & Category & Percentage \\
\hline Gender & & Race & & Family Status & \\
\hline Female & 47.5 & Asian/Pacific Islander & 5 & Married & 36 \\
\hline Male & 52.1 & Black/African American & 13.2 & Single & 40.3 \\
\hline Other & 0.3 & Hispanic & 18.2 & Divorced & 7.3 \\
\hline Age & & Mixed Ethnicity & 2.6 & In relationship & 16.5 \\
\hline $18-25$ & 25.7 & Native American & 1.7 & Educational Level & \\
\hline $26-33$ & 31.4 & White/Caucasian & 57.4 & $\begin{array}{l}\text { High school } \\
\text { diploma/GED }\end{array}$ & 40.6 \\
\hline $34-41$ & 21.5 & Other & 2 & Associate's & 28.7 \\
\hline $42-49$ & 11.6 & Number of Children & & Bachelor's & 19.1 \\
\hline $50-57$ & 5.3 & No children & 47.2 & Master's & 9.6 \\
\hline 58 or older & 4.6 & 1 child & 23.4 & Doctorate & 2 \\
\hline $\begin{array}{l}\text { Average \# of } \\
\text { Hours Worked Per } \\
\text { Week }\end{array}$ & & 2 children & 15.2 & Tenure Level & \\
\hline $30-34$ & 15.8 & 3 children & 8.3 & 7-12 months & 19.5 \\
\hline $35-39$ & 17.5 & 4 or more children & 5.9 & 13-18 months & 11.2 \\
\hline 40 or more & 66.7 & Job Responsibilities & & 19-24 months & 10.9 \\
\hline Type of Industry & & Bookkeeping & 7.9 & Over 24 months & 58.4 \\
\hline Healthcare & 17.8 & Computer competencies & 35.6 & & \\
\hline Service & 41.3 & Accounting & 10.9 & & \\
\hline Media & 5.9 & Other & 45.5 & & \\
\hline Technology & 21.8 & & & & \\
\hline $\begin{array}{l}\text { Financial } \\
\text { Services }\end{array}$ & 13.2 & & & & \\
\hline
\end{tabular}




\section{Correlations}

Table 2.0 displays the correlations between major variables in the dataset and shows some interesting data. All major variables were positively and significantly correlated with each other though some correlations were stronger than others. The correlation coefficients ranged from 0.190 to 0.767 . Occupational Role Salience (ORS) had a strong and significant correlation with Job Crafting (JC) (0.767) where JC and Job Performance (JP) had a weaker correlation (0.190) but still statistically significant. These correlations are reflected in the measurement model presented in Figure 4. The coefficients of determination (R squared) were estimated for all endogenous variables (JC, LC, WE, PWB, JP) and represent the proportion of variance explained by each major variable. JC shared $58.8 \%$ of the common variance (large correlation), LC shared $19.7 \%$ of the common variance (medium correlation), WE shared $19.2 \%$ of the common variance (medium correlation), PWB shared $18.1 \%$ of the common variance (medium correlation) and JP shared $7.3 \%$ of the common variance (small correlation).

Table 4.0

Correlations and Significance (Two-Tailed) of the Major Variables

\begin{tabular}{|c|c|c|c|c|c|c|c|}
\hline & ORS & $\mathrm{JC}$ & $\mathrm{LC}$ & WE & PWB & JP & $\begin{array}{c}\text { Cronbach's } \\
\text { Alpha }\end{array}$ \\
\hline ORS & 1 & & & & & & 0.726 \\
\hline $\mathrm{JC}$ & $0.767 * *$ & 1 & & & & & 0.861 \\
\hline $\mathrm{LC}$ & $0.444 * *$ & $0.685^{* *}$ & 1 & & & & 0.91 \\
\hline WE & $0.438 * *$ & $0.657 * *$ & 0.420 ** & 1 & & & 0.926 \\
\hline PWB & $0.425 * *$ & $0.530 * *$ & $0.409 * *$ & $0.586^{* *}$ & 1 & & 0.922 \\
\hline JP & $0.270 * *$ & $0.391 * *$ & $0.190^{* *}$ & $0.350 * *$ & $0.290 * *$ & 1 & $\begin{array}{l}0.802^{*} \\
(0.767)\end{array}$ \\
\hline
\end{tabular}

Note: $*$ JP5New was deleted to obtain alpha level $* *$ Correlation is significant at the 0.01 level (2-tailed) 


\section{Reliability}

The reliability coefficients for the six factors above were $\alpha=0.802,0.726,0.861$, 0.91, 0.926 and 0.922 for JP, ORS, JC, LC, PWB, and WE respectively. Based on Cohen (1988) guidelines, all of these coefficients are in the acceptable range. Reliability coefficients reflect the proportion of observed-score variance attributable to true-scores (Cohen, 1988). Coefficients at or above 0.80 are often considered sufficiently reliable to make decisions about individuals based on their observed scores (Cohen, 1988).

The analytical software used to create the structural equation model in this study was IBM AMOS version 25. This software is able to perform a CFA among other statistical modeling. An advantage to using AMOS to perform a CFA is that it takes into account the measurement error of each indicator (Kline, 2011). This is significant because each measurement error represents the unique variance of the indicator which is the variance not explained by the latent factor. The arrows leading from the factor to an indicator represent only the variance the factor explains in the indicator. AMOS can also empirically modify the model by adding parameters in order to improve model fit (Kline, 2011). These are called Modification Indices (MI) and the univariate Lagrange multipliers expressed as chi-square statistics with a single degree of freedom (Kline, 2011). The higher the MI value, the greater the theoretical improvement in model fit (Kline, 2011). Modification indices for the measurement model and each subsequent revision were evaluated but not reported in this study due to low values that would not have yielded significant improvements in model fit. 


\section{Exploratory Factor Analysis}

Prior to completing data reduction and assessing for potential factor solutions, the factorability of the major variables and indicator variables were evaluated using a number of research-supported procedures. Inspection of the correlation matrix indicated that 60 of the 66 items produced a correlation of at least 0.3 with one or more items (Tabachnik \& Fidell, 2007). The items that failed to correlate with other items were deleted.

Multicollinearity was assessed using Variance Inflation Factor (VIF) and Tolerance tests. Mulitcollinearity was not detected within the data thus the assumption of collinearity was met (see Table 3.0). Allison (1999) proposed that VIF's above ten or Tolerance scores below 0.10 imply extreme multicollinearity.

Bartlett's test of sphericity was investigated and was statistically significant (chi square $(2145)=12173.195), \mathrm{p}<0.001)$ which suggests that the variables are related, suitable for structure detection and a factor analysis may be of assistance. Kaiser-MeyerOlkin's (KMO) test of sampling adequacy was also evaluated for further evidence for the factorability of a correlation matrix. The KMO measure of sampling adequacy was 0.889 , well above the minimum recommended value of 0.60 (Tabachnick \& Fidell, 2001). Based on the outcome of tests, the data appeared suitable for an EFA.

A main assumption of factor analytic procedures is normality in the distribution of the data (Tabachnik \& Fidell, 2007). Normality of the data was assessed in two ways: (a) descriptive statistics examining skewness and kurtosis of the 60 items and (b) the Shapiro-Wilk test (Kenny, 2010). The scale items for JC, LC, ORS, WE, PWB and JP indicated a non-normal distribution and the Shapiro-Wilk test for each of the items was significant (Table 4.0). To address the issue of non-normality, a principal axis factoring 
(PAF) analysis in SPSS was performed given that PAF does not require a normal distribution (Kenny \& McCoach, 2003). Eigenvalues were first examined to determine the amount of variance explained by the scale items and items with Eigenvalues greater than 1.0 were considered appropriate. The initial model had 13 factors with eigenvalues greater than 1.0 and these thirteen factors explained $58.37 \%$ of the total variance.

A scree plot was also inspected to estimate the possible number of factor solutions (Figure 1.0). The scree plot indicated a more parsimonious six-factor model might be appropriate. A drawback of the scree plot is its vulnerability to subjectivity and ambiguity (Tabachnisk \& Fidell, 2007; Haynes et. al., 2011). Due to the large difference between the factor structures observed in the eigenvalues vs. scree plot, it was difficult to interpret the underlying latent structure. The following process required an analysis of individual items for possible removal based on the values of the item loadings and cross loadings on the factors as well as communality estimates.

Pett et. al. (2003) discussed that an item should be deleted if its factor loading is less than 0.40. Five items failed to meet these inclusion criteria and were removed. An item was also considered for deletion if it had a cross loading that exceeded 0.32 on two or more factors (Tabacknick \& Fidell, 2001). Five items were dropped for having crossloadings above 0.32 . Costello \& Osborne (2005) argued that item communality below 0.40 is seen as potentially problematic and should not retained. No items were removed based on this criterion.

A second principal axis factoring analysis with varimax rotation method was performed with the remaining 50 items. Tabacknick \& Fidell (1996) recommended retaining all factors with eigenvalues at or greater than 1.0 for further analyses. Following 
this method, the eigenvalues suggested an eleven-factor model, which accounted for $59.8 \%$ of the cumulative variance (Table 6.0). To further assess the best factor solution, a parallel analysis was performed. O'Connor (2000) generated a syntax that could be downloaded @ http://people.ok.ubc.ca/brioconn/nfactors/nfactors.html for the purposes of executing parallel analysis. Results from the parallel analysis supported an elevenfactor solution as well. The correlations of the factor structure (Table 5) showed the strength and relationship between each factor outlined in the EFA. Most factors appear to have a statistically significant and strong relationship other than five JP_NEG loadings and three JC_DHJD loadings. No revisions to the factor structure were performed but these loadings were checked in further analyses as they have the potential to impact the validity of the study. Table 6.0 represents the factor matrix from the EFA and shows high loadings for each item and these items are loading upon separate factors.

The following are the factor solutions outlined in the EFA (Table 6.0) and a description of each:

Factor 1 was labeled Psychological Well Being (PWB: 10 items; accounting for $25.17 \%$ of the total variance); factor 2 was labeled Leisure Crafting (LC: 9 items; accounting for $8.1 \%$ of the total variance); factor 3 was labeled Work Engagement (WE: 8 items; accounting for 5.5\% of the total variance); factor 4 was labeled Job Performance (JP: 4 items accounting for $4.57 \%$ of the total variance); factor 5 was labeled Occupational Role Commitment (ORC: 4 items; accounting for $4.42 \%$ of the total variance); Factor 6 was labeled Increasing Structural Job Resources (ISJR: 4 items; accounting for $3.4 \%$ of the total variance); factor 7 was labeled Decreasing Hindering Job Demands (DHJD: 4 items; accounting for $2.5 \%$ of the total variance); factor 8 was 
labeled Increasing Social Job Resources (ISJR: 3 items; accounting for $1.95 \%$ of the total variance); factor 9 was labeled Increasing Challenging Job Demands (ICJD: 5 items; accounting for $1.68 \%$ of the total variance); factor 10 was labeled Negative Job Performance Behaviors (NJPB: 2 items; accounting for 1.29\% of the total variance); factor 11 was labeled Occupational Role Reward (ORR; 3 items; accounting for 1.17\% of the total variance). Based on the literature and theoretical support, the eleven-factor solution was chosen for further analysis within the measurement model. Note: Kline (2018) recommends deleting factors with two or less items unless the factor loadings are great. Both NJPB items had high loadings so this factor was retained for further analysis. Once the factor structure was solidified, implied correlations were performed to evaluate composite reliability $(C R)$ and average variance extracted $(A V E)$ for the finalized factor structure (Table 9.0). $C R$ and $A V E$ display the level of convergent validity and internal consistency between scale items (Hair et. al., 2010). General acceptable values for $C R$ are greater than 0.40 and 0.60 for $A V E$ (Hair et. al., 2010). The majority of factors fell at or above these recommended levels so structural equation modeling was commenced. 
Table 9.0:

EFA Factor Matrix

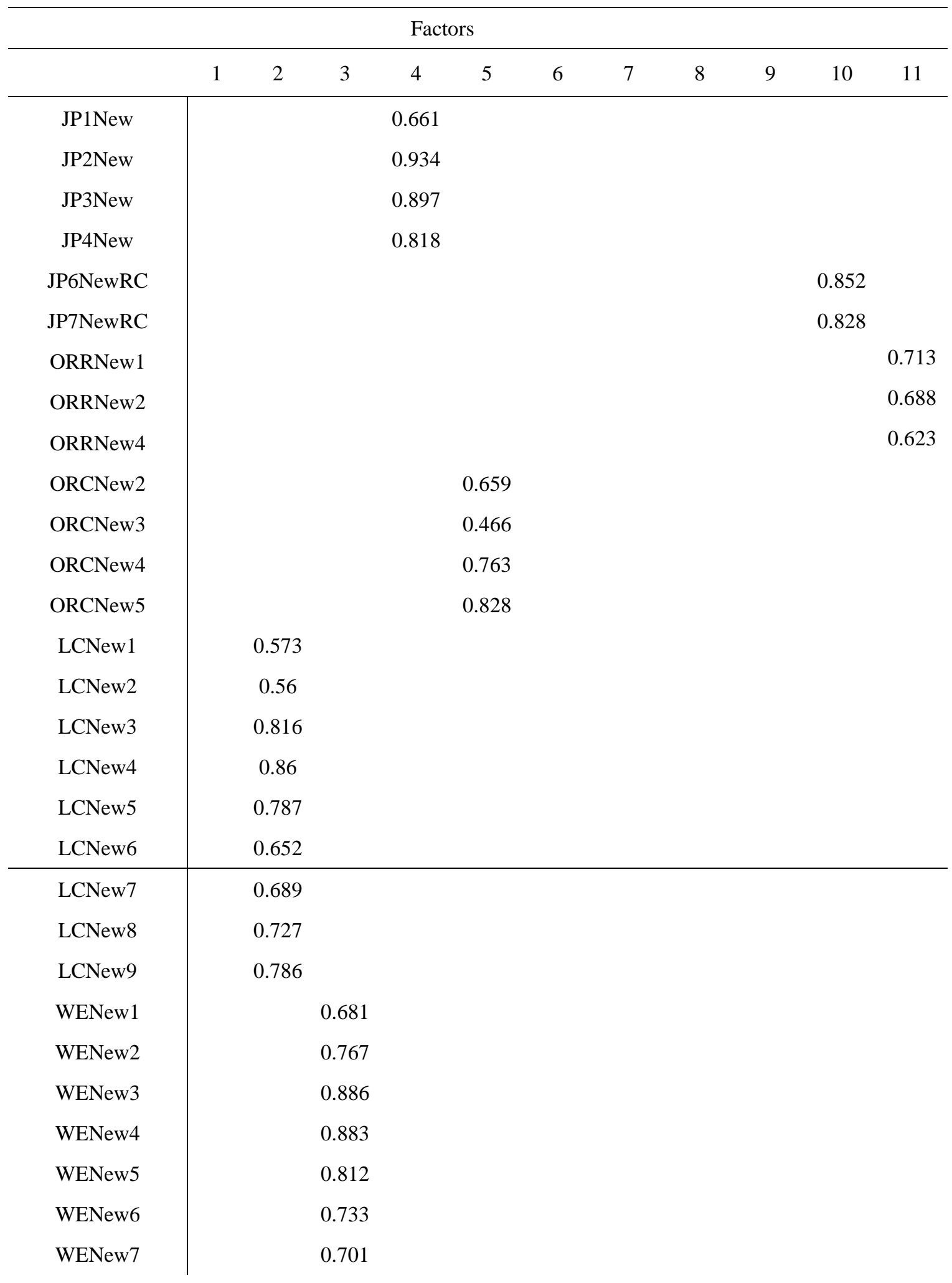




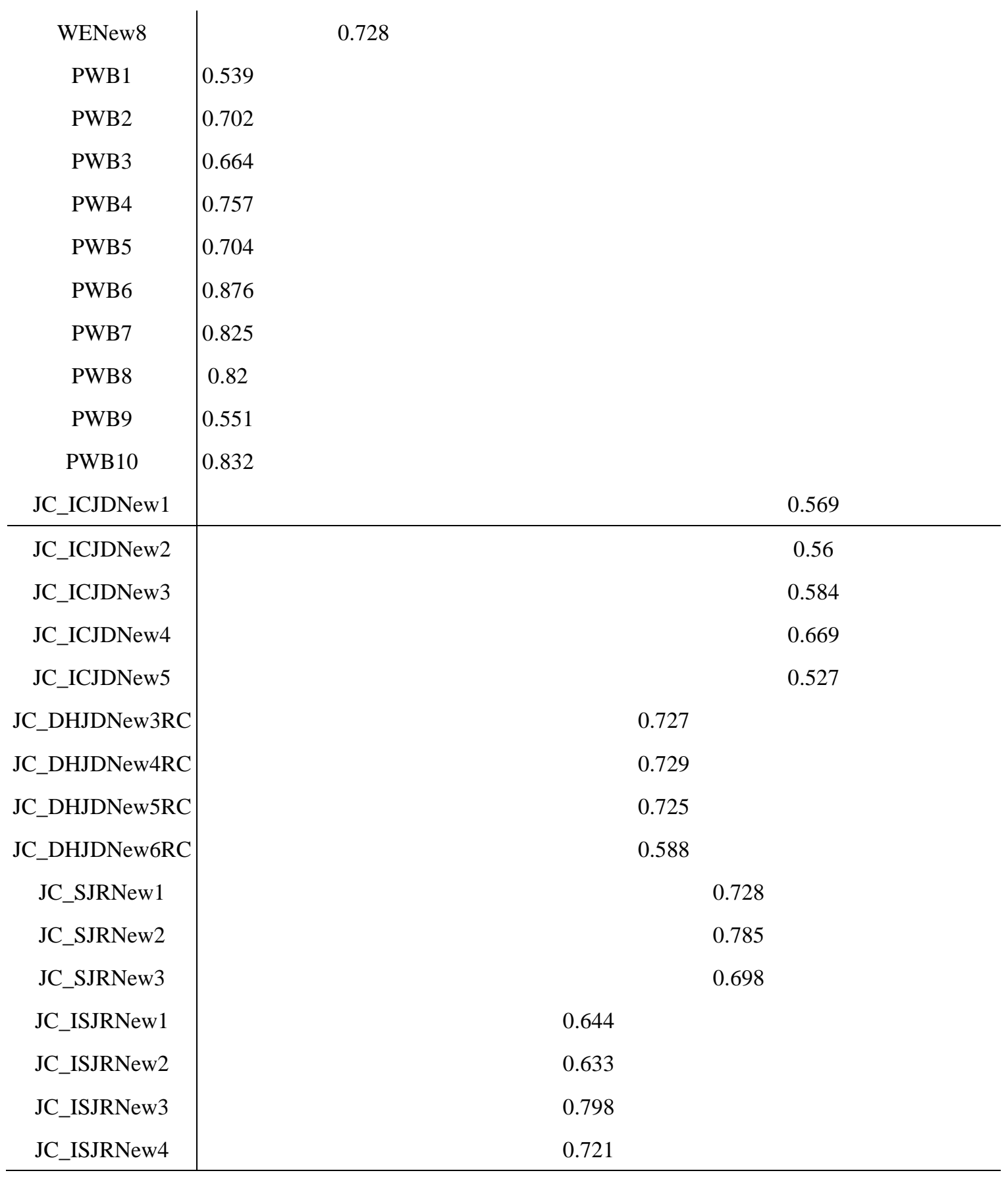




\section{Measurement Models}

Table 7.0 details the global fit indices for the measurement models assessed. Based upon guidance from Schumacker \& Lomax (2010), initial data fit was assessed using an eleven factor correlated measurement model. Item scores were used as indicators for the latent variable of occupational role reward, occupational role commitment, increasing structural job resources, increasing social job resources, increasing challenging job demands, decreasing hindering job demands, leisure crafting, work engagement, psychological well being, positive job performance behaviors and negative job performance behaviors. The 11 factor correlated model (Model 1) failed to produce a desired CFI (0.893) value of 0.95 or greater (Kline, 2016). Fit for Model 1 was found to be acceptable with RMSEA (0.049). Due to low CFI, the model also failed to meet specific guidelines recommended by Hair, Black, Babin \& Anderson (2010) for models with $\mathrm{N}>250$ and 30 or more observed variables although CFI may not be that informative based on the RMSEA value. Kenny, D.A. \& McCoach, D.B. (2003) suggests that CFI not be computed if the RMSEA of the null model is less than 0.158 or otherwise either the RMSEA or CFI will obtain too small a value for the CFI. Kenny \& McCoach (2003) also recommends focusing more on the TLI value vs. CFI value. CFI pays a penalty of one for every parameter estimated and because TLI and CFI are highly correlated, Kenny \& McCoach (2003) suggests only reporting one of the two. Based on this literature, the CFI nor TLI will be computed as measures of model fit. SRMR will be used instead to determine model fit due to SRMR paying no penalty for model complexity (Kenny \& McCoach, 2003). Please note that CFI will be reported on tables showing model fit indices but will not be assessed for statistical decision-making. SRMR 
for this model was reported at 0.0564 , which is in the acceptable range. Though global model fit for Model 1 was in the acceptable range, local model fit was unsatisfactory. To improve upon this, second order factoring was used. Job crafting was placed as a second order factor to increasing structural job resources, increasing social job resources, increasing challenging job demands and decreasing hindering job demands; occupational role salience was placed as a second order factor to occupational role reward and occupational role commitment; job performance was placed as a second order factor to positive and negative job performance behaviors. Current literature on these factors also supports the decision to use second order factoring.

Model 2 using second order factors was assessed for model fit. Model 2 has three first order factors (WE, PWB \& LC) and three second order factors (JC: ICJD, ISJR, DHJD \& SJR; JP: JP_POS \& JP_NEG; ORS: ORR \& ORC). RMSEA was in the acceptable range (0.051) and SRMR was strong (0.0681). As noted before, CFI and TLI were not computed thus not reported. An issue arose with standardized regression weights from the second order factor to job performance (Factor 4). A Heywood case was identified with a loading of 2.105. Schumacker \& Lomax (2010) recommended assessing the factor and item structure(s) when a Heywood case is present and ensure there is not vulnerability in the structure that could cause these phenomena. Upon reviewing items and factors for job performance, it was determined that Factor 10 (Negative Job Performance Behaviors) only having 2 items per factor has a high likelihood of causing issues with loadings. Kline (2016) notes that in a standard CFA, a single factor needs at least three indicators based on technical issues when computing and ensuring that 
reliability remains consistent. Thus, a decision was made to remove Factor 10 and its two subsequent scales for this reason.

Model 3 without Factor 10 was assessed for model fit. Model 3 contained four first order factors (WE, PWB, JP \& LC) and two second order factors (ORS: ORC \& ORR; JC: ICJD, ISJR, DHJD \& SJR). RMSEA was in the acceptable range (0.051) and SRMR was strong (0.0653). No issues with standardized regression weights were found and all weights were above the 0.50 cutoff threshold. Compared to the other measurement models evaluated, Model 3 had the best model fit and this model was accepted for further analysis. The reliability coefficients for the six factors were $\alpha=0.85$, 0.81, 0.82, 0.79, 0.88 and 0.76 for ORS, JC, WE, PWB, JP and LC, respectively. Table 11.0

CFA Fit Indices for Measurement Models

\begin{tabular}{cccccccc}
\hline Model & Chi 2 & DF & RMSEA & CFI & SRMR & AIC & BIC \\
\hline Model 1 & 2461.549 & 1429 & 0.049 & 0.893 & 0.057 & 2795.549 & 3415.742 \\
Model 2 & 2607.369 & 1461 & 0.051 & 0.896 & 0.0681 & 2877.369 & 3378.723 \\
Model 3 & 2413.551 & 1356 & 0.051 & 0.883 & 0.0653 & 2671.551 & 3150.622 \\
\hline
\end{tabular}

Table 12.0 displays the standardized path and structure coefficients for the finalized measurement model. The findings from this analysis verified the presence of 6 factors in the measurement model. Each item had a significant factor structure and pattern coefficients whose range was 0.621 to 0.90 which is in the acceptable range. 
Table 12.0

Standardized Path (P) and Structure (S) Coefficients for Finalized Measurement Model

\begin{tabular}{|c|c|c|c|c|c|c|c|c|c|c|c|c|}
\hline \multirow[t]{2}{*}{$\begin{array}{l}\text { Construct } \\
\text { Variable }\end{array}$} & \multicolumn{2}{|c|}{ ORS } & \multicolumn{2}{|c|}{ JC } & \multicolumn{2}{|c|}{$\mathrm{LC}$} & \multicolumn{2}{|c|}{ WE } & \multicolumn{2}{|c|}{ PWB } & \multicolumn{2}{|c|}{ JP } \\
\hline & $\mathrm{P}$ & $\mathrm{S}$ & $\mathrm{P}$ & $\mathrm{S}$ & $\mathrm{P}$ & $\mathrm{S}$ & $\mathrm{P}$ & $S$ & $\mathrm{P}$ & $\mathrm{S}$ & $\mathrm{P}$ & $\mathrm{S}$ \\
\hline ORS & & & & & & & & & & & & \\
\hline ORRNewl & 0.70 & 0.70 & & 0.473 & & 0.263 & & 0.249 & & 0.245 & & 0.123 \\
\hline ORRNew2 & 0.634 & 0.634 & & 0.428 & & 0.237 & & 0.225 & & 0.221 & & 0.111 \\
\hline ORRNew4 & 0.741 & 0.741 & & 0.501 & & 0.278 & & 0.263 & & 0.259 & & 0.13 \\
\hline ORCNew2 & 0.621 & 0.621 & & 0.426 & & 0.236 & & 0.224 & & 0.22 & & 0.11 \\
\hline ORCNew3 & 0.667 & 0.667 & & 0.458 & & 0.254 & & 0.241 & & 0.237 & & 0.119 \\
\hline ORCNew4 & 0.801 & 0.801 & & 0.550 & & 0.305 & & 0.289 & & 0.284 & & 0.143 \\
\hline $\begin{array}{c}\text { ORCNew5 } \\
\text { JC }\end{array}$ & 0.788 & 0.788 & & 0.541 & & 0.300 & & 0.284 & & 0.28 & & 0.14 \\
\hline ICJDNew1 & & 0.481 & 0.73 & 0.598 & & 0.443 & & 0.402 & & 0.305 & & 0.202 \\
\hline ICJDNew2 & & 0.469 & 0.711 & 0.583 & & 0.431 & & 0.391 & & 0.298 & & 0.197 \\
\hline ICJDNew3 & & 0.441 & 0.67 & 0.549 & & 0.406 & & 0.368 & & 0.28 & & 0.185 \\
\hline ICJDNew4 & & 0.437 & 0.663 & 0.543 & & 0.402 & & 0.365 & & 0.278 & & 0.183 \\
\hline ICJDNew5 & & 0.48 & 0.728 & 0.597 & & 0.441 & & 0.401 & & 0.305 & & 0.201 \\
\hline ISJRNew1 & & 0.446 & 0.766 & 0.554 & & 0.41 & & 0.372 & & 0.283 & & 0.187 \\
\hline ISJRNew2 & & 0.446 & 0.804 & 0.58 & & 0.429 & & 0.389 & & 0.296 & & 0.196 \\
\hline ISJRNew3 & & 0.436 & 0.751 & 0.541 & & 0.401 & & 0.364 & & 0.277 & & 0.183 \\
\hline ISJRNew4 & & 0.415 & 0.714 & 0.516 & & 0.382 & & 0.346 & & 0.263 & & 0.174 \\
\hline DHJDNew3 & & -0.141 & 0.741 & -0.176 & & -0.13 & & -0.118 & & -0.09 & & -0.059 \\
\hline DHJDNew4 & & -0.149 & 0.782 & -0.186 & & -0.137 & & -0.125 & & -0.095 & & -0.063 \\
\hline DHJDNew5 & & -0.129 & 0.677 & -0.161 & & -0.119 & & -0.108 & & -0.082 & & -0.054 \\
\hline DHJDNew6 & & -0.112 & 0.587 & -0.139 & & -0.103 & & -0.094 & & -0.071 & & -0.047 \\
\hline SJRNewl & & 0.303 & 0.742 & 0.377 & & 0.279 & & 0.253 & & 0.192 & & 0.127 \\
\hline SJRNew2 & & 0.332 & 0.81 & 0.413 & & 0.305 & & 0.277 & & 0.211 & & 0.139 \\
\hline $\begin{array}{l}\text { SJRNew3 } \\
\text { LC }\end{array}$ & & 0.304 & 0.746 & 0.379 & & 0.28 & & 0.254 & & 0.193 & & 0.128 \\
\hline LCNew 1 & & 0.277 & & 0.459 & 0.62 & 0.62 & & 0.241 & & 0.235 & & 0.108 \\
\hline LCNew 2 & & 0.295 & & 0.489 & 0.661 & 0.661 & & 0.257 & & 0.251 & & 0.115 \\
\hline LCNew3 & & 0.346 & & 0.574 & 0.775 & 0.775 & & 0.302 & & 0.294 & & 0.135 \\
\hline LCNew4 & & 0.359 & & 0.594 & 0.803 & 0.803 & & 0.313 & & 0.305 & & 0.14 \\
\hline LCNew5 & & 0.349 & & 0.578 & 0.781 & 0.781 & & 0.304 & & 0.296 & & 0.136 \\
\hline LCNew6 & & 0.298 & & 0.494 & 0.668 & 0.668 & & 0.260 & & 0.254 & & 0.116 \\
\hline LCNew 7 & & 0.331 & & 0.548 & 0.741 & 0.741 & & 0.288 & & 0.281 & & 0.129 \\
\hline LCNew8 & & 0.335 & & 0.556 & 0.751 & 0.751 & & 0.292 & & 0.285 & & 0.131 \\
\hline $\begin{array}{c}\text { LCNew9 } \\
\text { WE }\end{array}$ & & 0.34 & & 0.563 & 0.761 & 0.761 & & 0.296 & & 0.289 & & 0.133 \\
\hline WENew 1 & & 0.319 & & 0.507 & & 0.294 & 0.754 & 0.754 & & 0.419 & & 0.247 \\
\hline WENew2 & & 0.346 & & 0.55 & & 0.319 & 0.82 & 0.82 & & 0.456 & & 0.269 \\
\hline WENew3 & & 0.352 & & 0.559 & & 0.324 & 0.834 & 0.834 & & 0.463 & & 0.273 \\
\hline WENew4 & & 0.363 & & 0.576 & & 0.334 & 0.859 & 0.859 & & 0.477 & & 0.281 \\
\hline WENew5 & & 0.331 & & 0.526 & & 0.305 & 0.784 & 0.784 & & 0.435 & & 0.257 \\
\hline WENew6 & & 0.34 & & 0.541 & & 0.314 & 0.805 & 0.805 & & 0.448 & & 0.264 \\
\hline WENew7 & & 0.324 & & 0.515 & & 0.299 & 0.765 & 0.765 & & 0.427 & & 0.251 \\
\hline WENew8 & & 0.307 & & 0.488 & & 0.283 & 0.726 & 0.726 & & 0.404 & & 0.238 \\
\hline PWB & & & & & & & & & & & & \\
\hline$P W B 1$ & & 0.255 & & 0.33 & & 0.232 & & 0.34 & 0.611 & 0.611 & & 0.164 \\
\hline$P W B 2$ & & 0.309 & & 0.312 & & 0.282 & & 0.412 & 0.74 & 0.74 & & 0.199 \\
\hline$P W B 3$ & & 0.29 & & 0.379 & & 0.264 & & 0.387 & 0.696 & 0.696 & & 0.187 \\
\hline PWB4 & & 0.341 & & 0.355 & & 0.311 & & 0.455 & 0.819 & 0.819 & & 0.22 \\
\hline PWB5 & & 0.314 & & 0.418 & & 0.286 & & 0.419 & 0.753 & 0.753 & & 0.202 \\
\hline PWB6 & & 0.336 & & 0.385 & & 0.306 & & 0.449 & 0.808 & 0.808 & & 0.217 \\
\hline$P W B 7$ & & 0.303 & & 0.412 & & 0.276 & & 0.405 & 0.729 & 0.729 & & 0.196 \\
\hline$P W B 8$ & & 0.322 & & 0.372 & & 0.294 & & 0.43 & 0.775 & 0.775 & & 0.208 \\
\hline$P W B 9$ & & 0.269 & & 0.395 & & 0.245 & & 0.359 & 0.645 & 0.645 & & 0.173 \\
\hline PWB10 & & 0.33 & & 0.405 & & 0.301 & & 0.441 & 0.794 & 0.794 & & 0.213 \\
\hline JP & & & & & & & & & & & & \\
\hline JPNew1 & & 0.137 & & 0.222 & & 0.115 & & 0.216 & & 0.177 & 0.658 & 0.658 \\
\hline JPNew2 & & 0.188 & & 0.304 & & 0.157 & & 0.295 & & 0.242 & 0.9 & 0.9 \\
\hline JPNew3 & & 0.187 & & 0.302 & & 0.156 & & 0.294 & & 0.241 & 0.898 & 0.898 \\
\hline JPNew4 & & 0.17 & & 0.275 & & 0.142 & & 0.276 & & 0.219 & 0.813 & 0.813 \\
\hline
\end{tabular}




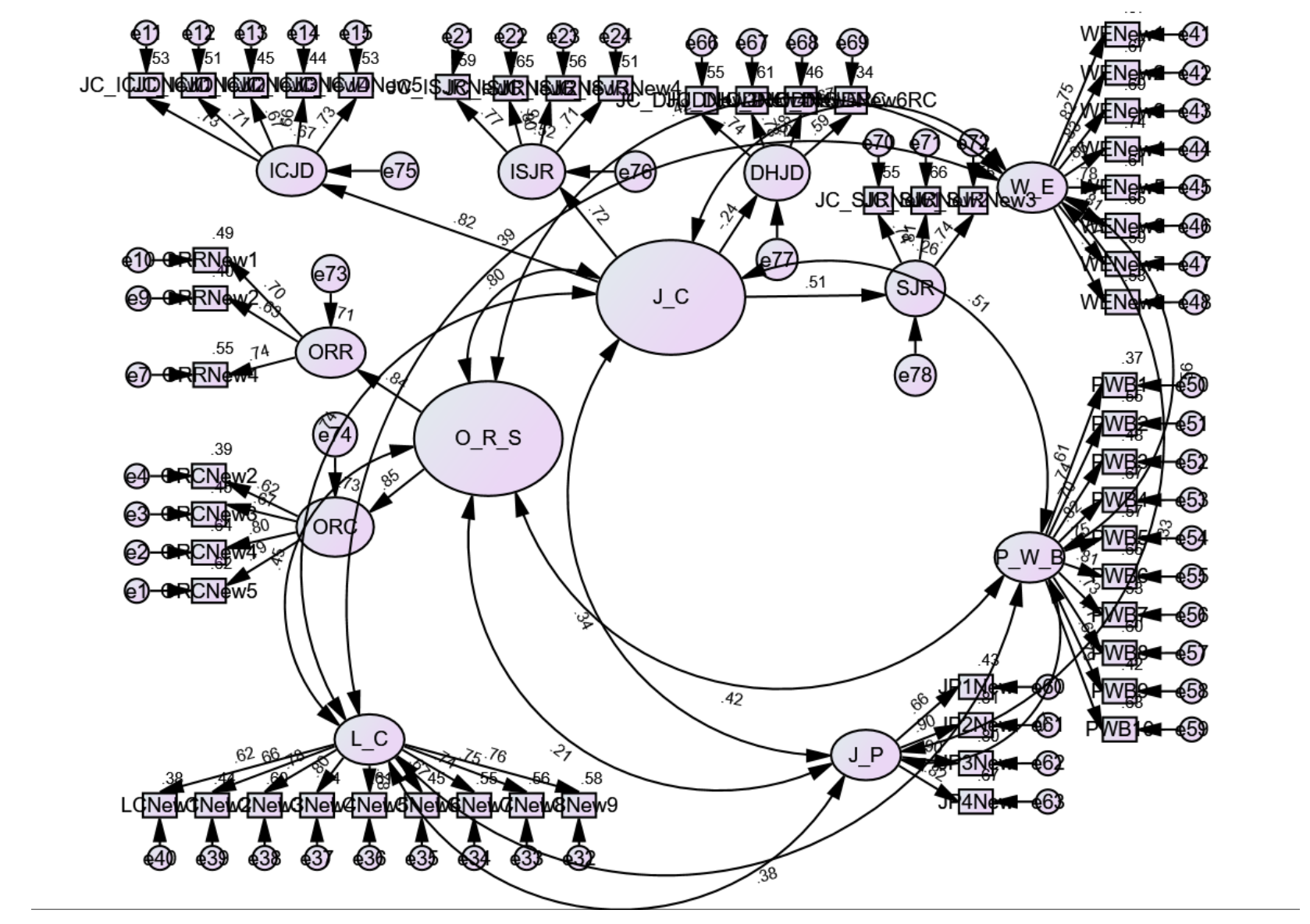

Figure 5. Final measurement model 


\section{Structural Models}

Four structural models were examined. Model 1 as indicated in Figure 4, represents the modified theoretical model representing occupational role salience as having an indirect effect on work engagement, job performance and psychological well being through job and leisure crafting; Model 2, a similar model to Model 1 but with the additional direct effect of job crafting on leisure crafting; Model 3, structural model with direct effect of leisure crafting on job crafting; Model 4; an intervening model where occupational role salience has an indirect effect on the outcome variables through job crafting and leisure crafting only affects the outcome variables through job crafting. Based on the data presented in Table 13.0 and theoretical reasoning, the alternative model (Model 4) was accepted as the best fitting model. Though Model 4 has two additional degrees of freedom compared to Model 1 and 3, it represents the more parsimonious of the other initially tested models based on the AIC and BIC despite other models retaining less degree of freedom. Kline (2016) recommends that AIC and BIC be used exclusively to assess parsimony among the model fit indices.

Table 13.0

CFA Fit Indices for Structural Models

\begin{tabular}{cccccccc}
\hline Model & Chi 2 & DF & RMSEA & CFI & SRMR & AIC & BIC \\
\hline Model 1 & 2491.164 & 1363 & 0.052 & 0.893 & 0.0728 & 2735.164 & 3188.239 \\
Model 2 & 2492.329 & 1364 & 0.052 & 0.888 & 0.0726 & 2734.329 & 3183.691 \\
Model 3 & 2479.608 & 1363 & 0.052 & 0.884 & 0.0738 & 2723.608 & 3176.684 \\
Model 4 & 2458.953 & 1365 & 0.052 & 0.884 & 0.0726 & 2698.953 & 3144.601 \\
\hline
\end{tabular}




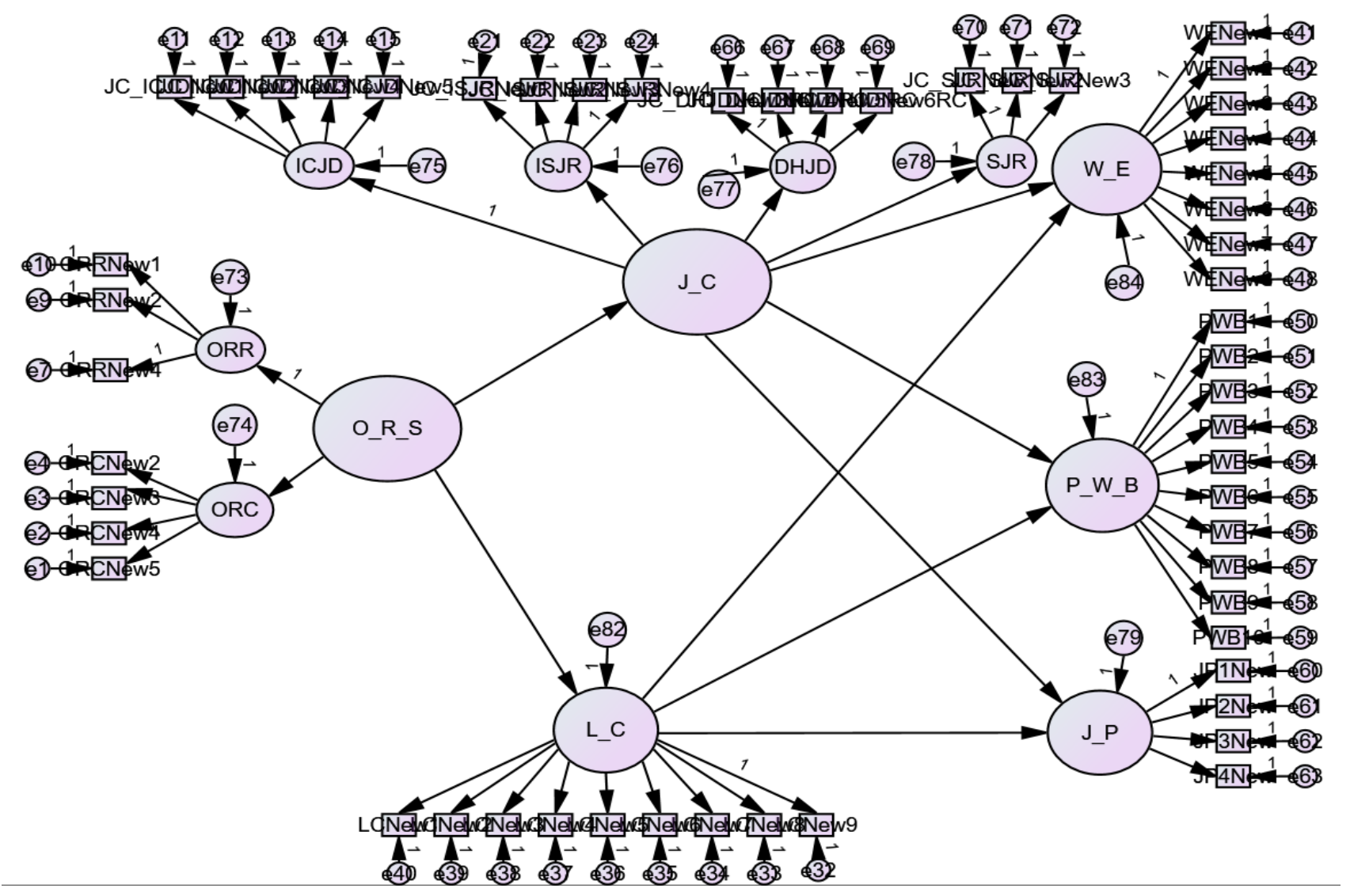

Figure 6. Structural model 1 


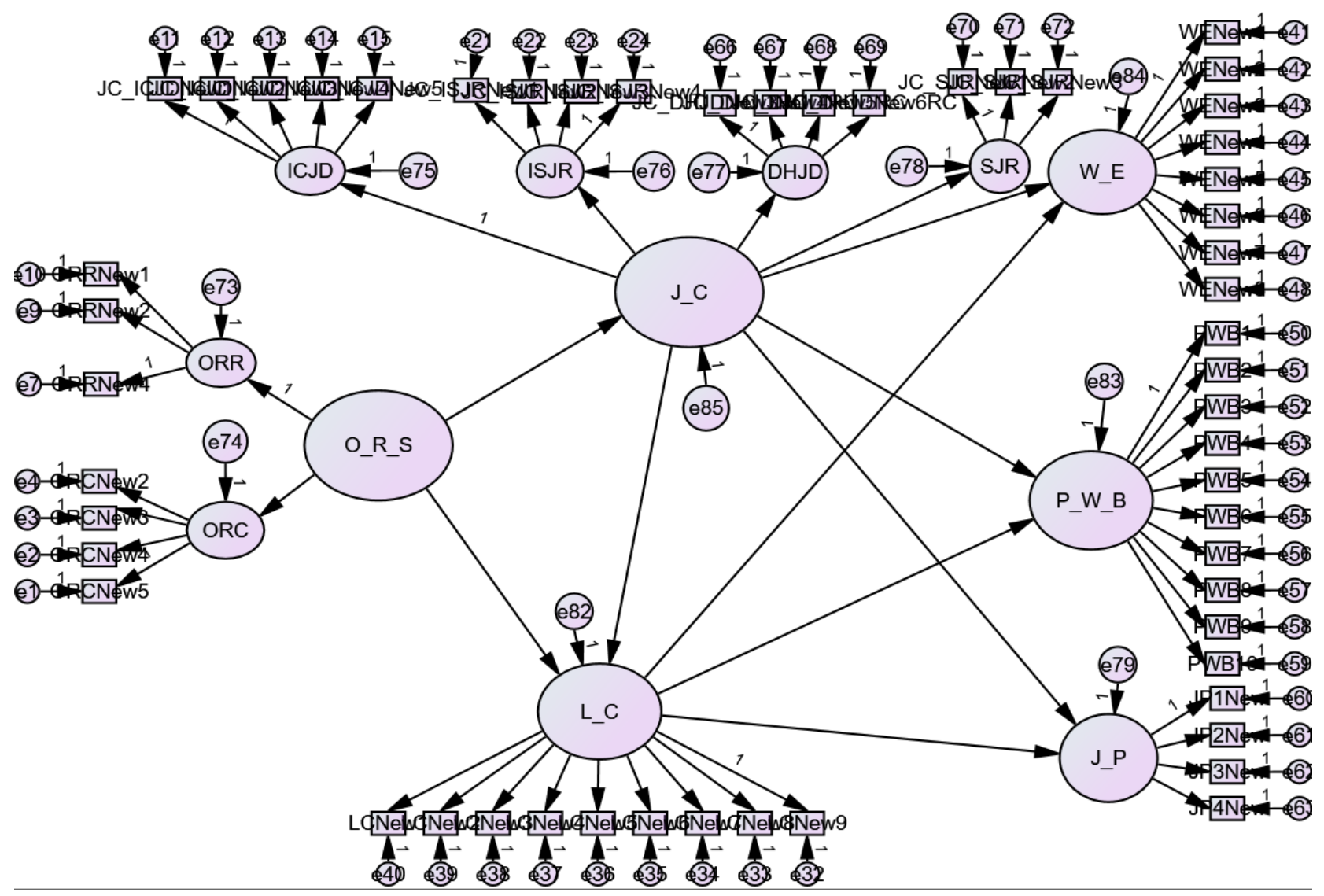

Figure 7. Structural model 2 


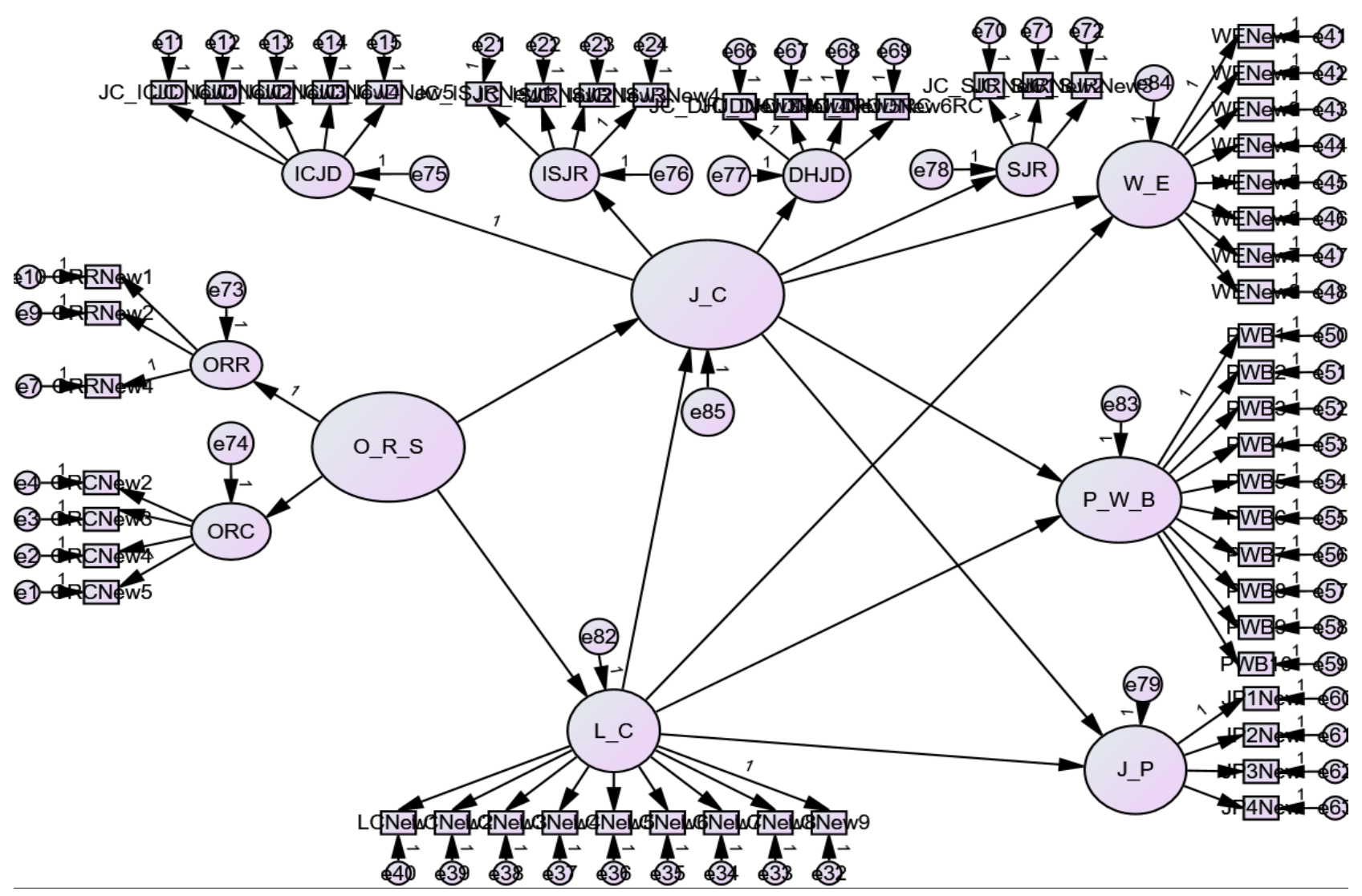

Figure 8. Structural model 3 


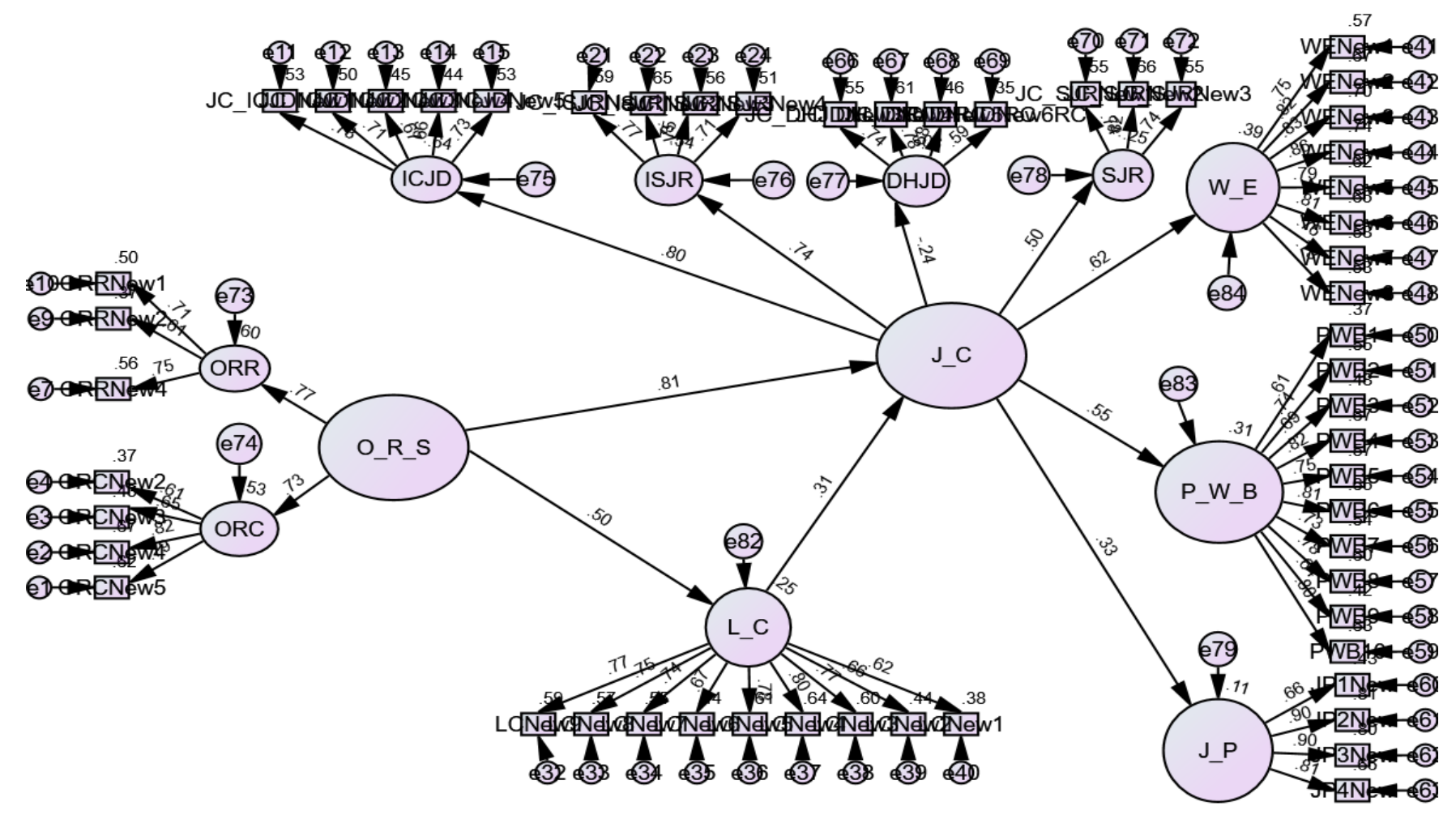

Figure 9. Structural model 4 
The following are the research questions that were asked at the beginning of this study. All direct, indirect and total effects are displayed on Table 11.0. Each question will be answered based on the results found from previous analysis:

\section{Research Question 1}

"Is there a significant mediating effect of job crafting on the relationship between leisure crafting and work engagement?" Job crafting had a significant positive mediating effect between leisure crafting and work engagement (LC--->JC $(c=0.31)$; JC--->WE $(c$ $=0.62)$.

\section{Research Question 2}

Does leisure crafting have a significant mediating effect on the relationship between job crafting and work engagement?" Since the best fitting model does not include a pathway with LC to JC, this research question is no longer valid. Figure 5 included this pathway.

\section{Research Question 3}

“Does job crafting have a significant direct effect on work engagement?" Job crafting has a significant direct effect on work engagement $\left(c^{\prime}=0.62, p<0.05\right)$. This effect was statistically significant based on the $p$ value and practically significant based on the effect size.

\section{Research Question 4}

“Does job crafting have a significant direct effect on job performance?” Job crafting had a significant direct effect on job performance $\left(c^{\prime}=0.33, p<0.05\right)$. This effect was statistically significant based on the $p$ value and practically significant based on the effect size. 


\section{Research Question 5}

"Does job crafting have a significant direct effect on psychological well-being?" Job crafting had a significant direct effect on psychological well being $\left(c^{\prime}=0.55, p<0.05\right)$.

\section{Research Question 6}

"Does leisure crafting have a significant direct effect on work engagement?" Since the best fitting model does not include a pathway with LC to WE, this research question is no longer valid. Figure 5 included this pathway.

\section{Research Question 7}

"Does leisure crafting have a significant direct effect on job performance?" Since the best fitting model does not include a pathway with LC to JP, this research question is no longer valid. Figure 5 included this pathway.

\section{Research Question 8}

"Does leisure crafting have a significant direct effect on psychological well-being?" Since the best fitting model does not include a pathway with LC to PWB, this research question is no longer valid. Figure 5 included this pathway.

\section{Research Question 9}

"Does occupational role salience have a significant direct effect on job crafting?" Occupational role salience had a significant positive direct effect on job crafting $\left(c^{\prime}=\right.$ $0.81, \mathrm{p}<0.05$ ). This effect has statistically and practically significance based on the $p$ value and effect size. 
Table 11.0

Direct, Indirect and Total Effects of Latent Factors

\begin{tabular}{cccc}
\hline Variables & Direct Effect $\left(c^{\prime}\right)$ & Indirect Effect $(a b)$ & Total Effect $(c)$ \\
\hline ORS ---> JC & $0.81^{*}$ & $0.155^{*}$ & $0.965^{*}$ \\
ORS ---> LC & $0.5^{*}$ & 0 & $0.5^{*}$ \\
ORS ---> WE & 0 & $0.5^{*}$ & $1.43^{*}$ \\
ORS ---> PWB & 0 & $0.45^{*}$ & $1.36^{*}$ \\
ORS ---> JP & 0 & $0.27^{*}$ & $1.14^{*}$ \\
JC ---> WE & $0.62^{*}$ & 0 & $0.62^{*}$ \\
JC ----> PWB & $0.55^{*}$ & 0 & $0.55^{*}$ \\
JC ---> JP & $0.33^{*}$ & 0 & $0.33^{*}$ \\
LC ---> JC & $0.31^{*}$ & 0 & $0.31^{*}$ \\
\hline
\end{tabular}




\section{CHAPTER V}

\section{DISCUSSION}

This chapter presents a summary of the study and important conclusions drawn from the findings presented in Chapter 4. It provides a discussion of the findings and the implications for action and recommendations for further research.

The purpose of this study is to look at how an individuals' ability to job craft relates to work engagement, job performance and their psychological well-being. Moreover, when job crafting opportunities are low, how leisure crafting can compensate to provide the individual similar personal outcomes. Along these same lines, this study examines when job-crafting opportunities are high, how these positive effects can spillover onto other aspects of an individuals' life such as leisure.

This study also examines the extent to which an individual views work as a mean of self-identification and how this relates to job crafting. To expand the understanding of job crafting and leisure crafting, this study expanded the growing body of research by contributing evidence towards the following research questions:

1. Is there a significant mediating effect of job crafting on the relationship between leisure crafting and work engagement?

2. Does job crafting have a significant direct effect on a) work engagement; b) job performance; c) psychological well-being and; d) work engagement? 


\section{Summary of the Study}

In previous decades, most people viewed work as a linear progression to retirement. This ideology of work has evolved and is now viewed by most individuals as a part of their self-definition. To accompany this evolution, the workplace is accommodating alternative work schedules, work from home options, telecommuting, etc. to meet this thirst for self-exploration. But the workplace still remains for the most part a top down decision-making process where managers and executives observe trends and make corrections to increase production, engagement and overall satisfaction. Though these alterations do result in increases in work engagement and task performance, there is no "one size fits all" solution and certain individuals are left out. Job crafting brings the individual back into the process, allows each person to take control and make the decisions that will ultimately affect who they are inside and outside work (Wrzesniewski \& Dutton, 2001). This study explored the relationship between how an individual identifies with their work and the changes employees engage in inside and outside of work with the aim to align their jobs with their own preferences to affect work engagement at work, psychological well-being and job performance on the job.

\section{Discussion of Results}

At the onset of this study, two main objectives were listed due to the lack of their exploration in current literature: the use of ORS as a predictor variable and the interaction/relationship of leisure crafting on job crafting as it relates to the compensation and spillover hypotheses. Spillover hypothesis states that positive experiences within one domain such as work repeat themselves in other domains such as leisure (Petrou \& 
Bakker, 2016). Compensation hypothesis states that unattained goals or desired states in one domain can be achieved through activities in other domains (Petrou \& Bakker, 2016). The original proposed model established JC and LC as interacting variables based on the above hypotheses and how they relate to one another as well as no direct effect between ORS and LC. But during the CFA, the pathway from JC to LC was not supported thus was removed from further analysis. Statistical relevance and a direct correlation between ORS and LC was made.

The best fitting structural model showed ORS having a strong and statistical significant predictive effect on both JC and LC, though there was no dual interaction between LC and JC. Based on the conclusions, an individuals' self identification to work (the extent to which work defines who a person is) has a significant effect on their likelihood of engaging in job crafting; the same self identification to work has a significant effect on their likelihood of engaging in leisure crafting which also has a significant effect on their ability to job craft. The relationships and effects that ORS has on JC and LC as well as the relationship of LC to JC creates significant impact on WE, PWB and JP.

The direct positive relationship between job crafting, job performance and work engagement have been well established in the literature but the aim of this study was to look at other variables including the mediating relationship of leisure crafting on job crafting (and visa versa) and the impact of this relationship on work engagement, job performance and psychological well being (Tims, Bakker, \& Derks, 2013). Within this context, this study yields two key findings: the intervening effect of leisure crafting on job crafting and the predictive value of occupational role salience within this model. 
The proposed model focused on JC and LC as interacting with one another, which would ultimately affect their relationship with the outcome variables. As noted in previous chapters, this model was not statistically supported. Thus, alternative models were developed. The best fitting model recommended LC as an intervening variable between ORS and JC as well as a direct effect between ORS and JC. The direct relationships between LC and the outcome variables were also not supported in the best fitting model, leaving JC with the only direct relationships on the outcome variables. The best-fitting model also minimizing the relevance and direct impact of the spillover and compensation hypotheses as LC and JC are not interacting in the best fitting model. ORS as a predictor variable on JC and LC was upheld in the best fitting model. Each pathway in the chosen model was statistically significant and maintained a significant effect size.

Though these results were not expected, they are important and significant to this study. The extent to which a person identifies work as part of who they are impacts their likelihood of crafting their leisure activities in an effort to increase job crafting at work. These relationships have a significant direct effect on a person's work engagement, psychological well-being and job performance. The results also indicate that a person does not necessarily have to craft their leisure activities to have an impact on job crafting at work. The extent to which a person identifies work as part of who they are has a significant and direct effect on job crafting at work which has an impact on work engagement, job performance and psychological well being.

\section{Implications for Theory}

The current literature on job crafting and its effect on work engagement and job performance have been well established and spans a multitude of settings (Lyons, 2008; 
Petrou et al., 2012; Tims \& Bakker, 2010; Wrzesniewski \& Dutton, 2001). But little attention in the literature has been given to leisure crafting and occupational role salience especially as a predictor variable. Previous literature only referenced occupational role salience as a mediating variable between various predictive and outcome variables and the idea of leisure crafting is relatively new to research and rarely is studied in collaboration with job crafting (Wrzesniewski \& Dutton, 2001; Petrou et al., 2012). The results from this study show the significant effect of occupational role salience as a predictive variable and show the intervening effect leisure crafting can have on job crafting. Future research on these topics should emerge to better understand the role of leisure crafting on job crafting (and visa versa) and the importance of occupational role salience as a predictor of these variables.

\section{Implications for Research}

Though this research establishes occupational role salience as a predictor of leisure and job crafting, this study did not control for gender variability as it relates to specific employment positions. The respondents in this study were $47.5 \%$ female and $52.1 \%$ male. There are professions where specific genders are the majority of employees such as nurses and teachers as it relates to females. These gender occupational differences may have an effect on the impact of occupational role salience and thus have a secondary effect on job and leisure crafting. Future research may want to explore gender specific professions in more depth to compare to the results of this study.

This study also supports the linkage between leisure and job crafting. Though the results of this study only indicate an intervening relationship of leisure crafting on job crafting, this suggests that the balance between work and life are significant as it relates 
to work engagement, psychological well-being and job performance. This linkage also shows that the purposeful adaptation of leisure activities to compensate for individuals needs in work environments where job crafting is not appropriate or supported is relevant for employees and managers to consider and understand its impact on defined organizational outcomes. This linkage contributes to the job crafting literature as well as HRD literature.

The results from this study also show a strong effect of job crafting on psychological well-being. Though this relationship existing within the study, the impact of psychological well-being on more external factors such as thriving are not throroughly explored (Schaufeli et al., 2002). Future research should focus on the potential outcomes that psychological well-being may have on applied factors such as thriving or happiness.

\section{Implications for Practice}

The results from this study not only offer insight for researchers but practitioners as well. As stated previously, occupational role salience has a significant effect on leisure crafting and job crafting. But this impact goes beyond theoretical and research implications as employers and managers should be aware of its power on employees especially when applying principles of job crafting and leisure crafting. If an employee identifies work as a strong attribute of self worth, managers should be knowledgeable on how this could affect their ability to engage in job crafting and affect job performance, psychological well-being and work engagement.

Along similar lines, managers should also be aware of how leisure activities can impact employees as it pertains to job crafting and listed outcome variables. This can also come into play when looking to acquire talent and hiring new employees via social 
media. Social media allows individuals to share ideas, express themselves to others and receive feedback from their peers. Though social media has negative aspects that reduce this sharing environment, organizations can use it as a tool to understand their employees outside of work and how their leisure activities impact their abilities at work. If a manager understands how an employee's leisure activities relate to their work, then they can better understand how these activities impact the crafting of their jobs for better or worse, which leads to alternating outcomes.

With generational shifts in the current workplace, organizations need to be aware of the want and need differences of different generations. As the baby boomer generation exits the workplace, a new generation is entering and forcing organizations to consider accommodating differences in how they define and apply work. This generation may want to see the value in their work and understanding of how their efforts make a difference. This generation may also want to adapt and change their job responsibilities to better fit their personal needs and feel more engaged in their work. This study follows this motif where keeping work as part of a self definition and bringing other aspects of your life into the workplace are important not only to the employee but the organization as well. Managers need to understand and embrace these generational differences so to better adapt the changing workplace to fulfill these needs and acquire talent, as millennials become a larger part of the work environment.

As technology continues to adapt the ways in which we work, the need for faceto-face and social interactions becomes less essential to a thriving organization. Telecommuting allows office workers to complete their daily tasks and responsibilities from the leisure of their own home or neighborhood coffee shop. Though the workplace 
environment is changing, the psychological and social needs of employees have not altered. Employees still want to feel engaged and appreciated for the work they do and supported by their organization. As this study represents, managers should pay attention to offsite employees and be in communication with them to understand how occupational role salience and leisure crafting are playing into the essential work functions they perform. 


\section{REFERENCES}

Amatea, E. S., Cross, G. E., Clark, J. E., \& Bobby, C. L. (1986). Assessing the work and family role expectations of career oriented men and women: The life role salience scales. Journal of Marriage and Family, 48(4), 831-838.

Bakker, A. B., \& Demerouti, E. (2007). The Job Demands-Resources model: state of the art. Journal of Managerial Psychology, 22(3), 309-328.

doi:10.1108/02683940710733115

Bakker, A. B., \& Demerouti, E. (2008). Towards a model of work engagement. Career Development International, 13(3), 209-223. doi:10.1108/13620430810870476

Bakker, A. B., Emmerik, H. v., \& Euwema, M. C. (2006). Crossover of burnout and engagement in work teams. Work and Occupations, 33(4), 464-489.

Bakker, A. B., Tims, M., \& Derks, D. (2012). Proactive personality and job performance: The role of job crafting and work engagement. Human Relations, 65(10), 13591378. doi:10.1177/0018726712453471

Bal, M. P., \& Kooij, D. (2011). The relations between work centrality, psychological contracts and job attitudes: The influence of age. European Journal of Work and Organizational Psychology, 20, 497-523.

Berg, J. M., Grant, A. M., \& Johnson, V. (2010). When Callings Are Calling: Crafting Work and Leisure in Pursuit of Unanswered Occupational Callings. Organization Science, 21(5), 973-994. doi:10.1287/orsc.1090.0497 
Deci, E. L., \& Ryan, R. M. (2000). The "what" and "why" of goal pursuits: Human needs and the self determination of behavior. Psychological Inquiry, 11(4), 227-268.

Golden, T. D., Veiga, J. F., \& Dino, R. N. (2008). The impact of professional isolation on teleworker job performance and turnover intentions: does time spent teleworking, interacting face-to-face, or having access to communication-enhancing technology matter? J Appl Psychol, 93(6), 1412-1421. doi:10.1037/a0012722

Grant, A. M. (2007). Relational job design and the motivation to make a prosocial difference. Academy of Management Review, 32(2), 393-417.

Gruys, M. L., \& Sackett, P. R. (2003). Investigating the dimensionality of counterproductive work behavior. International Journal of Selection and Assessment, 11(1), 30-42.

Guest, D. E. (2002). Perspectives on the Study of Work-life Balance. Social Science Information, 41(2), 255-279. doi:10.1177/0539018402041002005

Hakanen, J. J., Bakker, A. B., \& Schaufeli, W. B. (2006). Burnout and work engagement among teachers. Journal of School Psychology, 43(6), 495-513. doi:10.1016/j.jsp.2005.11.001

Hirschfeld, R. R., \& Feild, H. S. (2000). Work centrality and work alienation: Distinct aspects of a general commitment to work. Journal of Organizational Behavior, 21(1), 789-800.

Karasek, R. A. (1979). Job demands, job decision latitude: implications for job redesign. Administrative Science Quarterly, 24, 285-308. 
Leana, C., Appelbaum, E., \& Shevchuk, I. (2009). Work process and quality of care in early childhood education: The role of job crafting. Academy of Management Journal, 52(6), 1169-1192.

Lepine, J. A., Podsakoff, N. P., \& LepIne, M. A. (2005). A meta-analytic test of the challenge stressor-hindrance stressor framework: an explanation for inconsistent relationships among stressors and performance. Academy of Management Journal, 48(5), 764-775.

Lyons, P. (2008). The Crafting of Jobs and Individual Differences. Journal of Business and Psychology, 23(1-2), 25-36. doi:10.1007/s10869-008-9080-2

Nielsen, K., \& Abildgaard, J. S. (2012). The development and validation of a job crafting measure for use with blue-collar workers. Work Stress, 26(4), 365-384. doi:10.1080/02678373.2012.733543

Parker, S. K. (2016). `That is my job'. Human Relations, 60(3), 403-434. doi: $10.1177 / 0018726707076684$

Petrou, P., \& Bakker, A. B. (2016). Crafting one's leisure time in response to high job strain. Human Relations, 69(2), 507-529. doi:10.1177/0018726715590453

Petrou, P., Bakker, A. B., \& van den Heuvel, M. (2017). Weekly job crafting and leisure crafting: Implications for meaning-making and work engagement. Journal of Occupational and Organizational Psychology, 90(2), 129-152.

doi:10.1111/joop. 12160

Petrou, P., Demerouti, E., Peeters, M. C. W., Schaufeli, W., \& Hetland, J. (2012). Crafting a job on a daily basis: Contextual correlates and the link to work 
engagement. Journal of Organizational Behavior, 33(8), 1120-1141. doi:10.1002/job.1783

Rosso, B. D., Dekas, K. H., \& Wrzesniewski, A. (2010). On the meaning of work: A theoretical integration and review. Research in Organizational Behavior, 30, 91127. doi:10.1016/j.riob.2010.09.001

Salanova, M., Agut, S., \& Peiro, J. M. (2005). Linking organizational resources and work engagement to employee performance and customer loyalty: the mediation of service climate. J Appl Psychol, 90(6), 1217-1227. doi:10.1037/00219010.90.6.1217

Schaufeli, W., \& Bakker, A. B. (2004). Job demands, job resources, and their relationship with burnout and engagement: a multi-sample study. Journal of Organizational Behavior, 25(3), 293-315. doi:10.1002/job.248

Schaufeli, W., \& Salanova, M. (2007). Efficacy or inefficacy, that's the question: burnout and work engagement, and their relationships with efficacy beliefs. Anxiety Stress Coping, 20(2), 177-196. doi:10.1080/10615800701217878

Schaufeli, W., Salanova, M., Gonzalez-Roma, V., \& Bakker, A. B. (2002). The measurement of engagement and burnout: A two sample confirmatory factor analytic approach. Journal of Happiness Studies, 3, 71-92.

Steger, M. F., Dik, B. J., \& Duffy, R. D. (2012). Measuring Meaningful Work. Journal of Career Assessment, 20(3), 322-337. doi:10.1177/1069072711436160

Tims, M., \& Bakker, A. B. (2010). Job crafting: towards a new model of individual job redesign. SA Journal of Industrial Psychology, 36(2), 1-9. 
Tims, M., Bakker, A. B., \& Derks, D. (2012). Development and validation of the job crafting scale. Journal of Vocational Behavior, 80(1), 173-186. doi:10.1016/j.jvb.2011.05.009

Tims, M., Bakker, A. B., \& Derks, D. (2013). The impact of job crafting on job demands, job resources, and well-being. J Occup Health Psychol, 18(2), 230-240. doi:10.1037/a0032141

Tims, M., Bakker, A. B., \& Derks, D. (2015). Examining Job Crafting from an Interpersonal Perspective: Is Employee Job Crafting Related to the Well-Being of Colleagues? Applied Psychology, 64(4), 727-753. doi:10.1111/apps.12043

Tims, M., Bakker, A. B., Derks, D., \& van Rhenen, W. (2013). Job Crafting at the Team and Individual Level. Group \& Organization Management, 38(4), 427-454. doi: $10.1177 / 1059601113492421$

Tims, M., Derks, D., \& Bakker, A. B. (2016). Job crafting and its relationships with person-job fit and meaningfulness: A three-wave study. Journal of Vocational Behavior, 92, 44-53. doi:10.1016/j.jvb.2015.11.007

van den Heuvel, M., Demerouti, E., Schreurs, B. H. J., Bakker, A. B., \& Schaufeli, W. B. (2009). Does meaning-making help during organizational change? Career Development International, 14(6), 508-533. doi:10.1108/13620430910997277 van Wingerden, J., Bakker, A. B., \& Derks, D. (2017). Fostering employee well-being via a job crafting intervention. Journal of Vocational Behavior, 100, 164-174. doi:10.1016/j.jvb.2017.03.008 
Van Wingerden, J., Derks, D., \& Bakker, A. B. (2017). The Impact of Personal Resources and Job Crafting Interventions on Work Engagement and Performance. Human Resource Management, 56(1), 51-67. doi:10.1002/hrm.21758

Vogel, R. M., Rodell, J. B., \& Lynch, J. W. (2015). Engaged and Productive Misfits: How Job Crafting and Leisure Activity Mitigate the Negative Effects of Value Incongruence. Academy of Management Journal, 59(5), 1561-1584. doi:10.5465/amj.2014.0850

Weseler, D., \& Niessen, C. (2016). How job crafting relates to task performance. Journal of Managerial Psychology, 31(3), 672-685. doi:10.1108/jmp-09-2014-0269

Williams, L. J., \& Anderson, S. E. (1991). Job satisfaction and organizational commitment as predictors of organizational citizenship and in-role behaviors. Journal of Management, 17(3), 601-617.

Wrzesniewski, A., \& Dutton, J. E. (2001). Crafting a job: revisioning employees as active crafters of their work. Academy of Management Review, 26(2), 179-201.

Wrzesniewski, A., Dutton, J. E., \& Debebe, G. (2003). Interpersonal sensemaking and the meaning of work. Research in Organizational Behavior, 25, 93-135.

Wrzesniewski, A., LoBuglio, N., Dutton, J. E., \& Berg, J. M. (2013). Job crafting and cultivating positive meaning and identity in work. Advances in Positive Organizational Psychology, 1, 281-302.

Xanthopoulou, D., Bakker, A. B., Demerouti, E., \& Schaufeli, W. B. (2009). Reciprocal relationships between job resources, personal resources, and work engagement. Journal of Vocational Behavior, 74(3), 235-244. doi:10.1016/j.jvb.2008.11.003 
Zou, X., \& Ingram, P. (2013). Bonds and boundaries: Network structure, organizational boundaries, and job performance. Organizational Behavior and Human Decision Processes, 120(1), 98-109. doi:10.1016/j.obhdp.2012.09.002 


\section{Appendix A}

Tables and Scree Plot

Table 6.0

Mulitcollinearity Statistics

\begin{tabular}{ccc}
\hline Variable & Tolerance & VIF \\
\hline ORC & 0.564 & 1.772 \\
JC_ICJD & 0.503 & 1.987 \\
LC & 0.595 & 1.681 \\
JP -Positive & 0.788 & 1.269 \\
JC_ISJR & 0.568 & 1.761 \\
JP_Negative & 0.805 & 1.243 \\
JC_DHJD & 0.835 & 1.198 \\
JC_SJR & 0.716 & 1.398 \\
ORR & 0.615 & 1.626 \\
PWB & 0.749 & 1.335
\end{tabular}

Note: WE was used as dependent variable to evaluate mulitcollinearity 
Table 7.0

Tests of Normality (Shapiro-Wilk)

\begin{tabular}{cccc}
\hline Variable & Statistic & df & Sig. \\
\hline ORC & 0.936 & 303 & 0.001 \\
JC_ICJD & 0.973 & 303 & 0.001 \\
LC & 0.976 & 303 & 0.001 \\
WE & 0.917 & 303 & 0.001 \\
PWB & 0.95 & 303 & 0.001 \\
JP & 0.696 & 303 & 0.001 \\
JC_ISJR & 0.86 & 303 & 0.001 \\
JP_NEG & 0.688 & 303 & 0.001 \\
JC_DHJD & 0.979 & 303 & 0.001 \\
JC_SJR & 0.964 & 303 & 0.001 \\
ORR & 0.911 & 303 & 0.001 \\
\hline
\end{tabular}


Table 8.0

Correlations of Factor Structure

\begin{tabular}{|c|c|c|c|c|c|c|c|c|c|c|c|}
\hline Variable & 1 & 2 & 3 & 4 & 5 & 6 & 7 & 8 & 9 & 10 & 11 \\
\hline 1. ORC & 1 & & & & & & & & & & \\
\hline 2. ICJD & $.392 * *$ & 1 & & & & & & & & & \\
\hline 3. $\mathrm{LC}$ & $.342 * *$ & $.576 * *$ & 1 & & & & & & & & \\
\hline 4. WE & $.251 * *$ & $.511 * *$ & $.372 * *$ & 1 & & & & & & & \\
\hline 5. PWB & $.271^{* *} *$ & $.373^{* *}$ & $.368 * *$ & $.517 * *$ & 1 & & & & & & \\
\hline 6. JP_POS & 0.092 & $.216^{* *}$ & $.145^{*}$ & $.320 * *$ & $.259 * *$ & 1 & & & & & \\
\hline 7. ISJR & $.509^{* *}$ & $.473 * *$ & $.393 * *$ & $.434 * *$ & $.366^{* *}$ & $.324 * *$ & 1 & & & & \\
\hline 8. JP_NEG & -0.058 & -0.034 & -0.086 & 0.032 & 0.015 & $.290 * *$ & $.118^{*}$ & 1 & & & \\
\hline 9. DHJD & $-.146^{*}$ & $-.116^{*}$ & $-.238 * *$ & 0.022 & -0.02 & 0.009 & -0.082 & $.282 * *$ & 1 & & \\
\hline 10. SJR & $.271 * *$ & $.462 * *$ & $.338 * *$ & $.308 * *$ & $.163 * *$ & 0.021 & $.185^{* *}$ & $-.146^{*}$ & $-.249 * *$ & 1 & \\
\hline 11. ORR & $.563^{* *}$ & $.357 * *$ & $.314 * *$ & $.325^{* *}$ & $.325^{* *}$ & $.142 *$ & $.400^{* * *}$ & -0.11 & $-.113^{*}$ & $.300 * *$ & 1 \\
\hline
\end{tabular}

Note: **Correlation is significant at the 0.01 level (two-tailed)

*Correlation is significant at the 0.05 level (two-tailed) 
Figure 4.0

Scree Plot of Initial EFA Model

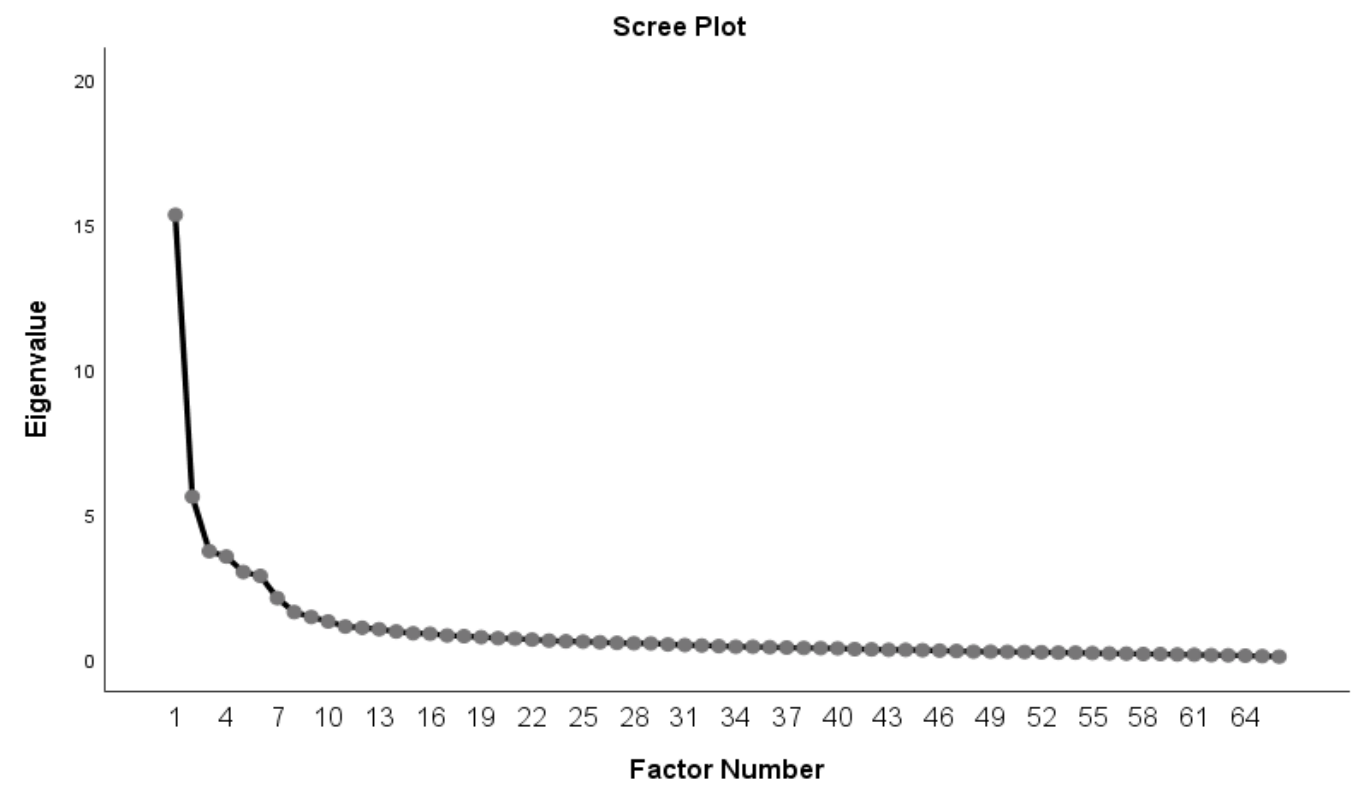


Table 10.0

Implied Correlations (n-303)

\begin{tabular}{ccccccccccccc}
\hline Variable & 1 & 2 & 3 & 4 & 5 & 6 & 7 & 8 & 9 & 10 & 11 & 12 \\
\hline 1. J_C & 0.616 & & & & & & & & & & & \\
2. O_R_S & 0.804 & 0.846 & & & & & & & & & & \\
3. J_P & 0.338 & 0.209 & 0.823 & & & & & & & & & \\
4. P_W_B & 0.511 & 0.416 & 0.269 & 0.739 & & & & & & & & \\
5. W_E & 0.671 & 0.423 & 0.328 & 0.556 & 0.794 & & & & & & & \\
6. L_C & 0.74 & 0.447 & 0.174 & 0.38 & 0.389 & 0.731 & & & & & & \\
7. SJR & 0.508 & 0.409 & 0.172 & 0.26 & 0.341 & 0.376 & 0.766 & & & & & \\
8. DHJD & -0.237 & -0.191 & -0.08 & -0.121 & -0.159 & -0.176 & -0.121 & 0.809 & & & & \\
9. ORC & 0.686 & 0.853 & 0.178 & 0.355 & 0.36 & 0.381 & 0.349 & -0.163 & 0.835 & & & \\
10. ISJR & 0.722 & 0.581 & 0.244 & 0.369 & 0.485 & 0.534 & 0.367 & -0.171 & 0.495 & 0.877 & & \\
11. ICJD & 0.819 & 0.659 & 0.277 & 0.418 & 0.55 & 0.606 & 0.416 & -0.194 & 0.562 & 0.591 & 0.905 & \\
12. ORR & 0.676 & 0.84 & 0.175 & 0.35 & 0.355 & 0.375 & 0.343 & -0.16 & 0.717 & 0.488 & 0.554 & 0.693 \\
\hline CR & 0.572 & 0.834 & 0.892 & 0.923 & 0.931 & 0.911 & 0.81 & 0.792 & 0.812 & 0.752 & 0.636 & 0.734 \\
AVE & 0.38 & 0.716 & 0.677 & 0.547 & 0.631 & 0.535 & 0.587 & 0.654 & 0.697 & 0.769 & 0.819 & 0.48
\end{tabular}

Note: Square root of the average on the diagonal 


\section{Appendix B}

\section{IRB Approval}

\section{univensistry of LOUISVILLE}

Human Subjects Protection Program Office

MedCenter One - Suite 200

501 E. Broadway

Louisville, KY 40202-1798

Office: 502.852 .5188 Fax: 502.852 .2164
DATE:

TO:

FROM:

IRB\#:

STUDY TITLE:

REFERENCE \#:

DATE OF REVIEW:

IRB STAFF CONTACT:
April 15, 2019

Meera Alagaraja, PhD

The University of Louisville Institutional Review Board

19.0337

The Making of a Whole Person: The Relationship between Job Crafting and Leisure Crafting on Work Engagement, Psychological Well-Being and Job Performance

681653

$04 / 15 / 2019$

Jackie Powell, CIP

852-4101

jspowe01@louisville.edu

This study was reviewed on 04/15/2019 and determined by the Chair of the Institutional Review Board that the study is exempt according to 45 CFR 46.101(b) under category 2: Research that only includes interactions involving educational tests (cognitive, diagnostic, aptitude, achievement), survey procedures, interview procedures, or observation of public behavior (including visual or auditory recording) if at least one of the following criteria is met: i. The information obtained is recorded by the investigator in such a manner that the identity of the human subjects cannot readily be ascertained, directly or through identifiers linked to the subjects; ii. Any disclosure of the human subjects' responses outside the research would not reasonably place the subjects at risk of criminal or civil liability or be damaging to the subjects' financial standing, employability, educational advancement, or reputation; or iii. The information obtained is recorded by the investigator in such a manner that the identity of the human subjects can readily be ascertained, directly or through identifiers linked to the subjects, and an IRB conducts a limited IRB review to make the determination required by $.111(a)(7)$.

This study was also approved through 45 CFR 46.117 (c), which means that an IRB may waive the requirement for the investigator to obtain a signed informed consent form for some or all subjects.

Documents/Attachments reviewed and approved:

\begin{tabular}{|c|c|c|c|c|}
\hline \multicolumn{5}{|c|}{ Submission Components } \\
\hline \multicolumn{2}{|l|}{ Form Name } & \multicolumn{2}{|l|}{ Version } & Outcome \\
\hline \multicolumn{2}{|l|}{ Submit for Initial Review } & \multicolumn{2}{|l|}{ Version 1.0} & Exempt \\
\hline \multicolumn{2}{|c|}{$\begin{array}{l}\text { Review Response Submission } \\
\text { =orm }\end{array}$} & \multicolumn{2}{|l|}{ Version 1.0} & Exempt \\
\hline \multicolumn{2}{|l|}{ IRB Study Application } & \multicolumn{2}{|l|}{ Version 1.1} & Exempt \\
\hline \multicolumn{5}{|l|}{ Study Document } \\
\hline Title & \multicolumn{2}{|c|}{ Version \# } & Version Date & Outcome \\
\hline Protocol & \multicolumn{2}{|c|}{ Version 2.0} & $04 / 08 / 2019$ & Approved \\
\hline Survey & \multicolumn{2}{|c|}{ Version 1.0} & $03 / 25 / 2019$ & Approved \\
\hline Preamble Clean & \multicolumn{2}{|c|}{ Version 2.0} & $04 / 08 / 2019$ & Approved \\
\hline
\end{tabular}

Since this study was determined to be exempt, the consent document does not contain the IRB approval stamp. 
Requirements for an exempt study:

Any study documents submitted with this protocol must be used in the form in which they were approved. Human Subjects \& HIPAA Research training are required for all study personnel. It is the responsibility of the investigator to ensure that all study personnel maintain current Human Subjects \& HIPAA Research training while the study is ongoing.

Personnel amendments must be submitted to the IRB to add/remove research personnel from your study team. If your research focus or activities change, please submit an Amendment to the IRB for review to ensure that the indicated exempt category still applies.

Additional reporting, such as submission of continuation reviews, is not required.

For guidance on using iRIS, including finding your approved documents, please follow the instructions at https://louisville.edu/research/humansubjects/iRISSubmissionManual.pdf

Site Approval

If this study will take place at an affiliated research institution, such as KentuckyOne Health, Norton Healthcare or University of Louisville Hospital, permission to use the site of the affiliated institution is necessary before the research may begin. If this study will take place outside of the University of Louisville Campuses, permission from the organization must be obtained before the research may begin (e.g. Jefferson County Public Schools). Failure to obtain this permission may result in a delay in the start of your research.

\section{Privacy \& Encryption Statement}

The University of Louisville's Privacy and Encryption Policy requires such information as identifiable medical and health records: credit card, bank account and other personal financial information; social security numbers; proprietary research data; dates of birth (when combined with name, address and/or phone numbers) to be encrypted. For additional information: http://security.louisville.edu/PolStds/ISO/PS018.htm.

Implementation of Changes to Previously Approved Research

Prior to the implementation of any changes in the approved research, the investigator will submit any modifications to the IRB and await approval before implementing the changes, unless the change is being made to ensure the safety and welfare of the subjects enrolled in the research. If such occurs, a Protocol Deviation/Violation should be submitted within five days of the occurrence indicating what safety measures were taken, along with an amendment to revise the protocol.

Unanticipated Problems Involving Risks to Subjects or Others (UPIRTSOs)

In general, these may include any incident, experience, or outcome, which has been associated with an unexpected event(s), related or possibly related to participation in the research, and suggests that the research places subjects or others at a greater risk of harm than was previously known or suspected. UPIRTSOs may or may not require suspension of the research. Each incident is evaluated on a case by case basis to make this determination. The IRB may require remedial action or education as deemed necessary for the investigator or any other key personnel. The investigator is responsible for reporting UPIRTSOs to the IRB within 5 working days. Use the UPIRTSO form located within the iRIS system to report any UPIRTSOs.

\section{Payments to Subjects}

Full Accreditation since June 2005 by the Association for the Accreditation of Human Research Protection Programs, Inc.

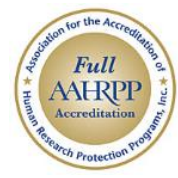


As a reminder, in compliance with University policies and Internal Revenue Service code, all payments (including checks, pre-paid cards, and gift certificates) to research subjects must be reported to the University Controller's Office. For additional information, please contact the Controller's Office at 852-8237 or controll@louisville.edu. For additional information: http://louisville.edu/research/humansubjects/policies/PayingHumanSubjectsPolicy201412.pdf

\section{Pate $m$ Lusanch}

Peter M. Quesada, Ph.D., Chair

Social/Behavioral/Educational Institutional Review Board

$\mathrm{PMO} / \mathrm{jsp}$

We value your feedback. Please let us know how you think we are doing: https://www.surveymonkey.com/r/CCLHXRP

Full Accreditation since June 2005 by the Association for the Accreditation of

Human Research Protection Programs, Inc.

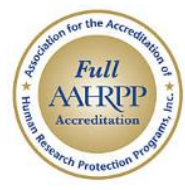


Appendix C

Subject Informed Consent Document

\section{Dear Participant:}

You are being invited to participate in a research study by answering questions in the attached survey about how an individuals' ability to job craft and leisure craft relates to work engagement, job performance and their psychological well being. This study is conducted by Dr. Meera Alagaraja of the University of Louisville and Josh Anna, MA (co-investigator). There are no known risks for your participation in this research study. The information collected may not benefit you directly. The information learned in this study may be helpful to others. The information you provide will be used to assess the relationship between how individuals craft their work and leisure activities on their engagement at work, performance on the job and overall psychological well-being. Your completed survey will be stored on the co-investigator's personal laptop, which is password protected and the data will be encrypted. The survey will take approximately 15 minutes time to complete. Each participant who completes the survey will be offered a $\$ 5$ e-gift card. Twenty-four hours after completing the survey, the participant will receive an email containing instructions on how to redeem the e-gift card and collect payment. The e-gift card will be in the form of MasterCard or Visa and can be used where these payments are accepted.

Individuals from the Department of Education and Organizational Development, the Institutional Review Board (IRB), the Human Subjects Protection Program Office (HSPPO) and other regulatory agencies may inspect these records. In all other respects, however, the data will be held in confidence to the extent permitted by law. Should the data be published, your identity will not be disclosed.

Taking part in this study is voluntary. By answering survey questions you agree to take part in this research study. You do not have to answer any questions that make you uncomfortable. You may choose not to take part at all. If you decide to be in this study you may stop taking part at any time. If you decide not to be in this study or if you stop taking part at any time, you will not lose any benefits for which you may qualify.

If you have any questions, concerns, or complaints about the research study, please contact Meera Alagaraja, PhD at (502) 852-0617.

If you have any questions about your rights as a research subject, you may call the Human Subjects Protection Program Office at (502) 852-5188. You can discuss any questions about your rights as a research subject, in private, with a member of the 
Institutional Review Board (IRB). You may also call this number if you have other questions about the research, and you cannot reach the research staff, or want to talk to someone else. The IRB is an independent committee made up of people from the University community, staff of the institutions, as well as people from the community not connected with these institutions. The IRB has reviewed this research study.

If you have concerns or complaints about the research or research staff and you do not wish to give your name, you may call 1-877-852-1167. This is a 24 hour hot line answered by people who do not work at the University of Louisville.

Sincerely,

\section{Meera Alagaraja, Ph.D}

(502) 852-0617

meera.alagaraja@louisville.edu
Josh Anna, MA

(502) 939-0167

joshua.anna@louisville.edu 


\section{Appendix D}

\section{Survey Questions}

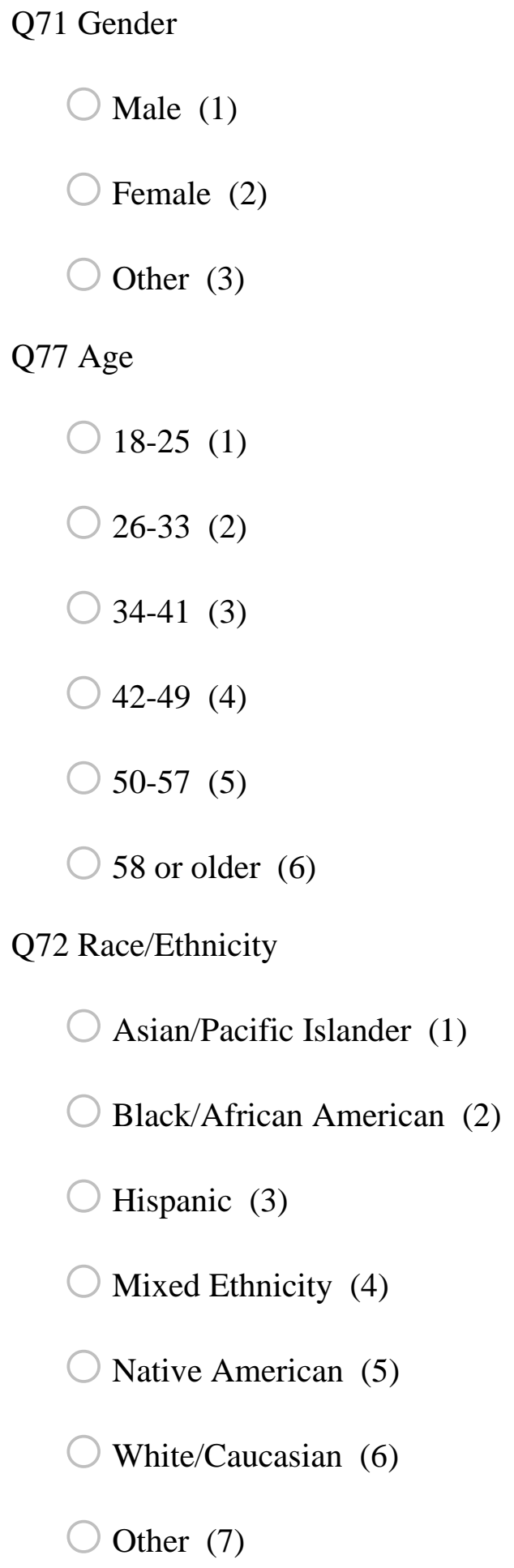




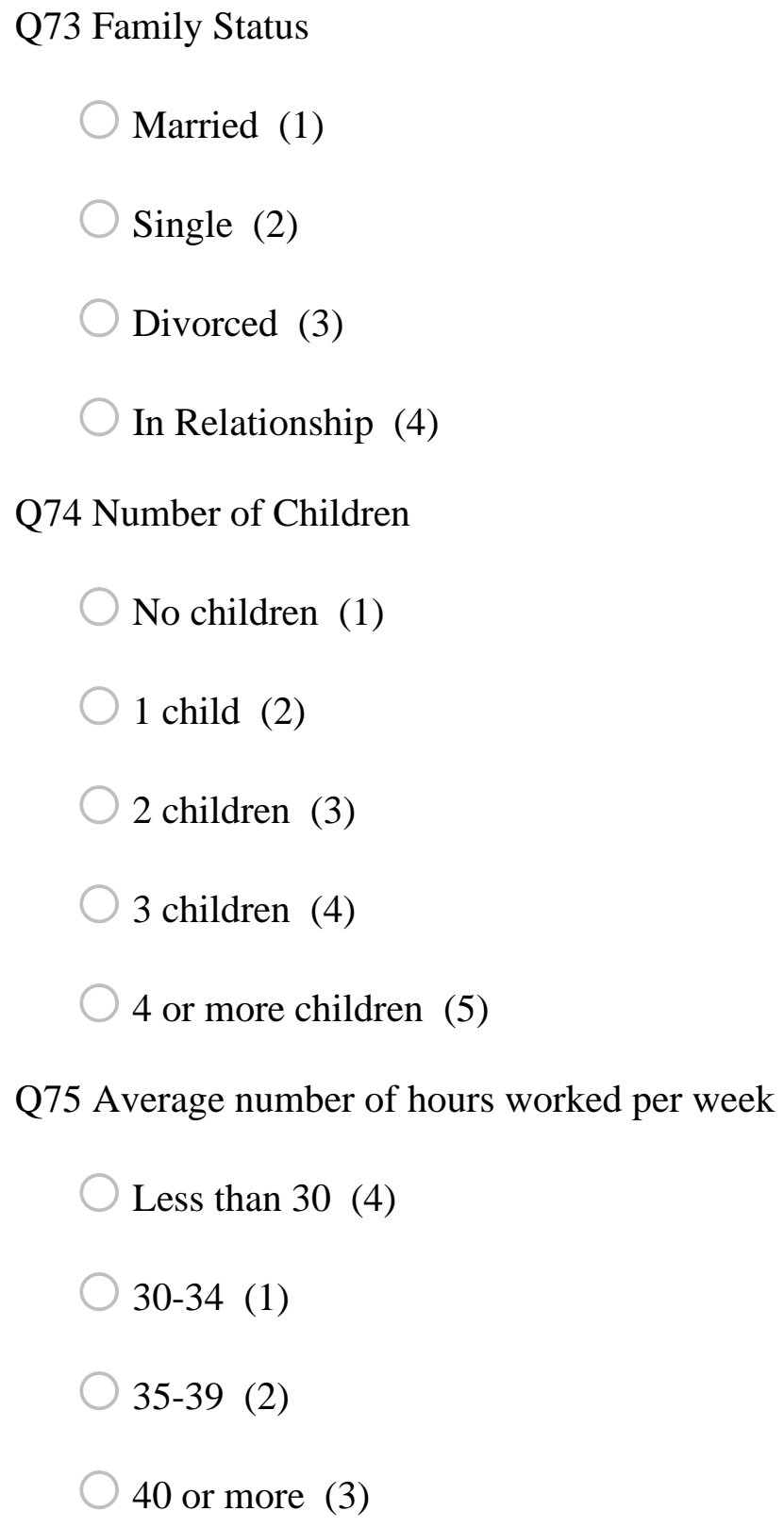


Q76 Highest level of education completed

High school diploma/GED (1)

Associate's (2)

Bachelor's (3)

Master's (4)

Doctorate (5)

Q86 How many jobs do you have?

Only 1 (1)

2-3 (2)

More than 3 (3)

Q78 Tenure at current organization

0-6 month (1)

7-12 months (2)

13-18 months (3)

19-24 months (4)

Over 24 months (5) 
Q85 What does your job responsibilities entail?

Manual Labor (1)

Book Keeping (2)

Computer competencies (7)

Accounting (4)

Other (6)

Q79 Type of industry employed in

Healthcare (1)

Manufacturing (2)

Service (3)

Media (4)

Technology (5)

Financial services (6)

Construction (7)

Gardening (8) 
Q64 I adequately complete assigned duties.

Strongly disagree (1)

Disagree (2)

Neither agree or disagree (3)

Agree (4)

Strongly agree (5)

Q65 I fulfill responsibilities specified in job description.

Strongly disagree (1)

Disagree (2)

Neither agree or disagree (3)

Agree (4)

Strongly agree (5)

Q66 I perform tasks that are expected of me.

Strongly disagree (1)

Disagree (2)

Neither agree or disagree (3)

Agree (4)

Strongly agree (5) 
Q67 I meet formal performance requirements of the job.

Strongly disagree (1)

Disagree (2)

Neither agree or disagree (3)

Agree (4)

Strongly agree (5)

Q68 I engage in activities that will directly affect my performance evaluation.

Strongly disagree (1)

Disagree (2)

Neither agree or disagree (3)

Agree (4)

Strongly agree (5)

Q69 I neglect aspects of the job I am obligated to perform.

Strongly disagree (1)

Disagree (2)

Neither agree nor disagree (3)

Agree (4)

Strongly agree (5) 
Q70 I fail to perform essential duties.

Strongly disagree (1)

Disagree (2)

Neither agree nor disagree (3)

Agree (4)

Strongly agree (5)

Q1 Having work/a career that is interesting and exciting to me is my most important life goal.

Disagree (1)

Somewhat disagree (2)

Neither agree or disagree (3)

Somewhat agree (4)

Agree (5)

Q2 I expect my job/career to give me more real satisfaction than anything else I do.

Disagree (1)

Somewhat disagree (2)

Neither agree or disagree (3)

Somewhat agree (4)

Agree (5) 
Q4 Building a name and reputation for myself through work/a career is not one of my life goals.

Disagree (1)

Somewhat disagree (2)

Neither agree or disagree (3)

Somewhat agree (4)

Agree (5)

Q5 It is important to me that $\mathrm{i}$ have a job/career in which I can achieve something of importance.

Disagree (1)

Somewhat disagree (2)

Neither agree or disagree (3)

Somewhat agree (4)

Agree (5)

Q6 It is important to me to feel successful in my work/career.

Disagree (1)

Somewhat disagree (2)

Neither agree or disagree (3)

Somewhat agree (4)

Agree (5) 
Q7 I want to work, but I do not want to have a demanding career.

\section{Disagree (1)}

Somewhat disagree (2)

Neither agree or disagree (3)

Somewhat agree (4)

Agree (5)

Q8 I expect to make as many sacrifices as are necessary in order to advance in my work / career.

\section{Disagree (1)}

Somewhat disagree (2)

Neither agree or disagree (3)

Somewhat agree (4)

Agree (5)

Q9 I value being involved in a career and expect to devote the time and effort needed to develop it.

\section{Disagree (1)}

Somewhat disagree (2)

Neither agree or disagree (3)

Somewhat agree (4)

Agree (5) 
Q10 I expect to devote a significant amount of my time to building my career and developing

the skills necessary to advance in my career.

\section{Disagree (1)}

Somewhat disagree (2)

Neither agree or disagree (3)

Somewhat agree (4)

Agree (5)

Q11 I expect to devote whatever time and energy it takes to move up in my job/career field.

\section{Disagree (1)}

Somewhat disagree (2)

Neither agree or disagree (3)

Somewhat agree (4)

Agree (5)

Q12 I try to develop my capabilities.

Never (1)

Rarely (2)

Sometimes (3)

Fairly often (4)

Often (5) 
Q13 I try to develop myself professionally.

Never (1)

Rarely (2)

Sometimes (3)

Fairly often (4)

Often (5)

Q14 I try to learn new things at work.

Never (1)

Rarely (2)

Sometimes (3)

Fairly often (4)

Often (5)

Q15 I make sure that I use my capacities to the fullest.

Never (1)

Rarely (2)

Sometimes (3)

Fairly often (4)

Often (5) 
Q16 I decide on my own how I do things.

Never (1)

Rarely (2)

Sometimes (3)

Fairly often (4)

Often (5)

Q17 I make sure that my work is mentally less intense.

Never (1)

Rarely (2)

Sometimes (3)

Fairly often (4)

Often (5)

Q18 I try to ensure that my work is emotionally less intense.

Never (1)

Rarely (2)

Sometimes (3)

Fairly often (4)

Often (5) 
Q19 I manage my work so that I try to minimize contact with people whose problems affect me emotionally.
Never (1)
Rarely (2)
Sometimes (3)
Fairly often (4)
Often (5)

Q23 I organize my work so as to minimize contact with people whose expectations are unrealistic.
Never (1)
Rarely (2)
Sometimes (3)
Fairly often (4)

\section{Often (5)}

Q21 I try to ensure that I do not have to make many difficult decisions at work.
Never (1)
Rarely (2)
Sometimes (3)
Fairly often (4)
Often (5) 
Q22 I organize my work in such a way to make sure that I do not have to concentrate for too long a period at once.
Never (1)
Rarely (2)
Sometimes (3)
Fairly often (4)
Often (5)

Q24 I ask my supervisor to coach me.
Never (1)
Rarely (2)
Sometimes (3)
Fairly often (4)
Often (5)

Q25 I ask whether my supervisor is satisfied with my work.
Never (1)
Rarely (2)
Sometimes (3)
Fairly often (4)
Often (5) 
Q26 I look to my supervisor for inspiration.

Never (1)

Rarely (2)

Sometimes (3)

Fairly often (4)

Often (5)

Q27 I ask others for feedback on my job performance.

Never (1)

Rarely (2)

Sometimes (3)

Fairly often (4)

Often (5)

Q28 I ask colleagues for advice.

Never (1)

Rarely (2)

Sometimes (3)

Fairly often (4)

Often (5) 
Q30 When an interesting project comes along, I offer myself proactively as project coworker.
Never (1)
Rarely (2)
Sometimes (3)
Fairly often (4)
Often (5)

Q31 If there are new developments, I am one of the first to learn about them and try them out.
Never (1)
Rarely (2)
Sometimes (3)
Fairly often (4)

\section{Often (5)}

Q32 When there is not much to do at work, I see it as a chance to start new projects.
Never (1)
Rarely (2)
Sometimes (3)
Fairly often (4)
Often (5) 
Q33 I regularly take on extra tasks even though I do not receive extra salary for them.

Never (1)

Rarely (2)

Sometimes (3)

Fairly often (4)

Often (5)

Q34 I try to make my work more challenging by examining the underlying relationships between aspects of my job.

Never (1)

Rarely (2)

Sometimes (3)

Fairly often (4)

Often (5)

Q35 I try to build relationships through leisure activities.

Not at all (1)

Rarely (2)

Sometimes (3)

Often (4)

Very much (5) 
Q36 I try to find challenging activities outside of work.

Not at all (1)

Rarely (2)

Sometimes (3)

Often (4)

Very much (5)

Q37 I try to increase my skills through leisure activities.

Not at all (1)

Rarely (2)

Sometimes (3)

Often (4)

Very much (5)

Q38 I try to increase my learning experiences through leisure activities.

Not at all (1)

Rarely (2)

Sometimes (3)

Often (4)

Very much (5) 
Q39 I try to set myself new goals to achieve through leisure activities.

Not at all (1)

Rarely (2)

Sometimes (3)

Often (4)

Very much (5)

Q40 Through my leisure activities, I look for inspiration from others.

Not at all (1)

Rarely (2)

Sometimes (3)

Often (4)

Very much (5)

Q41 Through my leisure activities, I try to obtain novel experiences.

Not at all (1)

Rarely (2)

Sometimes (3)

Often (4)

Very much (5) 
Q42 My leisure time is a chance for me to grow and develop.

Not at all (1)

Rarely (2)

Sometimes (3)

Often (4)

Very much (5)

Q43 I look for new experiences through leisure activities to keep myself mentally stimulated.

Not at all (1)

Rarely (2)

Sometimes (3)

Often (4)

Very much (5)

Q45 At my work, I feel bursting with energy.

Never (1)

A few times a year or less (2)

Once a month or less (3)

A few times a month (4)

Once a week (5)

A few times a week (6)

Every day (7) 
Q46 At my job, I feel strong and vigorous.

Never (1)

A few times a year or less (2)

Once a month or less (3)

A few times a month (4)

Once a week (5)

A few times a week (6)

Every day (7)

Q47 I am enthusiastic about my job.

Never (1)

A few times a year or less (2)

Once a month or less (3)

A few times a month (4)

Once a week (5)

A few times a week (6)

Every day (7) 
Q48 My job inspires me.

Never (1)

A few times a year or less (2)

Once a month or less (3)

A few times a month (4)

Once a week (5)

A few times a week (6)

Every day (7)

Q49 When I get up in the morning, I feel like going to work.

Never (1)

A few times a year or less (2)

Once a month or less (3)

A few times a month (4)

Once a week (5)

A few times a week (6)

Every day (7) 
Q50 I feel happy when I am working intensely.

Never (1)

A few times a year or less (2)

Once a month or less (3)

A few times a month (4)

Once a week (5)

A few times a week (6)

Every day (7)

Q51 I am proud of the work that I do.

Never (1)

A few times a year or less (2)

Once a month or less (3)

A few times a month (4)

Once a week (5)

A few times a week (6)

Every day (7) 
Q52 I am immersed in my work.

Never (1)

A few times a year or less (2)

Once a month or less (3)

A few times a month (4)

Once a week (5)

A few times a week (6)

Every day (7)

Q53 I get carried away when I'm working.

Never (1)

A few times a year or less (2)

Once a month or less (3)

A few times a month (4)

Once a week (5)

A few times a week (6)

Every day (7) 
Q54 Given my current physical condition, I am satisfied with what I can do. (1=never; $7=$ all or nearly all the time)
$1(0)$
$2(1)$
$3(2)$
$4(3)$
$5(4)$
$6(5)$
7 (6)

Q55 I have confidence in my ability to sustain important relationships. (1=never; $7=$ all or nearly all the time)
$1(0)$
2 (1)
$3(2)$
$4(3)$
5 (4)
$6(5)$
7 (6) 
Q56 I feel hopeful about my future. Sispe:(1=never; 7=all or nearly all the time)

$1(0)$

$2(1)$

$3(2)$

$4(3)$

$5(4)$

$6(5)$

7 (6)

Q57 I am often interested and excited about things in my life. is : $(1=$ never; $7=$ all or nearly all the time)

$1(0)$

$2(1)$

3 (2)

4(3)

5 (4)

6 (5)

7 (6) 
Q58 I am able to have funișep. (1=never; 7=all or nearly all the time)
$1(0)$
$2(1)$
$3(2)$
$\bigcirc$ (3)
$5(4)$
6 (5)
7 (6)

Q59 I am generally satisfied with my psychological health. (1=never; 7=all or nearly all the time)
1 (1)
$2(2)$
$3(3)$
4(4)
5 (5)
6 (6)
7 (7) 
Q60 I am able to forgive myself for my failures. sis: $(1=$ never; $7=$ all or nearly all the time)

$1(0)$

$2(1)$

$3(2)$

4 (3)

$5(4)$

$6(5)$

7 (6)

Q61 My life is progressing according to my expectations. (1=never; 7=all or nearly all the time)

1 (0)

2 (1)

3 (2)

4 (3)

$5(4)$

$6(5)$

7 (6) 
Q62 I am able to handle conflicts with others. sept $(1=$ never; $7=$ all or nearly all the time)

$1(0)$

$2(1)$

$3(2)$

$4(3)$

$5(4)$

6 (5)

7 (6)

Q63 I have peace of mind. (1=never; 7=all or nearly all the time)

$1(0)$

$2(1)$

$3(2)$

$4(3)$

$5(4)$

$6(5)$

7 (6) 


\section{CURRICULUM VITAE}

\section{Joshua David Anna}

\section{EDUCATION}

University of Louisville: Louisville, KY

Doctorate of Philosophy (Ph.D) in Educational Leadership and Development

Concentration: Human Resources and Organizational Development

Expected Graduation: December 2019

Spalding University: Louisville, KY

Masters of Arts in Applied Behavior Analysis

Concentration: Organizational Behavior Management/Developmental Disabilities

Bellarmine University: Louisville, KY

Bachelor's Degree in the Department of Psychology with an Emphasis in Human Resources

Bachelors Degree in Criminal Justice

\section{CERTIFICATIONS/LICENSES}

Board Certified Behavior Analyst

Licensed Behavior Analyst

WORK EXPERIENCE

Anna Behavioral Services, LLC

Owner/Operator

- Responsible for contacting insurance providers to file and submit claims, prior authorizations and referrals

- Procurement of payment for services provided

- Successfully negotiated contracts with major insurance providers

- Timely submission of claims within specified time period

- Effective time management with scheduling services for clients

- Proficient with diagnosis and procedure codes

- In charge of human resources and employee relations

- Develop monthly and annual budgets to ensure financial stability

- Made financial decisions affecting the future of the organization

- Provide supervision to associates to ensure continuity of care as well as compliance with state/federal mandates 
- Continual care of patients with various levels of disability

- Provide supervision and training to direct associates to develop staffs' skill sets

Central State Hospital ICF-MR Louisville, KY March 2012 - Sept 2013 Behavior Analyst

- Provide behavioral support services to individuals with intellectual and developmental disabilities

- Responsible for training staff on behavior support plans and various objectives related to behavioral health

- Collaborated with other departments to improve the quality of care given to individuals

Carriage House Educational Services Louisville, KY August 2011 - February 2012 Behavior Specialist

- Provide behavioral support services to clients with developmental disabilities

Carriage House Educational Services

Louisville, KY Sept 2010 - August 2011

Teacher assistant

- Worked in the Endeavor Program, a preschool designed for children with developmental disabilities

\section{INTERNSHIPS}

\section{Carriage House}

Worked with children with developmental disabilities/MR

- Fluent with Michelle P. waiver

\section{Dismas Charities}

Counseled residents who were finishing sentences on probation

- Updated residents' criminal files with any new information

\section{Probation and Parole Office}

Conducted house visits on individuals who were on parole through Louisville Metro

- Participated on police ride-along to survey local neighborhoods and update on felonies status

\section{March of Dimes}

Assisted fundraising director in contacting local businesses in an effort to raise money for March of Dimes events and March for Babies walks

- Help other co-workers with any other projects such as Signature Chefs auction and other fundraisers

- Organize March of Dimes walks by collaborating with volunteers to make signs, send thank you notes, and receive donations

\section{ACHIEVEMENTS}

- $\quad$ Attendee at VB-MAPP Training Seminar (instructed by Mark Sundberg), 2012

- $\quad$ Attendee at PECS Basic Training, 2011

- Member of Organizational Behavior Management Network, 2011

- Member of Kentucky Association of Behavior Analysis, 2011

- $\quad$ Certified in CPR/First Aid, 2012

- Professional Grant Writing Seminar, 2011 
- Member of Bellarmine University Psychology Club, 2008

- Monsignor Treece Scholarship Award, 2005 - 2009

- Bellarmine Tuition Grant, 2005 - 2009

- Habitat for Humanity: South Carolina 2004

- $\quad$ Big Brother, Big Sister: Student Mentor 2005

- $\quad$ Volunteer for Everyone Reads, 2008

\section{COMPUTER SKILLS}

Proficient in all aspects of Microsoft Word, PowerPoint and Excel

Proficient in web page design and functions of Internet

Statistical assessment with SPSS software with five years of research psychology

\section{REFERENCES}

Available upon request 